\title{
WestVirginiaUniversity
}

THE RESEARCH REPOSITORY @ WVU

Graduate Theses, Dissertations, and Problem Reports

2001

\section{Using virtual reality for requirements validation}

Dejan Desovski

West Virginia University

Follow this and additional works at: https://researchrepository.wvu.edu/etd

\section{Recommended Citation}

Desovski, Dejan, "Using virtual reality for requirements validation" (2001). Graduate Theses, Dissertations, and Problem Reports. 1111.

https://researchrepository.wvu.edu/etd/1111

This Thesis is protected by copyright and/or related rights. It has been brought to you by the The Research Repository @ WVU with permission from the rights-holder(s). You are free to use this Thesis in any way that is permitted by the copyright and related rights legislation that applies to your use. For other uses you must obtain permission from the rights-holder(s) directly, unless additional rights are indicated by a Creative Commons license in the record and/ or on the work itself. This Thesis has been accepted for inclusion in WVU Graduate Theses, Dissertations, and Problem Reports collection by an authorized administrator of The Research Repository @ WVU. For more information, please contact researchrepository@mail.wvu.edu. 


\title{
USING VIRTUAL REALITY FOR REQUIREMENTS VALIDATION \\ by \\ Dejan Desovski
}

\author{
Thesis submitted to the \\ College of Engineering and Mineral Resources \\ at West Virginia University \\ in partial fulfillment of the requirements \\ for the degree of
}

\begin{abstract}
Master of Science
in

Computer Science
\end{abstract}

Approved by

Bojan Cukic, Ph.D., Committee Chairperson

Ali Mili, Ph.D.

Frances VanScoy, Ph.D.

Department of Computer Science and Electrical Engineering

Morgantown, West Virginia

2001

Keywords: High Consequence Systems, Requirements Validation, Requirements Visualization, Virtual Reality (VR) Environments, Stable Reactive Systems.

Copyright $@ 2001$ Dejan Desovski 


\section{ABSTRACT}

\section{Using Virtual Reality for Requirements Validation by Dejan Desovski}

Failures of high consequence systems are intolerable. Studies have shown that a significant percentage of safety problems can be traced back to errors in the specification. An important problem that arises during validation is how to include a domain expert in this process. Although the domain experts have exclusive knowledge about the system operation, they may not understand formalisms used for system specification.

Essential type of "evidence" of the correctness of the formalization process must be provided by human-based calculation. Human calculation can be significantly amplified by shifting from symbolic representation to graphical representations. This, in turn, provides an environment for validation of the system model.

We have developed a virtual environment model for the Production Cell robotic system, which runs in an ImmersaDesk Virtual Reality environment. Although it introduces higher cost in the requirements formalization phase, this approach can be very beneficial in the development of high consequence systems. 


\section{DEDICATION}

Dedicated to my family who has always supported me.

Zoran

Vidanka

Angelina 


\section{ACKNOWLEDGMENTS}

There are many people who need to take credit for making this work possible. First of all I would like to thank my advisor and mentor Dr. Bojan Cukic for his support and understanding, and for giving me the opportunity to work with him at West Virginia University. This thesis is primarily based on the previous work of Dr. Victor Winter and I like to say thank you for his support and the opportunity that I had working with him during the summer of 2000 at Arizona State University. I would like to thank the other two members of my Graduating Committee, Dr. Ali Mili and Dr. Frances VanScoy for their support and providing me with precious knowledge that I have gathered during my studies at West Virginia University.

Finally I like to say big thank you to my friends Bratislav and Dragana, Weena and Cici, who had cheered me during the difficult moments of working on this thesis. 
TABLE OF CONTENTS

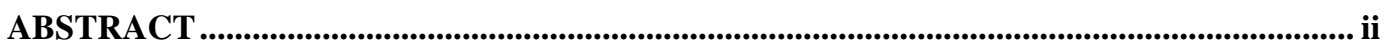

DEDICATION.......................................................................................................................................... ii

ACKNOWLEDGMENTS .................................................................................................................. iv

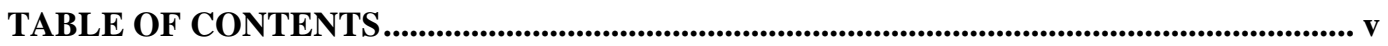

LIST OF FIGURES .......................................................................................................... vii

LIST OF SYMBOLS / NOMENCLATURE .......................................................................... viii

CHAPTER 1: INTRODUCTION......................................................................................................... 1

CHAPTER 2: RELATED WORK.................................................................................................... 3

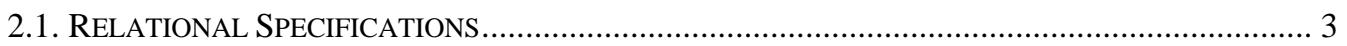

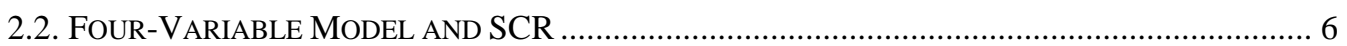

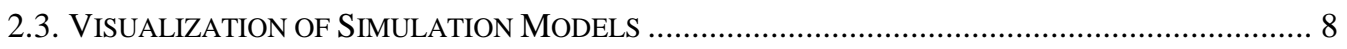

2.4. USING VIRTUAL ENVIRONMENTS FOR CERTIFICATION....................................................... 9

CHAPTER 3: FORMAL MODELS.................................................................................................. 11

3.1. THE BOUNDARY BETWEen A Formal MOdel AND USER PERCEPTION ……….................... 11

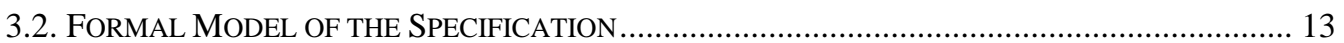

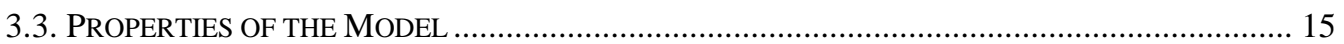

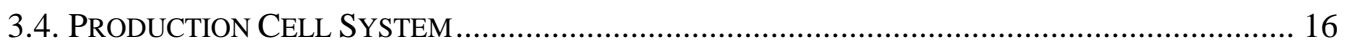

CHAPTER 4: USING VR FOR VALIDATION....................................................................................... 22

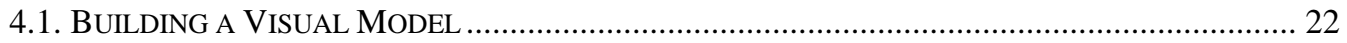

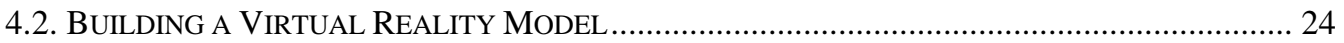

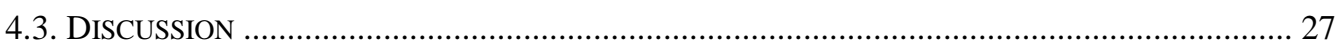

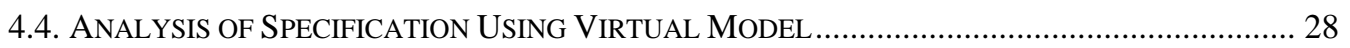

CHAPTER 5: CONCLUSIONS \& FUTURE WORK .......................................................................... 33

BIBLIOGRAPHY .................................................................................................................................. 35

APPENDIX A: MODEL OF THE PRODUCTION CELL ................................................................... 37

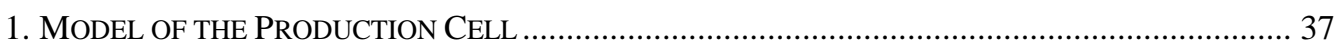

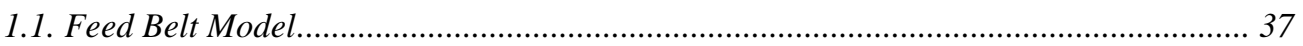

1.2. Elevating Rotating Table Model .............................................................................. 38

1.3. Robot Model ...................................................................................................... 39

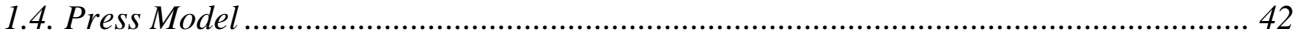

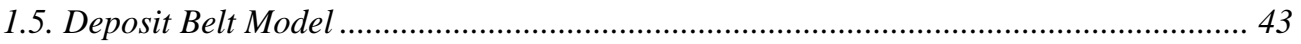

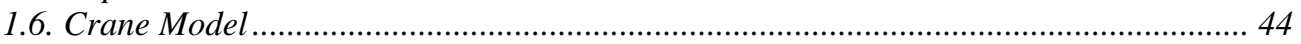

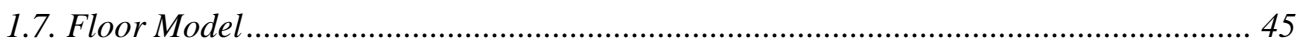

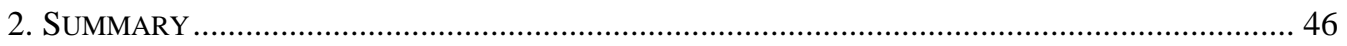


APPENDIX B: A FORMAL SPECIFICATION OF THE PRODUCTION CELL........................ 47

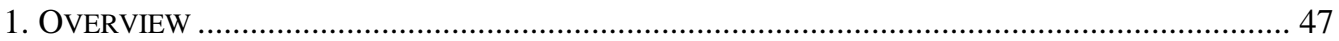

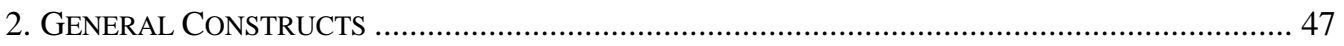

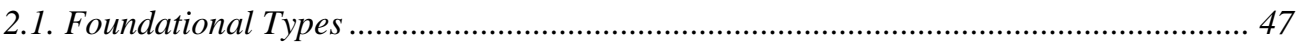

2.2. Graphical Types, Identifiers, Constants, and Variables ............................................. 47

2.3. Aggregate Concrete Graphical Types …………...................................................... 49

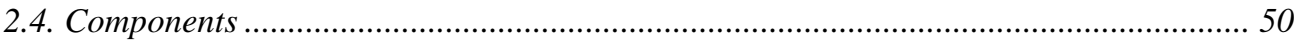

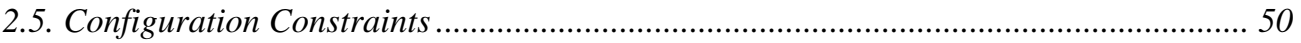

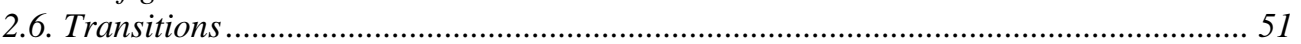

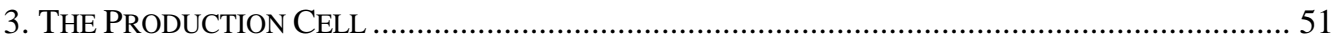

3.1. Primitive Graphical Types for the Production Cell .................................................... 51

3.2. Identifiers of Graphical Types for the Production Cell ............................................... 51

3.3. Display Instances of a Graphical Type for the Production Cell.................................. 51

3.4. Aggregate Concrete Graphical Types for the Production Cell..................................... 52

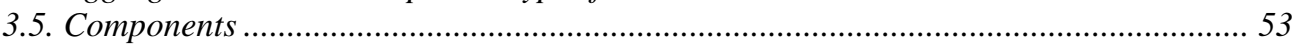

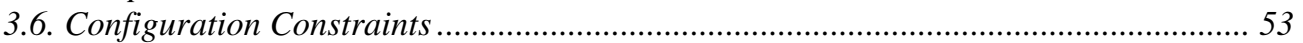

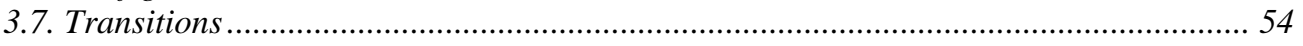

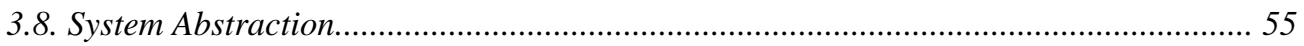

APPENDIX C: SAFETY CONSTRAINTS IN THE PRODUCTION CELL.................................... 77

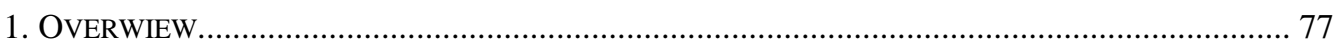

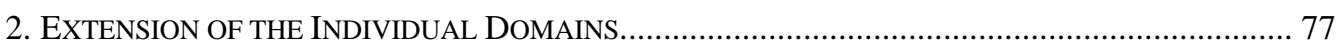

2.1. Extension of the Symbolic Foundational Types ............................................................ 77

2.2. Extension of the display instances of the graphical types............................................. 78

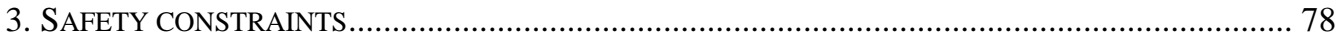

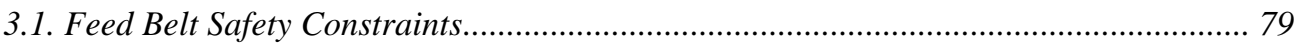

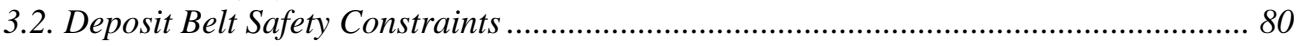

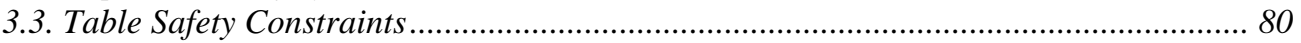

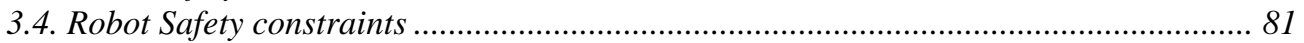

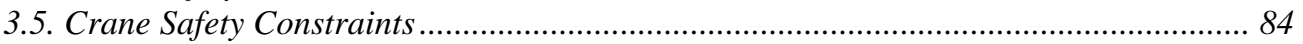

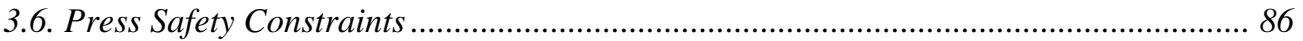




\section{LIST OF FIGURES}

FIGURE 1: BOUNDARY BETWEEN FORMAL SPECIFICATION AND DOMAIN EXPERT'S PERCEPTION................... 12

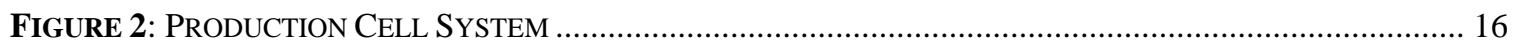

Figure 3: Total State SPace of the Elevating Rotating Table ........................................................ 18

Figure 4: AbStracted State Space of the Elevating Rotating Table ........................................... 19

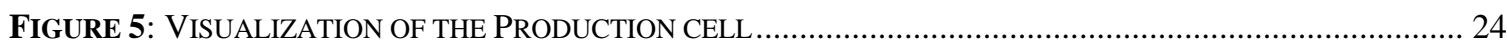

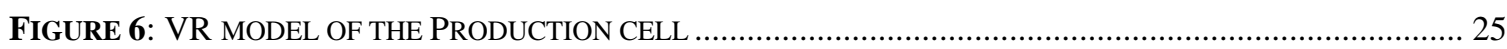

FIGURE 7: THE STATE SPACE OF THE SUBSYSTEM CONTAINING THE PRESS AND ROBOT ARMS...................... 29

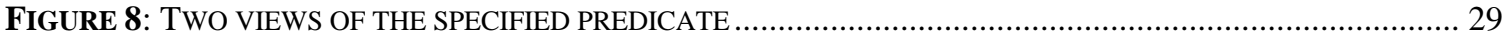

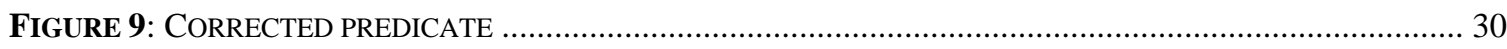

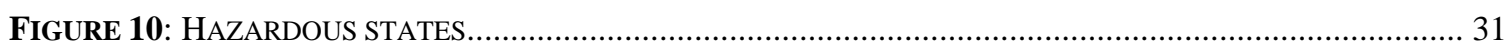

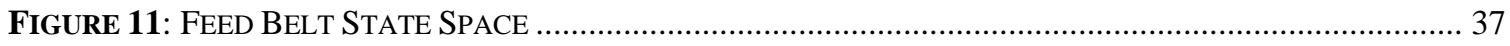

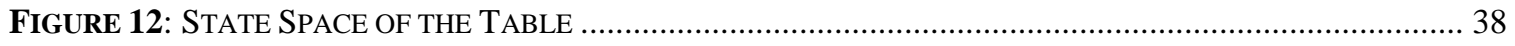

FiguRE 13: AbSTRACTED STATE SPACE OF THE TABLE ..................................................................... 38

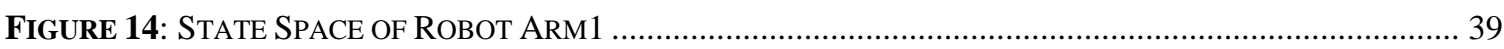

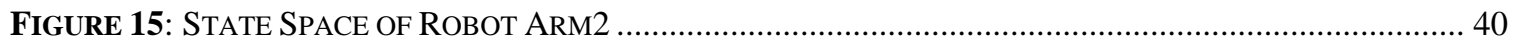

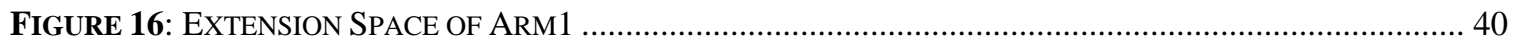

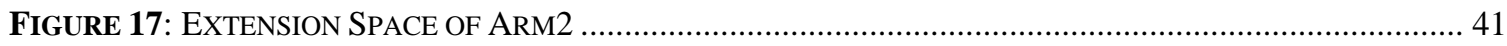

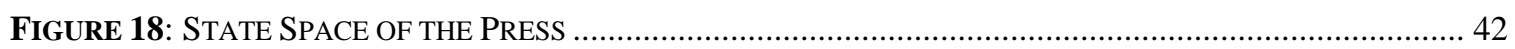

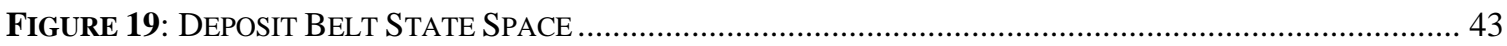

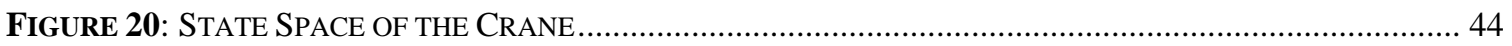

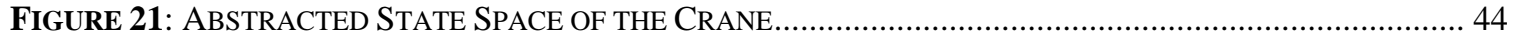

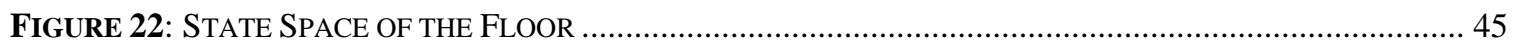




\section{LIST OF SYMBOLS / NOMENCLATURE}

\begin{tabular}{|c|c|}
\hline$\sqsupseteq$ & - Relation Refinement \\
\hline$\subseteq$ & - Subset \\
\hline$\cap$ & - Set Intersection \\
\hline$\epsilon$ & - Set Membership \\
\hline$\times$ & - Set Product \\
\hline$\circ$ & - Composition of Relations \\
\hline$R$ & - Relation \\
\hline$L$ & - Total Relation \\
\hline $\operatorname{dom}(R)$ & - Domain of Relation $R$ \\
\hline$[P]$ & - Functional Abstraction of Program $P$ \\
\hline$\sqcup$ & - Least Upper Bound, join \\
\hline$\sqcap$ & - Greatest Lower Bound, meet \\
\hline$\vec{m}$ & - Vector of Monitored Variables \\
\hline$\vec{c}$ & - Vector of Control Variables \\
\hline$P(\vec{m}) \stackrel{\vec{c}}{\longrightarrow} F(\vec{m})$ & $\begin{array}{l}\text { - Transition. } P: \vec{m} \rightarrow \text { bool is a predicate on the observable state, } \\
\text { and } F: \vec{m} \rightarrow \vec{m} \text { is a function on the observable state. }\end{array}$ \\
\hline$P(\vec{m}) \longrightarrow F(\vec{m})$ & $\begin{array}{l}\text { - Safety Constraint. } P: \vec{m} \rightarrow \text { bool represents a predicate on the } \\
\text { observable state, and } F: \vec{m} \rightarrow \vec{m} \text { is a function on the } \\
\text { observable state. Predicate } P \text { represents the precondition of the } \\
\text { safety constraint and function } F \text { modifies the state by assigning } \\
\{\text { error, hazard }\} \text { to the states that are in some type of safety } \\
\text { violation. }\end{array}$ \\
\hline $1 \mathrm{D}, 2 \mathrm{D}, 3 \mathrm{D}$ & - One Dimension, Two Dimensions, Three Dimensions \\
\hline SCR & - Software Cost Reduction \\
\hline NAT & - Relation describing the natural constraints of a system \\
\hline REQ & - Relation describing desired behavior of a system \\
\hline
\end{tabular}


IN

OUT SOFT

$\mathrm{VE}$

VR
- Relation describing the desired behavior of the input devices

- Relation describing the desired behavior of the output devices

- Relation describing the mapping between the input and output

- Virtual Environment

- Virtual Reality 


\section{CHAPTER 1: INTRODUCTION}

Technology advances make it possible to realize increasingly sophisticated behaviors and control functions by digital implementations. Because of this capability, digital systems being developed are responsible for carrying out "critical" operations. We define an operation or behavior to be "critical" if the failure to carry it out correctly leads to an unacceptable loss, such as the loss of human life or a significant monetary loss. For example, production facilities can be automated using robots, producing more uniform and accurate products, and requiring fewer workers, but an incorrect robotic manufacturing system can result in the destruction of costly equipment (i.e., the robots) as well as an extended shutdown of the manufacturing plant. Any system that has one or more "critical" operations can be defined as High Consequence System. Because of the high cost associated with their failure, one must provide strong evidence that the design of a high consequence system is fault-free, or if that is out of the reach, to provide strong evidence that it is unlikely for the design to contain a fault.

Ideally, the development of High Consequence Systems begins with the formalization phase. In this phase, an informal problem description is mapped into a formal framework and it is completed when a formal specification has been obtained. The formalization phase is followed by the implementation phase, in which a formal specification is used to produce an executable implementation. Since both the specification and the implementation are formal objects (they have precise and welldefined semantics), it is possible, in principle, to formally verify the correctness of the implementation with respect to the specification by using mathematical proof techniques. However, we can never be sure that the formalization phase has been done correctly in the first place. This uncertainty arises from the fact that the formalization process is mapping informal knowledge into a formal framework. Thus, formalization, by its very nature, lies beyond the reach of verification.

Providing evidence concerning the correctness of specifications and the models they are comprised of is very important because studies have shown that a significant percentage of safety problems can be traced back to errors in the specification [3]. 
To date, most validation techniques are highly biased towards calculations involving symbolic representations of problems. These calculations are either formal (in the case of consistency and completeness checks), or informal in the case of code inspections. We believe that an essential type of "evidence" of the correctness of the formalization process must be provided by human-based calculation, because humans formulate and understand the original problem. We further believe that human calculation can be significantly amplified by shifting from symbolic representation to graphical representations.

If it is possible to construct a formally defined visual representation of the system model, then the formulas which represent the functional capabilities and safety constraints can be coupled and graphically displayed. Using this representation, the correctness of the system model can be validated by human inspection, much in the same way that the mathematically structured formulas are validated by human inspection. Our belief is that human intuition and understanding will be much more effective with respect to a three dimensional visual representation, than it would be in a mathematical domain.

Consequently, visual representation of the formal (symbolic) description of systems is the main goal of our research. Furthermore, we want to demonstrate the advantages of visual representation for the validation of requirements models in virtual reality environments.

We restrict our interest to the set of stable reactive systems [12]. They have the following properties: state transitions can be initiated only by the controller, transitions between the states are deterministic and the system can be halted in any state without the need for continuous monitoring and control. In this work, we use a robotic system called the production cell as a simple yet meaningful example for development and evaluation of suitability of visual models for software requirements analysis. The prototype implementation allowed us to visualize functional capabilities of the production cell, to inspect the correctness of the developed formal model, and to display and analyze the effects of several safety constraints. 


\section{CHAPTER 2: RELATED WORK}

\subsection{Relational Specifications}

Most of the previous work on requirements validation is concerned with formal constructs that are easy to understand by humans, possibly in an incremental fashion. Relational Specification is one of the specification methods that have well defined theory and constructs. As its name suggests, this method is based on relations defined on specified sets. We will assume that the reader is familiar with the properties of relations and we will give short description of this method, taken from [10][13].

Definition 1: A specification on space $S$ is a relation on $S$.

A specification $R$ on $S$ contains all the input output pairs that the specifier considers being correct.

Definition 2: A relation $R$ is said to refine relation $R^{\prime}\left(R \sqsupseteq R^{\prime}\right)$ if and only if:

$$
R^{\prime} \circ L \subseteq R \circ L \text { and } R \cap R^{\prime} \circ L \subseteq R^{\prime}
$$

Here the operation $A \circ B=A B=\{(a, b) \mid \exists c \in S:(a, c) \in A \wedge(c, b) \in B\}$ is with highest precedence, and $L$ is the total relation $S \times S$.

This definition basically states that $R \sqsupseteq R$ ' if and only if:

1) $\operatorname{dom}(R) \supseteq \operatorname{dom}\left(R^{\prime}\right)$

2) $(a, b) \in R \wedge a \in \operatorname{dom}\left(R^{\prime}\right) \rightarrow(a, b) \in R^{\prime}$

A program $P$ on space $S$ computes a function on $S$, which is called the functional abstraction of program $P$ and is defined as follows:

$[P]=\left\{\left(s, s^{\prime}\right) \mid\right.$ if $P$ starts execution in state $s$ then it terminates in state $\left.s^{\prime}\right\}$. 
Definition 3: $P$ is correct with respect to specification $R$ if and only if $[P] \sqsupseteq R$.

The relation refines is reflexive, anti-symmetric and transitive, and thus introduces a partial ordering on the set of specifications. Having this in mind we are interested in answering the questions whether two given relations $R$ and $R^{\prime}$ on $S$ have a least upper bound called join, $R \sqcup R$ ', and a greatest lower bound called meet, $R \sqcap R$ '. The following propositions answer these questions.

Proposition 1: Specifications $R$ and $R$ ' have a join if and only if:

$R L \cap R^{\prime} L=\left(R \cap R^{\prime}\right) L$

If this condition (the consistency condition) is satisfied, then:

$R \sqcup R^{\prime}=\left(R^{\prime} \cap \overline{R L}\right) \cup\left(R \cap R^{\prime}\right)$

Proposition 2: Any two specifications $R$ and $R$ ' have a greatest lower bound, given by the formula:

$R \sqcap R^{\prime}=R L \cap R^{\prime} L \cap\left(R \cup R^{\prime}\right)$

By using this theory we can address the issue of validation of a specification.

As the authors argue in [10]:

"When one writes a specification from a user requirement, one can never be sure to have captured all the requirements that the user has in mind (completeness); nor that he has not captured something that the user did not have in mind (minimality). On the other hand, because the user requirements are expressed in an informal document (typically using prose), one cannot check formally for completeness or minimality against the formal specification."

The proposed method of checking the completeness of a specification consists of the following two phases. 
Phase 1: Generating Properties. The verification and validation group, whose task is to generate properties for the purpose of completeness, asks questions of the form: "What aspects of the user requirements could the specifier have missed?"

This task of generating relations that capture some selected properties from informal sources is essentially the same as generating the whole specification. The main difference is that the specifiers group has the obligation to capture all of the user requirements (produce complete specification), whereas the verification and validation group has the obligation of being "the devil's advocate" - capturing properties that they suspect the specifiers may have overlooked.

Phase 2: Matching the Specification against the Properties. Given a specification $R$ and a property $V$, the question that the verification and validation group addresses now is:

"Does the specification $R$ contain all the input output information of $V$ ?"

Definition 3: A specification $R$ is said to be complete with respect to property $V$ if and only if $R \sqsupseteq V$.

The proposed method of checking the minimality of a specification consists of the following two phases.

Phase 1: Generating Properties. The verification and validation group, whose task is to generate properties for the purpose of minimality, asks questions of the form: "What the specifier could have recorded, that the user does not require?"

Phase 2: Matching the Specification against the Properties. Given a specification $R$ and a minimality property $W$, by its construction $W$ carries information that $R$ is not supposed to carry.

Definition 4: A specification $R$ is said to be minimal with respect to property $W$ if and only if $R$ does not refine $W$. 


\subsection{Four-Variable Model and SCR}

The Software Cost Reduction (SCR) method / specification language was developed in the late 1970s at the Naval Research Laboratory for the purpose of specifying the requirements of the Operational Flight Program of the U.S. Navy's A-7 Aircraft. SCR is based on the four-variable method and its tabular representation proposed by Parnas [4].

The four-variable model describes a system as a set of relations on four sets of variables, and may be considered at two levels of abstraction. At the first and higher level of abstraction, the system is considered as a whole in its environment. We can define two sets of variables: monitored variables and controlled variables. Monitored variables are those values in the environment that the user wants the system to measure, and the controlled variables are those values in the environment that the user wants the system to control.

At this higher level of abstraction, the relations that define the relationship between the monitored variables and controlled variables are NAT and REQ. NAT describes natural constraints imposed on the system by the physical laws and the environment. REQ describes the desired behavior of the system, capturing the relationship that the system must maintain between monitored and controlled variables. Together, NAT and REQ define the desired system behavior within the environment.

When the system is decomposed into its input devices, software and output devices, the other two sets of variables in Parnas's four-variable model emerge. At this lower level of abstraction, input devices are viewed as black boxes that convert the values of the monitored variables into input data items that the software can understand. The output devices are seen as black boxes that convert the software output data items into values of the controlled variables.

The relation IN describes the desired behavior of the input devices and the relation OUT describes the desired behavior of the output devices. The software's job is to transfer the output of the input devices, which are the input items, into appropriate 
output items, which will serve as input to the output devices. The mapping between the input items and the output items is defined by the relation SOFT. The relations IN, SOFT, and OUT are subsumed within NAT and REQ.

Based on this model, SCR uses several simple constructs including models and mode classes, events and conditions. A mode class is like a finite-state machine. A finite set of modes is defined for each mode class - representing the states in the machine. The input alphabet is a set of events, the transition function is represented in a mode transition table, and the initial state is the initial mode (which in SCR must be specified for each mode class).

Events occur when any of the system's input or output data items change value. Using this we can specify that a mode of the system's mode classes changes as a result of a change in an input or output data item. Events also occur when modes change; that is, when any mode class in the system changes from one mode to another, an event occurs that can be used to trigger another mode transition elsewhere. This allows decomposing the system specification in several finite state machines that communicate with each other, instead of building a single complex description.

Using events and conditions each of the variable's functional dependencies can be described by using tabular notation.

Further research on SCR by Heitmeyer [5] resulted in an automatic consistency and completeness checking tool called SCR*. Although a specification is automatically checked for consistency and completeness, this does not mean that the specification is correct with respect to the requirements.

One of the components of this tool is a simulator used for validation of the specification. The user can enter some events that change the monitored variables and observe whether the specified system behaves according to the expectations. The simulator has a capability to use custom defined visual representation of the system, so that the user can interact with the specified system in much of the same way as he/she would interact with the real system. A customized simulator front end for an attack aircraft specification has been described in [5]. 
SCR* also uses another third party tool called SPIN for the purpose of specification verification. SPIN takes as input a description of communicating finite-state machines and then builds and explores the state space of the complex state machine representing all of their interactions. SPIN verifies that certain completeness and consistency properties, which may be input by the user, hold in every state of that complex machine.

\subsection{Visualization of Simulation Models}

Simulation is extensively used for the purpose of validation of system models. By having a completely accurate simulation of the system, we can avoid the difficulties that exist in physical testing. For example: we cannot test one-shot systems like Arianne 5, or high consequence systems like nuclear plants in hope to find some failure. Unfortunately, the use of testing and simulation for the purpose of providing evidence that a system is fault free is highly questionable. One of the reasons being that testing of a suitable portion of the input space would simply take too much time, even if present day accelerated testing techniques are used. Another problem is the difficulty to obtain a completely accurate simulation of the real system model; often the simulation only represents a simplification of the reality.

Many simulation researchers extensively explored the process of visualizing simulation models [8], and today visualization has become a critical component of simulation technology. Some of the aspects where visualization is found to be very beneficial in simulations (as identified in [9]) are the following:

- Verification and Validation - The logic model and the real-world behavior can be verified by watching the model. Animation, combined with sound statistical analysis, is an unmatched approach to evaluating how good a model really is. 
- Understanding of Results - Often when the outcome from a model is not understood, the animation can provide insight. By watching the area(s) of interest, the modeler can "see" what is happening and understand how dynamic behavior of the system affects the results.

- Communication of Results - Visualization is critical in communicating the outcome of a simulation to the non-technical audience. Watching a few minutes of visualization can eliminate hours of long tedious discussions.

We have borrowed these ideas and applied them in our research.

\subsection{Using Virtual Environments for Certification}

Cruz-Neira and Lutz explored the potentials of using virtual environments (VE) for system certification [7]. A virtual environment can fit this purpose by building a visual simulation of the system that is considered for certification. Simulation trials are required in order to validate and certify the system.

In order to use VEs to certify a system, one must first validate that the VE accurately represents the real world that it is modeling. There are four key considerations for measuring the quality of simulators that offer useful guidelines for VE model analysis:

- Identify which environment variables the system must include and which it can ignore.

- Confirm the accuracy of representation of environmental factors.

- Confirm the accuracy and resolution of the system's calculations for each environmental variable.

- Confirm the adequacy of the timing considerations. 
Cruz-Neira and Lutz [7] conclude:

"Among the advantages of using VEs for certification are the possibility of more complete testing and their dual use as design and certification tools. These factors will contribute to increased use of VEs in the certification of safety-critical systems, especially in analysis of system responses to failure conditions and in testing of hazardous physical conditions."

Our research is following these ideas about using Virtual Environments for validation. 


\section{CHAPTER 3: FORMAL MODELS}

\subsection{The Boundary between a Formal Model and User Perception}

A specifier, based on the informal specification from the user (or the domain expert ${ }^{1}$ ), writes the formal system specification. This formal specification is based on the mental model (understanding of the system) that the specifier develops. It should be complete, minimal and consistent with respect to the domain expert's informal specification. After the mental model has been developed it is mapped into a formal domain, usually written in some form of formal notation or a domain specific language (eg. SCR [4][5], Z [11], Relational Specifications [10], etc.)

There are two sources of errors that can arise during the formalization process. The first source is the incomplete understanding of the informal specification (or the domain) resulting in the development of an incorrect system model. Second, the specifier can introduce errors by incorrectly mapping the (possibly correct) mental model into the formal domain. Both of these types of errors can be discovered to some extent by consistency and completeness checks and this procedure can be automated [4]. We note that completeness and consistency are necessary but not sufficient conditions in assuring that the developed model is correct.

The mathematical formulae that express the system can be very complicated, even if the system itself is of moderate size. System complexity increases the possibility that errors are included in the formal specification. The major difficulty lies in our ability to correctly express system behavior in terms of symbolic formulae. Research has been conducted on how to write and structure these formulae to support incremental understanding [4][5]. Our research addresses the same issue, but attempts to solve the problem in a graphical framework rather than in a mathematical framework.

${ }^{1}$ In the rest of the thesis, we use the terms user and domain expert interchangeably. While this is generally incorrect, in our case domain experts are the users of the VR modeling tool for requirements validation. 
Another issue in the formalization phase is the domain expert's understanding of the formal specification. Often the domain expert does not have the expertise in the specific form of formal notation and cannot validate whether the formal specification really captures all the desired features of the system correctly. This is the validation issue. It can be handled by having two specification groups that develop the specifications independently. The first group is responsible for development of the formal specification while the second group provides redundant information that can be used to validate the specification developed by the first group [10]. The drawback of this process is the fact that the domain expert is not involved in the validation, although he/she is the one that possesses the most complete knowledge of the required system behavior.

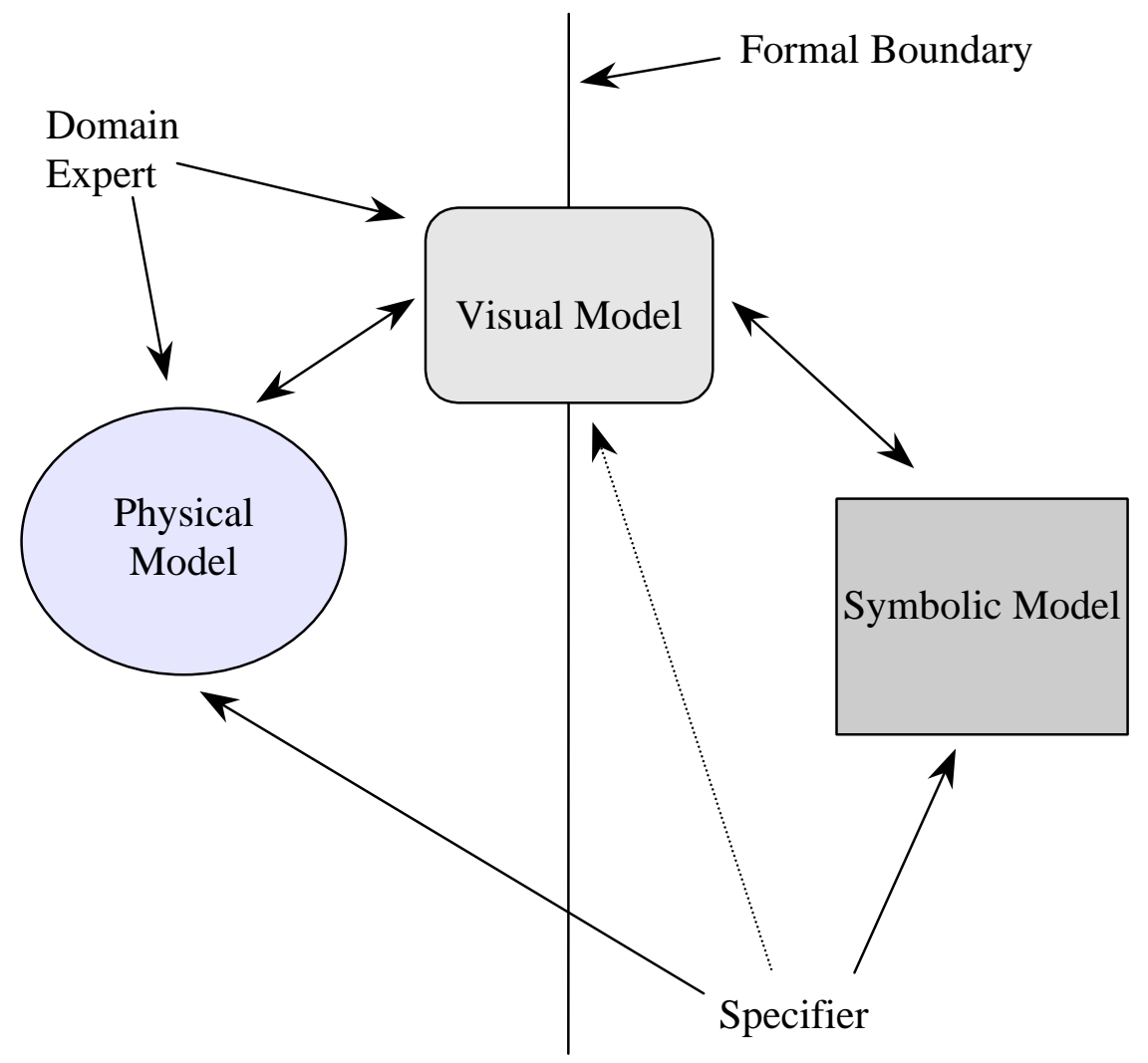

Figure 1: Boundary between formal specification and domain expert's perception. 
The domain expert can be included in the process of validating formal specification if the specification is rewritten in some easily understandable notation. Candidate notations are natural languages or visual models, but the automated rewriting is far from simple.

By using graphical representation of the formal system model, the domain expert is included in the validation process. The specifier also benefits, because visual model increases his/her ability to construct correct mental model and assists in the process of mapping this mental model to formal notations. Figure 1 depicts our intention to use visual model as a bridge over the typical boundary between the domain expert's knowledge and the formal model, which (supposedly) captures it.

\subsection{Formal Model of the Specification}

Our current research focuses on a subset of reactive systems classified as stable. Stable reactive systems have the following distinguishing properties:

1. Only the controller can initiate state transitions (e.g. the environment cannot initiate a state transition);

2. The transitions between the states are deterministic;

3. The system can be suspended in any state without the need for continuous monitoring and control (i.e. the reactive process can be suspended in any state).

A stable reactive system can be formally modeled as a vector of monitored and controlled variables, as shown below:

- Let $\vec{m}=\left\{m_{1} \in D_{1}, m_{2} \in D_{2}, \ldots, m_{j} \in D_{j}\right\}$ denote the observable states of the system, where $D_{i}, 1 \leq i \leq j$, is the domain of the monitored variable $m_{i}$.

- Let $\vec{c}=\left\{c_{1} \in C_{1}, c_{2} \in C_{2}, \ldots, c_{k} \in C_{k}\right\}$ represent the vector of controlled variables for the system, where $C_{i}, 1 \leq i \leq k$, is the domain of the controlled variable $c_{i}$. 
- Then $\vec{s}=\left\{m_{1}, m_{2}, \ldots, m_{j}, c_{1}, c_{2}, \ldots, c_{k}\right\}$ represents the state space of the system. Note that the state space $\vec{s}$ of the system contains $D_{1} \times \ldots \times D_{j} \times C_{1} \times \ldots \times C_{k}$ states.

- The transitions between the states are given by a set of equations in the form: $P(\vec{m}) \stackrel{\vec{c}}{\longrightarrow} F(\vec{m})$ where $P: \vec{m} \rightarrow$ bool is a predicate on the observable state, and $F: \vec{m} \rightarrow \vec{m}$ is a function on the observable state.

The transitions are specifying the functional capabilities of the system. In the high consequence realm, we are also interested in specifying the safety constraints of the system. In order to define the safety constraints, we extend the domains $D_{i}$ of some of the variables with two new values $\{$ error, hazard $\}$. Safety violation of type error denotes that some error has occurred in the system (e.g, collision). On the other hand, safety violation of type hazard represents that there is a possibility of error occurring, i.e., the current state of the system is one or more transitions away from an error state.

We use the notation similar to transitions for specification of safety constraints:

- $P(\vec{m}) \longrightarrow F(\vec{m}) . P: \vec{m} \rightarrow$ bool represents a predicate on the observable state, and $F: \vec{m} \rightarrow \vec{m}$ is a function on the observable state. Predicate $P$ represents the precondition of the safety constraint and function $F$ modifies the state by assigning \{error, hazard $\}$ to the states that are in some type of safety violation.

This work describes visual representations of systems that can be represented by formal models introduced above. One limitation is that these models do not address timing issues. Timing is, generally, very important, since high consequence systems usually have real-time performance constraints. However, our current goal is visual modeling as a methodology for model validation. Therefore, we chose to start with 
simple models. Timing issue will be addressed by extending the transition model with the time parameter, which expresses the interval needed/allowed for a transition to complete.

\subsection{Properties of the Model}

The proposed method of modeling stable reactive systems is very similar to the Parnas four-variable model on the higher level of abstraction. Also, it is consistent with the theory of systems where every system has monitored variables (variables that can be observed and measured) and control variables (variables that can guide and control the system behavior).

We should notice that the monitored variables usually represent just portion of the state in which the system is, because they represent set of variables that can be physically measured. Sometimes we must relay on the system history in order to gain insight of the real state of the system. This is done by introducing so called "virtual sensors" that are monitoring the history of some variables and produce new virtual variable that is then added to the monitored variables.

Reactive systems are systems that behave in certain environment. They receive input from the environment, represented by the control variables, and react accordingly, by changing the monitored variables. Almost all systems can be considered like reactive systems. By adding the stable property, we restrict the set of reactive systems by disallowing that they react and change the monitored variables without being supplied with control vector. That is, whenever there is absence of control, the System State does not change. This means that there are no disturbances in the environment and that the system itself is inherently stable. Usually, by careful engineering we can remove or make sure that the disturbances in the environment do not affect the system. And also, we are mainly interested in controlling stable systems. So this model represents almost all systems of practical interest.

One limitation of the way that we are modeling stable reactive systems was mentioned in the previous section, and that was the absence of timing information for the 
transitions. Similar like in SCR, this problem can be avoided by adding information about the time needed and allowed for a transition to finish.

This model has been used to specify variety of systems, one example being BART (Bay Area Rapid Transport System) - automated train system in San Francisco. We are using this model in order to specify a manufacturing robotic system, called "Production Cell”.

\subsection{Production Cell System}

We used a robotic system called the Production Cell as a case study for formal and visual modeling. This system has been widely used as a case study for the application of formal methods [2]. Furthermore, for a system to be a suitable candidate for visualization, it should have a strong and intuitively clear visual relationship between the observable states $\left(D_{1} \times \ldots \times D_{j}\right)$ and physical reality. Robotic systems often have this property and are prime candidates for visual display.

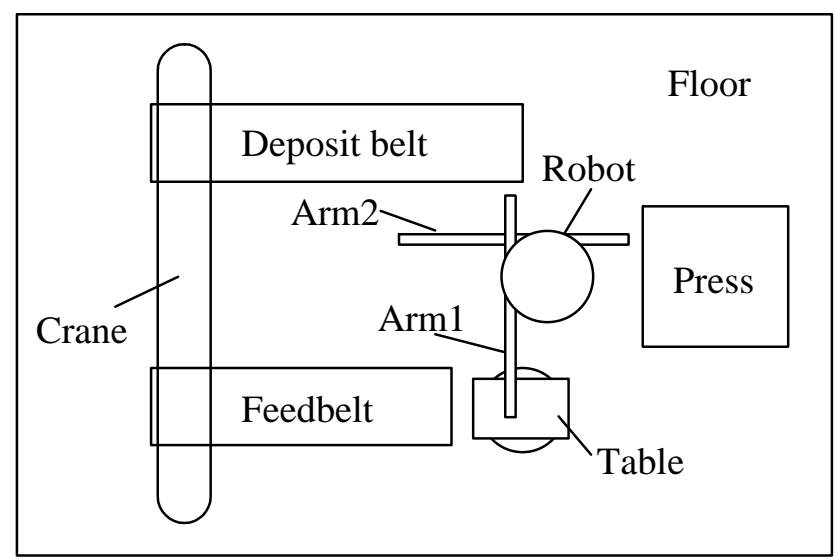

Figure 2: Production Cell System

The production cell, shown in Figure 2, consists of two conveyor belts, an elevating rotating table, a robot with two arms, a press, and a crane. The objective of the production cell is to process metal plates. A plate is processed as follows. First it is 
placed on the first conveyor belt (called the feed belt), which then transfers it to the elevating rotating table. The table then changes its position so that arm 1 of the robot can pick up the plate by using an electro-magnet. From there the plate is moved into the press where it is processed. Then, arm 2 of the robot removes the plate from the press and places it on the second conveyor belt (called the deposit belt) which transfers it to the crane. The crane takes the plate and places it on the feed belt and the cycle continues.

In addition of the desired behavior described above, the production cell can encounter numerous failures. For our purposes, some of the failures are considered to be of high consequence. These failures result in damaged system components, which may be expensive to replace, and prevent plant's continual operation.

The observable (stable) state of the production cell can be formally described by a vector of 25 monitored variables, $\vec{m}=\left\langle m_{1}, m_{2}, \ldots, m_{25}\right\rangle$. Some of the system attributes described by these variables are:

- The rotation and height of the elevating rotating table.

- The presence/absence of a plate on the rotating table.

- The presence of a plate on the left and right regions of a conveyor belt.

- The rotational position of the robot and the extension of both its arms.

- The state of the electro-magnet on the robot arms, as well as whether the arm is holding a plate.

Each of these variables is quantified over a specific domain. For example a variable denoting presence/absence of plate on the rotating table is quantified over a domain having two values (e.g., \{true, false $\}$ ). The variable denoting the angle of rotation of the elevating rotating table is quantified over the set of possible angles that the sensor can distinguish. 


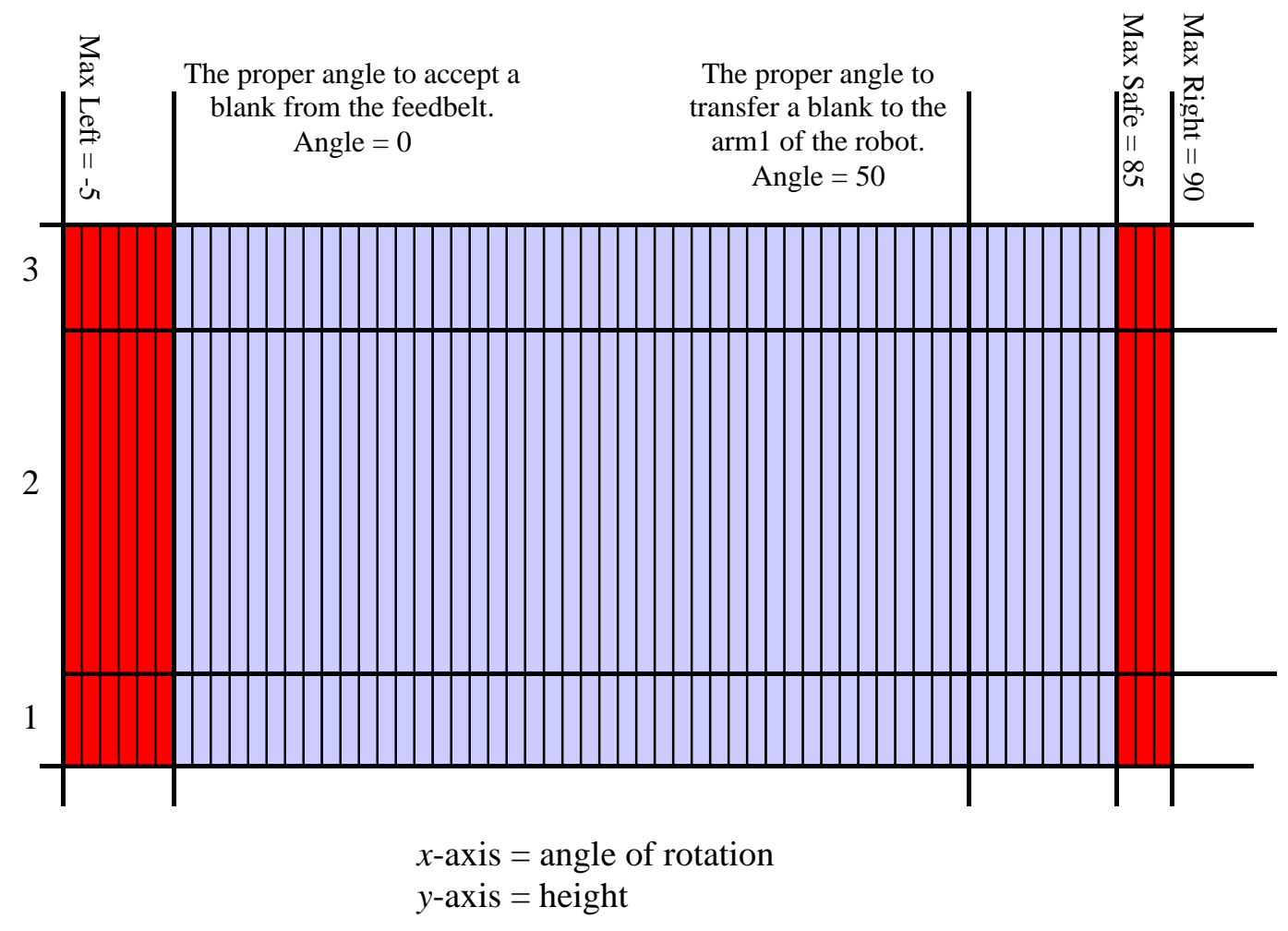

Figure 3: Total State Space of the Elevating Rotating Table

Modeling sensor data in its concrete form can result in variables being quantified over very large sets, containing over hundreds or even thousands of elements. Example of the total state space of the elevating rotating table is given in Figure 3. However, most of these values are not interesting from the perspective of the specification. It is possible to formally group sets of elements/values into equivalence classes. Intuitively, two elements belong to the same equivalence class if and only if the same control vector can be applied, in all cases, to both elements to achieve the desired overall system behavior.

Grouping elements in equivalence classes results in the corresponding monitored variable being quantified over an abstracted domain. For example, the concrete sensor data describing the angle of rotation of the elevating rotating table can be abstracted to a domain having six values Figure 4. This abstracted domain defines the equivalence classes that need to be distinguished by the controller to achieve the behavior described in the specification. 


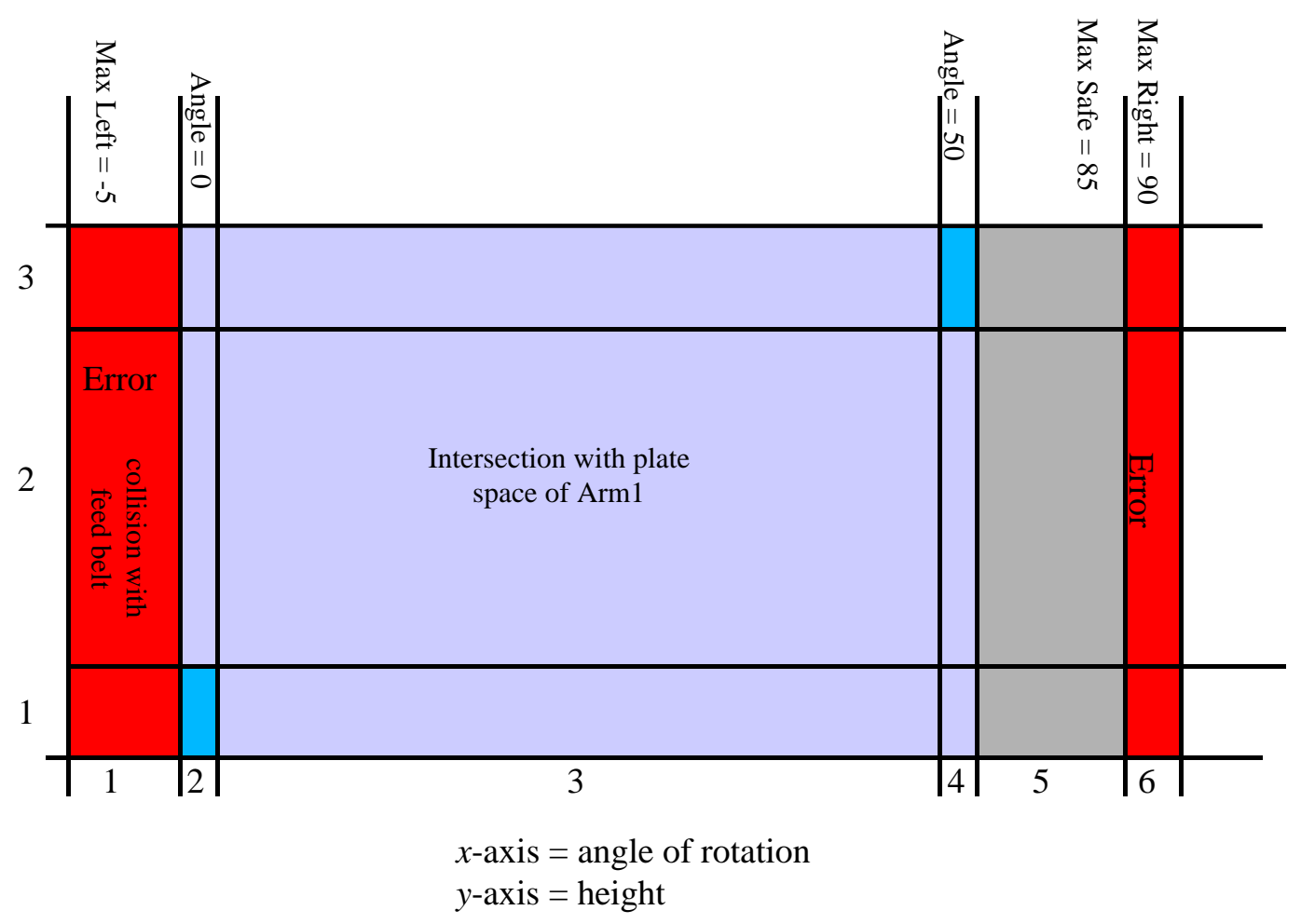

Figure 4: Abstracted State Space of the Elevating Rotating Table

For example the abstracted state space of the elevating rotating table is described as a triple $\left\langle x_{1}, x_{2}, x_{3}\right\rangle$, where $x_{1} \in D_{1}$ and $x_{2} \in D_{2}$ and $x_{3} \in D_{3}$.

The corresponding abstract domains are:

- $D_{1}=\{1,2,3\}$, height

- $D_{2}=\{1,2, \ldots, 6\}$, angle of rotation

- $D_{3}=\{0,1\} \cup\{$ error, hazard $\}$, the presence/absence of plate or safety violation

Given a model of the observable state space of this system, we need to define how the assignment of values to controlled variables changes the system's state. In the most fundamental form, one could explicitly enumerate all possible transitions from every single observable state. However, such an approach typically leads to a very large number of transitions. Even for modest systems, the observable state space can contain 
on the order of $10^{10}$ states, making an exhaustive enumeration approach infeasible. For this reason the state transitions are written in more compact and general terms. This has the unfortunate consequence of increasing their complexity, as well as the likelihood that they contain some errors. Abstractly, the transitions are of the form: $P(\vec{m}) \stackrel{c_{i}=v_{j}}{\longrightarrow} F(\vec{m})$, where $P$ is a predicate on the observable state, $c_{i}=v_{j}$ denotes the assignment of the value $v_{j}$ to the control variable $c_{i}$, and $F: \vec{m} \rightarrow \vec{m}$ is a function on the observable state. In practice, the notation we use is slightly different. We included the expression above to highlight the three aspects of a transition: (1) a boolean expression on the vector of monitored variables, (2) the assignment of a value to a control variable, and (3) a function defining a change of the monitored variables. An example of a transition, defined for the elevating table, is the following:

$\operatorname{system}\left(x \_f b, \operatorname{table}\left(x_{1}, x_{2}, x_{3}\right), x \_r o b o t, x \_p r e s s, x \_d b, x \_c r a n e, x \_f l o o r\right)$

$: x_{1}>1$

$\{$ the table is higher than its bottom position \}

$\rightarrow$ table_down $\rightarrow$

$\operatorname{system}\left(x \_f b, \operatorname{table}\left(x_{1}-1, x_{2}, x_{3}\right), x \_r o b o t, x \_p r e s s, x \_d b, x \_c r a n e, x \_f l o o r\right)$.

Defining physical transitions in the system in terms of symbolic expressions is a difficult step in the requirements engineering process. This is due to the complexity that is introduced by the interaction between system components. For example, if arm 1 of the robot has a particular range of extension, then rotating the robot can result in a collision with the press, given that the press is in particular (wrong) position. From this example, we see that from the perspective of safety, component interaction restricts the state space of components and creates dependencies between the domains that monitored 
variables are quantified over. That is, the values that a monitored variable can assume is constrained by properties of other monitored variables ${ }^{1}$.

As identified in [2] there are three more types of safety constraints in the production cell system other than the component collisions, explained in the previous example.

- Limitation of machine mobility: The robot, for instance, would destroy itself if rotated too far; the press would damage itself if opened too far.

- Demand to keep metal blanks from being dropped outside safe regions: The feed table has to make sure that the table is in the right position before transporting the blank too far.

- Necessities to keep the metal blanks sufficiently separate: Light barriers, for instance, can distinguish two consecutive blanks only if they have sufficient distance.

The safety constraints are very important part of the formal specification of any high consequence system, because they explicitly provide information about what should not happen during the operation of the system, as well as the possible hazardous situations. In order to specify the safety constraints we use the notation similar to transitions, $P(\vec{m}) \longrightarrow F(\vec{m})$. The only difference is the omission of the assignment of some value to a control variable. An example of a safety constraint on the elevating table is the following:

$\operatorname{system}\left(x \_f b, \operatorname{table}\left(x_{1}, x_{2}, x_{3}\right), x \_r o b o t, x \_p r e s s, x \_d b, x \_c r a n e, x \_f l o o r\right)$

$: x_{2}=1$

\{ the table has collided with the feed belt \}

$\rightarrow$

$\operatorname{system}\left(x \_f b, \operatorname{table}\left(x_{1}, x_{2}\right.\right.$, error $\left.), x \_r o b o t, x \_p r e s s, x \_d b, x \_c r a n e, x \_f l o o r\right)$

\footnotetext{
${ }^{1}$ For example, the monitored variable $m_{i}$ can only have value $r$ when the monitored variable $m_{j}$ has value that is less than $s$.
} 


\section{CHAPTER 4: USING VR FOR VALIDATION}

\subsection{Building a Visual Model}

Given a model of the state space of a system, $\vec{s}=\vec{m} \circ \vec{c}$, and a set of transitions and safety constraints, we are interested in graphically displaying the following fundamental aspects of the model:

- The observable state space $D_{1} \times \ldots \times D_{j}$, or subsets of the observable state space comprised of some of the defined domains, for example, $\left\{D_{i}, D_{k}, D_{m}\right\}$. where $1 \leq i, k, m \leq j$.

- Subsets of the observable state space defined by predicates (e.g., $P(\vec{m}))$. We found it useful to display these subsets in the context of the portion of observable state space (e.g., $\left.\left\{D_{i}, D_{k}, D_{m}\right\}\right)$ currently being viewed.

- Functions $F(\vec{m})$, in terms of explicit sets of input output pairs. We found that viewing these types of functions (graphical representation of sets), representing the totality of the input-output relation defined by the function, is useful.

- Transitions $P(\vec{m}) \stackrel{\vec{c}}{\longrightarrow} F(\vec{m})$. A transition can be displayed by first showing the subset defined by the $P(\vec{m})$ and then using this set as the input domain for $F$.

- Safety constraints $P(\vec{m}) \longrightarrow F(\vec{m})$ can be visualized by displaying the output of the function $F(\vec{m})$ for the current system state, and using different colors to represent different types of violations.

In addition to displaying the basic aspects of system models described above, we developed a set of operators and a calculus for displaying the behavioral aspects of these 
models. Animation operators that we found useful for understanding and validating system models are [1]:

- Finite repetition of transition,

- Transitive closure of transition,

- Sequential composition of transitions,

- Parallel composition of transitions, and

- Parallel composition transition sequences.

Our present approach is to display the observable state space as a collection of transparent geometric objects (mostly cubes) that stand in some geometric relationship to one another (e.g., touching, overlapping, etc.). Here, a geometric object represents a portion of the observable state. More precisely, geometric objects are defined by coordinate vectors that map directly onto subvectors of $\vec{m}$. In general, Euclidean relationships that objects need to satisfy are determined by the corresponding relationships present in the physical system. In this way, the objects in the model are bound to the objects (and reflect attributes) of the physical system.

In the Production Cell case study, we developed a formal model that describes the visualization of the state spaces of different components and the spatial relationships that these components have between each other. As a robotic system, most of the monitored variables represent positions in the three dimensional (3D) space of different system components. The most natural way to visualize them is to build a $3 \mathrm{D}$ model that represents the spatial information about different components and their interaction. We augmented the representation of the state space of the model in order to display animation operators, which represent the other formal constructs, such as transitions and safety constrains.

A prototype of this visualization system was developed at Sandia National Labs using OpenGL and GLUT libraries. It runs in Unix/Windows environments. Screenshot of this system is shown in Figure 5. The next section describes our effort to improve this system by porting it to a virtual reality environment. 


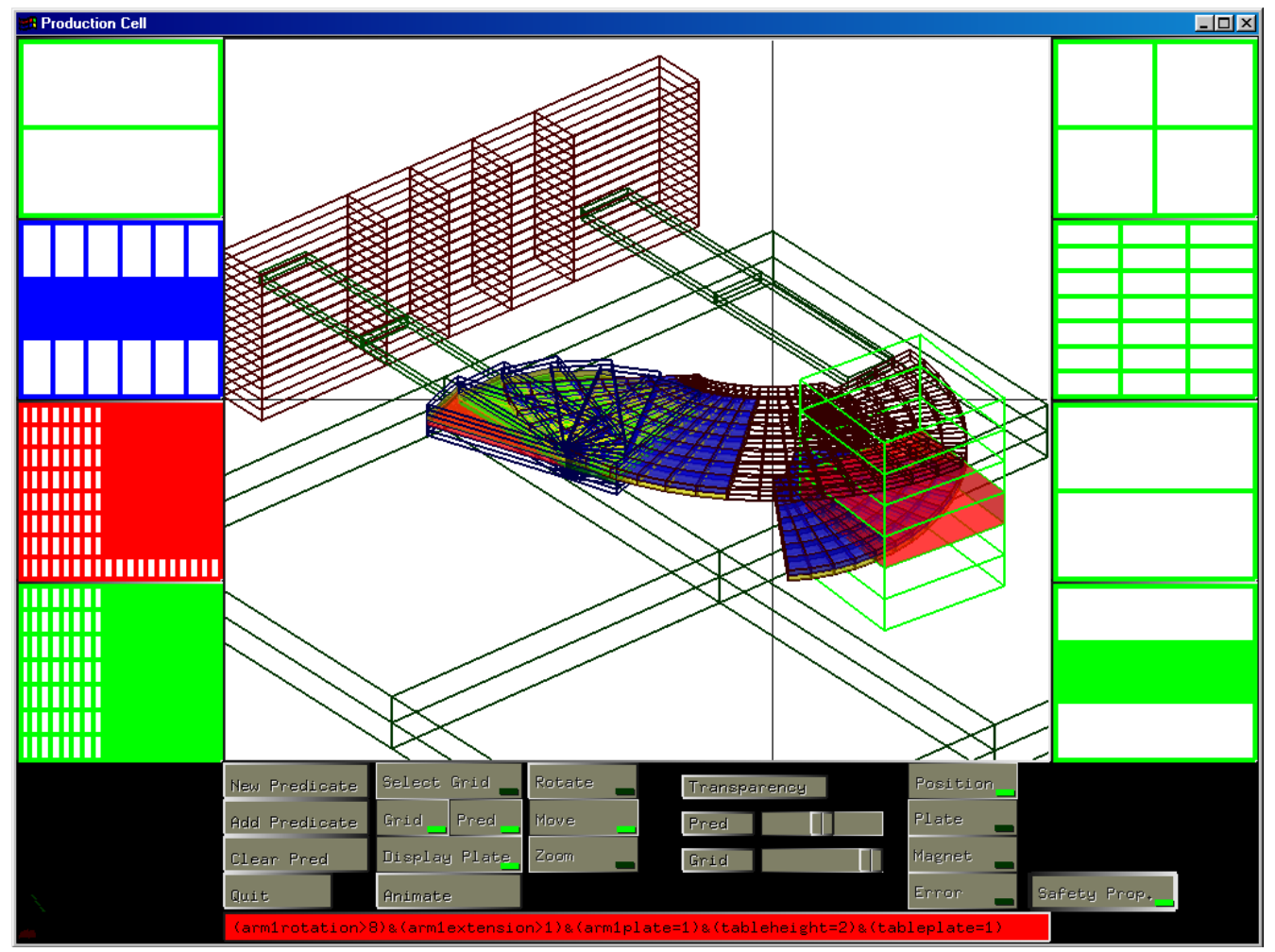

Figure 5: Visualization of the Production cell

\subsection{Building a Virtual Reality Model}

Viewing three-dimensional objects, representing the system state space, on a $2 \mathrm{D}$ display results in difficult understanding of the spatial relationships among different components. For this reason, we extended our visualization system to run on an ImmersaDesk Virtual Reality System (see Figure 6).

Virtual Reality (VR) can be defined as interactive computer graphics that provides viewer-centered perspective, large field of view, and stereo [6]. ImmersaDesk is a drafting table VR format display. It features a $65 \times 50$ inch rear projected screen at a 45-degree angle. Up to 5 users wear shutter glasses to view high-resolution stereoscopic images. 


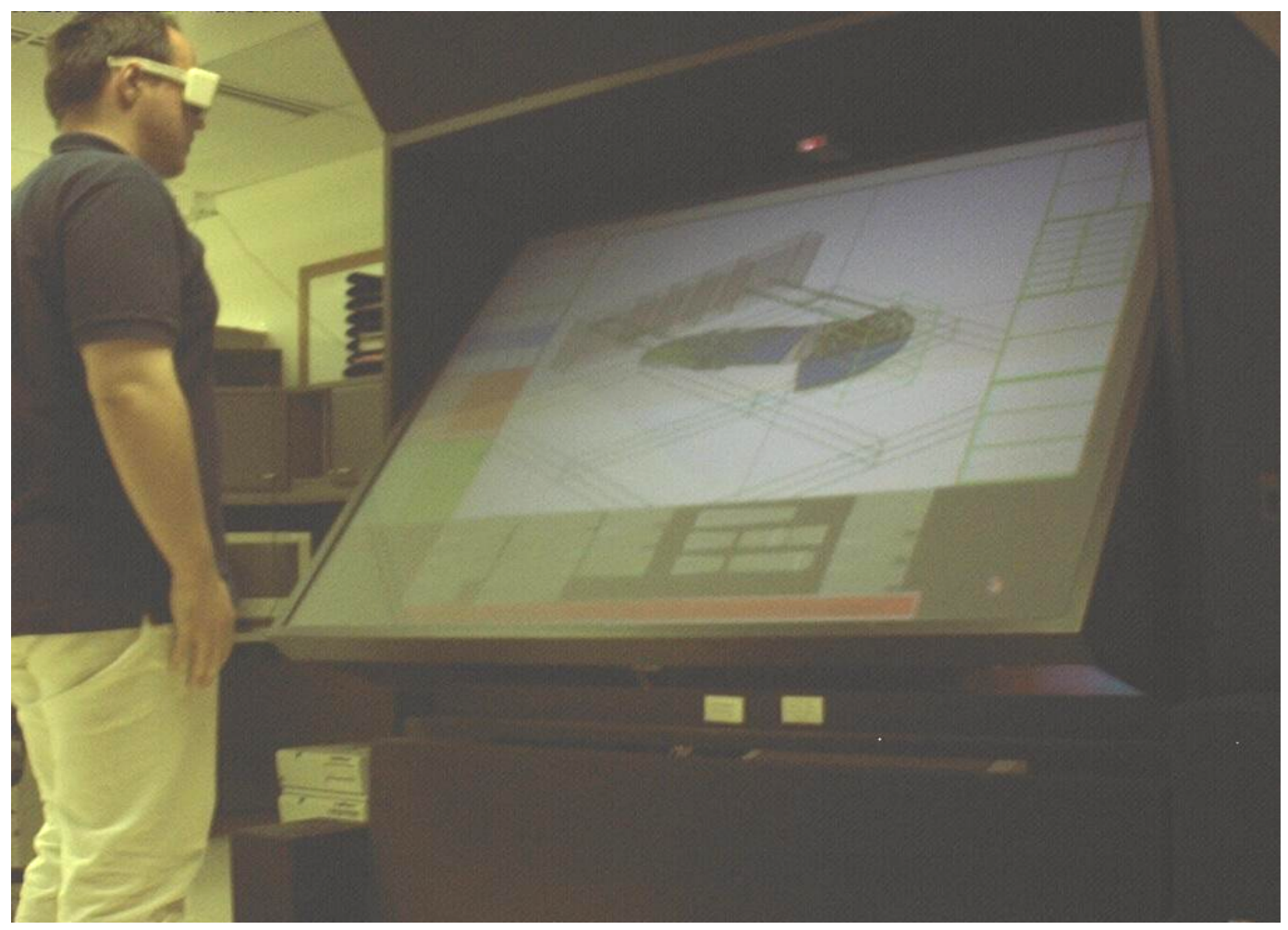

Figure 6: VR model of the Production cell

The prototype that was developed at Sandia National Labs was programmed in OpenGL and GLUT libraries. One of the main concerns during the building the Virtual Reality model of the Production Cell was to create a software that will run on both ImmersaDesk and PC with minimal changes. Having this in mind we have decided to continue the development using OpenGL and GLUT libraries instead of programming new prototype using legacy CAVE libraries or World Tool Kit that have full support for the ImmersaDesk hardware. One drawback of this approach was the fact that GLUT library currently does not have support for the wand controller and the tracking sensors, but one of our future goals is to develop interface for the GLUT library to these devices.

The improved prototype has eight panels that represent the state spaces of different components of the system. The states are represented as 3D cubes. By clicking on some state we can change the status of that state. The change is displayed in the main viewport that represents the whole system stereoscopically in 3D. Using the provided 
buttons we can change the status of different states, introduce new predicates in order to be displayed, and fly around the system in order to focus on some important detail. The current predicate that is displayed is presented in a text field in the bottom of the screen.

First step of the development was to extend the previous prototype with the ability to specify and display safety constraints that we have introduced. This was done by adding two new state variables to the representation of the states of the system, representing error and hazardous conditions. The display of hazardous safety violation is done by coloring the appropriate state of the system with red color, and similarly error safety violation is represented by black color.

Then, we have added an evaluation function that monitors the state of the system and displays the specified safety constraints. Whenever there is a change of the state of the system, the evaluation function determines whether some of the predicates of the safety constraints is satisfied, and displays the states that are specified in the safety constraint.

In order to have appropriate demonstration of the capabilities of the system, we have created an animation of the normal operation of the production cell. The life cycle of a plate is being followed trough the system, and possible hazards are displayed. The animations of separate component transitions were modified in order to take into account the newly defined safety constraints.

The final work was to modify the application in order to obtain stereoscopic view of the system. This was done by using the GLUT stereoscopic capability. Separate view is calculated (rendered) for the left and the right eye of the viewer applying appropriate transformations in order to obtain regular 3D view of the system. Then each of the views is displayed, synchronized with the stereoscopic glasses in order to obtain 3D viewing effect.

One of the advantages of using OpenGL and GLUT libraries is the fact that the same software written for the ImmersaDesk runs on a PC with appropriate graphic card that supports stereoscopic glasses, and if we don't like 3D display we can use any graphic card. On the other hand, for now, we are confined in using mouse and keyboard as input 
devices in the ImmersaDesk environment, which is not very appealing. We hope that in the future this problem will be solved.

\subsection{Discussion}

For software requirements analysis, the use of VR environment definitely increases the level of interaction between the system validator (domain expert, formal methods expert, etc.) with the model. The user is immersed in the system environment, which allows him to move the viewpoint and to focus his/her attention on different parts of the system.

As mentioned earlier, ImmersaDesk environment allows multiple users to interact together. This is a very attractive feature in the validation process. The domain experts and members of the formal specification team can go through the system, step by step, and discuss the features of the formal model in the VR environment. The system model would be validated the domain expert feels convinced that the VR model behaves according to the expectations. Ideally, the domain expert facing the VR model should feel satisfied with all the observed system behaviors, and should be unable to differentiate the virtual model from the final product, provided they have the same interface. From the behavioral point of view, the VR model and the final product must both behave the same way.

We also need to make a distinction between the simulation of the system and the proposed validation model. Each simulation represents one possible scenario in the system history. When the number of the possible states in the system is large, validating by simulation becomes infeasible, because the number of possible scenarios grows dramatically. On the other hand the proposed VR validation method is concerned with validating the formal model of the system, that is, validating the transitions with respect to the safety constraints. If each of the transitions is validated to be correct then the system model is validated. A superposition of multiple states can be specified in our prototype system, and we can observe the effects of transitions on them simultaneously. 
Unlike following a single trajectory through the system state space which is done during simulation. We believe that by using graphical representation, the process of validating the transitions can be greatly enhanced and expedited in contrast with using symbolic calculation. Most importantly, domain experts, formal methods experts and even the final system users can be included in the validation process in a very efficient way.

\subsection{Analysis of Specification Using Virtual Model}

This section provides a simple example in demonstration of the proposed methodology. We describe specifying the conditions under which the robot arml can deposit the plate on the press. We are also interested in displaying the safety constraints that exist under these conditions. The complexity in the real problem from which this example is derived, arises from the spatial dependencies that exist between the robot arms and the press. For example, if the robot arml is not in the proper position, it can drop the plate on the floor, thus violating the safety constraints. Furthermore, if the press is not in the right position for accepting the plate from the robot arml a collision can occur.

We begin by formally defining the abstracted observable state space of the robot and the press.

$$
\begin{aligned}
& \text { Robot }=\left\langle x_{1}, x_{2}, x_{3}, x_{4}, x_{5}, x_{6}, x_{7}\right\rangle \\
& \text { Press } \left.=<x_{8}, x_{9}\right\rangle \text { and } \\
& \forall i: 1 \leq i \leq 9 \rightarrow x_{i} \in D_{i} \text { where } \\
& D_{1}=\{1,2, \ldots, 19\}=\text { angle of rotation } \\
& D_{2}=\{1,2, \ldots, 8\}=\text { extension of arm } 1 \\
& D_{3}=\{0,1\}=\text { arm } 1 \text { magnet off / on } \\
& D_{4}=\{0,1, \text { error, hazard }\}=\text { absence / presence of plate for arm } 1 \text { or safety violation } \\
& D_{5}=\{1,2, \ldots, 7\}=\text { extensionof arm } 2 \\
& D_{6}=\{0,1\}=\text { arm } 2 \text { magnet off / on } \\
& D_{7}=\{0,1, \text { error, hazard }\}=\text { absence / presence of plate for arm } 2 \text { or safety violation } \\
& D_{8}=\{1,2,3\}=\text { press position } \\
& D_{9}=\{0,1, \text { error, hazard }\}=\text { absence / presence of plate for press or safety violation }
\end{aligned}
$$




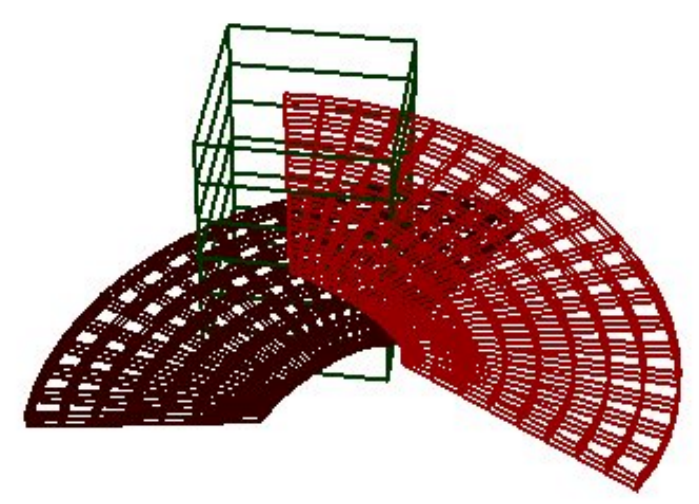

Figure 7: The state space of the subsystem containing the press and robot arms.

When building a visual representation, formal description of the abstracted state space is combined with the spatial knowledge about the system. We are interested in the spatial relationships among the states. In this particular example, we are interested in the spatial relationships between the states describing the press and arml.

Given the appropriate spatial information, we next construct a graphical representation corresponding to the formal description given above. The observable state space of the system is represented in Figure 7. Then we can proceed by projecting predicates onto the graphical representation and their validation.

We display the following predicate from the original version of the formal model: $P\left(x_{1}, x_{2}, x_{3}, x_{4}, x_{5}, x_{6}, x_{7}, x_{8}, x_{9}\right)=x_{1}<5 \wedge x_{2}>2 \wedge x_{8}=2$.
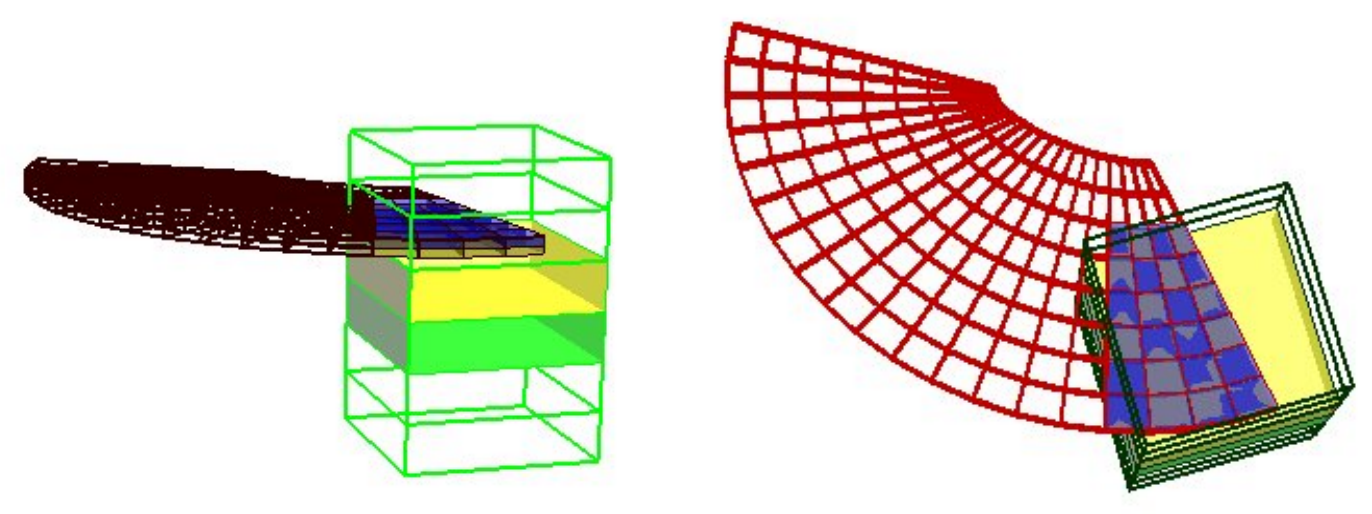

Figure 8: Two views of the specified predicate 
This predicate represents the portion of the space where the robot arml can safely deposit the plate to the press. The plate is deposited safely only if the press is in the proper position to accept the plate. Graphical representation of this predicate is presented in Figure 8. The ability to animate the viewpoint and to fly around the objects provides a great help in the comprehension of the spatial relationship between the objects. From the top view (Figure 8, right), we realized that some boundary states of the robot arm were not fully contained in the state space of the press. Dropping the plate in these states could result in a safety violation. So the correct predicate for the interaction between the arm 1 and the press should be the following:

$$
P\left(x_{1}, x_{2}, x_{3}, x_{4}, x_{5}, x_{6}, x_{7}, x_{8}, x_{9}\right)=x_{1}<4 \wedge x_{2}>3 \wedge x_{8}=2 .
$$

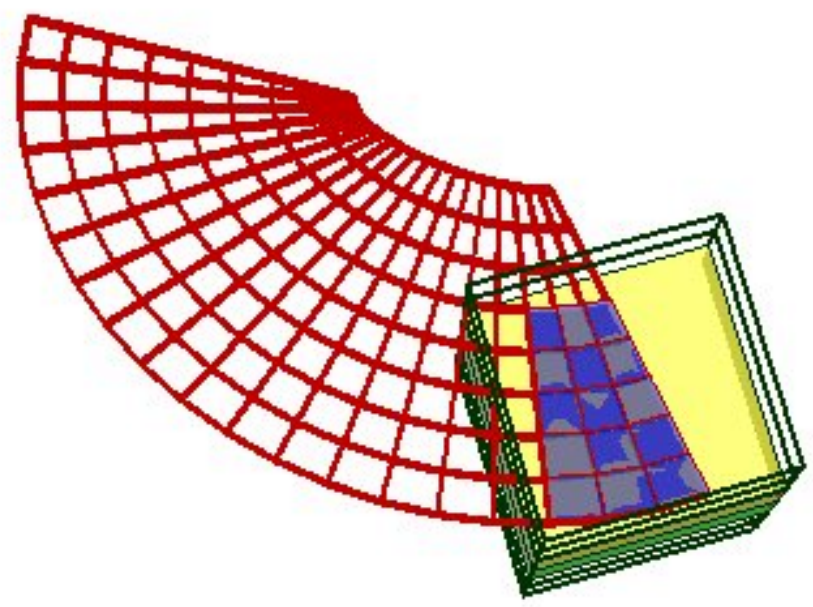

Figure 9: Corrected predicate

This new predicate is shown in Figure 9. Viewing this predicate helps us understand that it describes the intended portion of the state space. After validation, this predicate can be used as part of a precondition defining the following state transition: 
$\operatorname{system}\left(\operatorname{robot}\left(x_{1}, x_{2}, x_{3}, x_{4}, x_{5}, x_{6}, x_{7}\right), \operatorname{press}\left(x_{8}, x_{9}\right)\right)$

$: x_{1}<4 \wedge x_{2}>3 \wedge x_{3}=1 \wedge x_{4}=1 \wedge x_{8}=2 \wedge x_{9}=0$

$\rightarrow$ arm1_mag_off $\rightarrow$

$\operatorname{system}\left(\operatorname{robot}\left(x_{1}, x_{2}, 0,0, x_{5}, x_{6}, x_{7}\right), \operatorname{press}\left(x_{8}, 1\right)\right)$

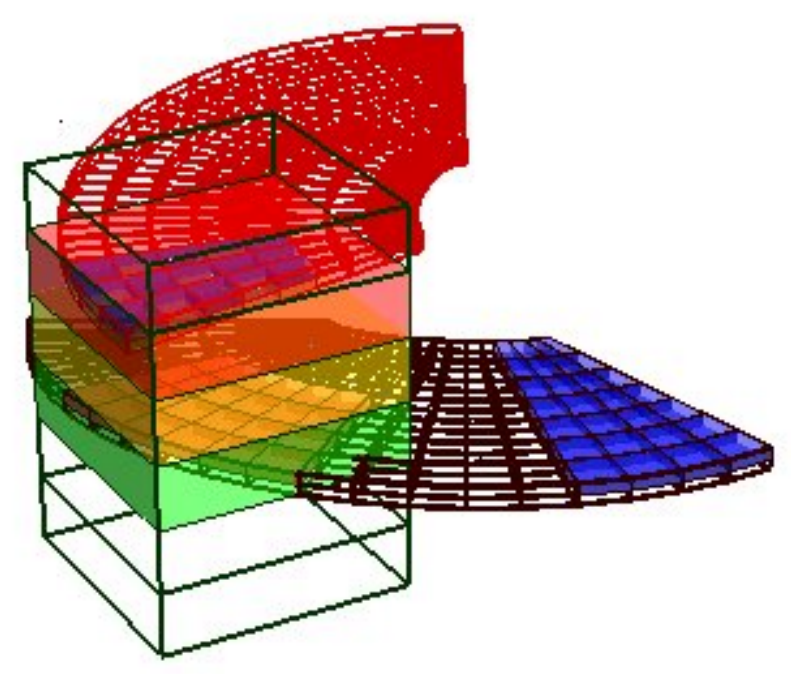

Figure 10: Hazardous states

We continue by displaying the safety constraints that exist in this state of the system.

In Figure 10, we can the possible hazards (represented with transparent red blocks) that can result in the states describing the interaction between the arml of the robot and the press. If the press moves up while the robot arml is in the position described by the previous predicate a collision can occur. Second, if the robot starts rotating right there is a possibility of a collision between the press and the robot arm2. 
An example of these safety constraints is the following:

$\operatorname{system}\left(\operatorname{robot}\left(x_{1}, x_{2}, x_{3}, x_{4}, x_{5}, x_{6}, x_{7}\right), \operatorname{press}\left(x_{8}, x_{9}\right)\right)$

$: x_{1}<5 \wedge x_{2}>2 \wedge x_{8}=2$

$\rightarrow$

$\operatorname{system}\left(\operatorname{robot}\left(x_{1}, x_{2}, x_{3}, x_{4}, x_{5}, x_{6}, x_{7}\right), \operatorname{press}\left(x_{8}+1\right.\right.$, hazard $\left.)\right)$

If we had a predicate that contains a collision condition, then the resulting safety violation is of type error. In the visual model, errors are represented by black transparent blocks. An example follows:

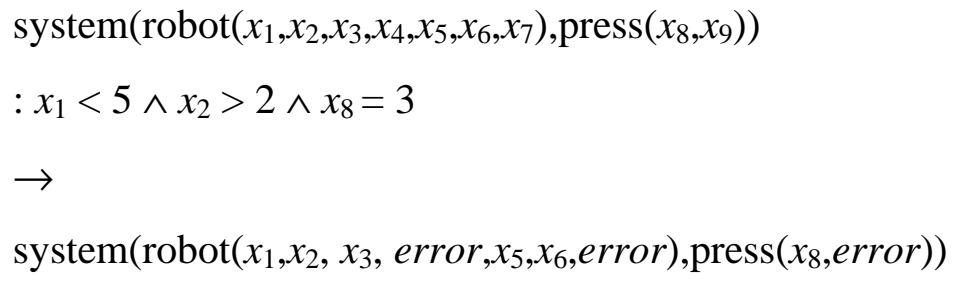




\section{CHAPTER 5: CONCLUSIONS \& FUTURE WORK}

Current requirements validation techniques do not address the problem of demonstrating the correctness of the formalization phase satisfactorily. This problem is especially significant in the realm of high consequence systems. Current techniques do not provide friendly interfaces for domain experts, although they have the most complete knowledge of the system being built. We believe that validation techniques based on reasoning about symbolic system representation do not take advantage of the human cognitive process. These problems can be addressed by having a suitable virtual environment system model in which symbolic formulas can be projected, visualized and validated.

A significant number of systems have physical characteristics that make them suitable candidates for visual validation techniques based on the ideas described in this paper. We developed an initial theoretical and practical framework for displaying such systems in virtual environments and described its use for validation purposes. We also developed a prototype system to demonstrate and refine our ideas. Although the proposed method induces higher cost in the requirements formalization phase, the cost can be justified in the development of high consequence systems.

Building the virtual model from the formal model can be expensive in terms of the required time, and VR capable hardware. The cost of VR capable hardware is a minor concern, since cheaper portable CAVE-like environments powered by high performance PCs are already available. Upon experimenting with our model we are convinced that the benefits gained, especially when high consequence systems are concerned, outweigh the development expense too.

One way to decrease this cost would be to build a tool that can automatically generate the virtual model of a given system, instead of creating them by hand like in the current prototype. In this case, the spatial constraints and relationships that exist among system components would become a part of the formal specification. Our prototype specification language for formal description of spatial relationships and constraints that 
a virtual model must satisfy is under development. Spatial relationships and constraints can be viewed in multiple visual representations describing systems and combinations of subsystems. Allowing multiple graphical representations is useful because they permit alterations that enhance understandability while preserving the specified properties. However, this approach complicates automatic generation of graphical interpretations. One of our research goals is to address this problem in a suitable manner.

Another pending question is: How well are the systems in general suited for visualization? As argued earlier, robotic system are very suitable candidates for virtual environment modeling because their state space is in 3D space. As such, it be easily mapped into a virtual environment. But it is certainly a challenging problem to find suitable visual models for some other types of systems. A good visual model must be intuitive and clear to both, the domain expert and the specifier.

It is our conclusion that using a virtual reality system, such as ImmersaDesk, greatly enhances the ability of the specifier to grasp the system model and spatial dependencies among different states. The ability to view the system in 3D using different viewpoints, and improved interaction between the domain expert and the model are the main arguments in favor of our conclusion. Furthermore, having the visual model allows multiple interested parties to argue and validate the correctness of different transitions and safety constrains. This introduces a new quality in the formalization process.

Another area of future work is to explore efficient ways of interaction between the users and virtual models, and the interaction between multiple users during system validation. 


\section{BIBLIOGRAPHY}

[1]. V. L. Winter, T. P. Caudell. Using Virtual Reality to Validate System Models. Proceedings of the Second International Conference on High Integrity Software (HIS), November 1999.

[2]. C. Lewerentz, T. Lindner. Formal Development of Reactive Systems: Case Study Producton Cell. Lecture Notes in Computer Science Vol. 981, Springer-Verlag.

[3]. N. G. Leveson. Software Safety: Why, What, and How. Computing Surveys, Vol. 18, No. 2, June 1986.

[4]. C. Heitmeyer, J. Kirby, B. Labaw, R. Bharadwaj. SCR*: A Toolset for Specifying and Analyzing Requrements. Proceedings of 10th Ann. Conference on ComputerAided Verification, (CAV'98), Vancouver, Canada, 1998

[5]. P. J. Courtois, D. L. Parnas. Documentation for Safety Critical Software. Proceedings of $15^{\text {th }}$ Intl. Conference on Software Engineering, Baltimore, MD, 17 - 21 May, 1993.

[6]. M. Czernuszenko, D. Pape, D. Sandin, T. DeFanti, G. L. Dawe, M. D. Brown. The ImmersaDesk and Infinity Wall Projection-Based Virtual Reality Displays. Computer Graphics, May 1997.

[7]. C. Cruz-Neira, R. R. Lutz. Using Immersive Virtual Environments for Certification. IEEE Software, Vol. 16, No. 4, July/August 1999.

[8]. C. L. Swider, K. W. Bauer Jr., T. F. Schuppe. The Effective Use of Animation in Simulation Model Validation. Proceedings of 1994 Winter Simulation Conference, Lake Buena Vista, FL, December 11-14, 1994.

[9]. M. W. Rohrer. Seeing is Believing: The Importance of Visualization in Manufacturing Simulation. Proceedings of the 2000 Winter Simulation Conference, Orlando, Fl.

[10]. N. Boudriga, F. Elloumi, A. Mili. On the lattice of specifications: Applications to a specification methodology. Formal Aspects of Computing, vol. 4, pp. 544-571, 1992. 
[11]. J. M. Spivey. Understanding Z: a specification language and its formal semantics. Cambridge University Press, 1988.

[12]. V. L. Winter. A Synchronous Paradigm for Modeling Stable Reactive Systems. Proceedings of the $4^{\text {th }}$ International Symposium on High Assurance Systems Engineering (HASE), November 1999.

[13]. A. Mili. Formal Methods in Software Engineering. Class notes, West Virginia University. Morgantown, WV, Fall 2000. 


\section{APPENDIX A: MODEL OF THE PRODUCTION CELL}

by Dr. Victor Winter, Dejan Desovski

\section{Model of the Production Cell}

\subsection{Feed Belt Model}

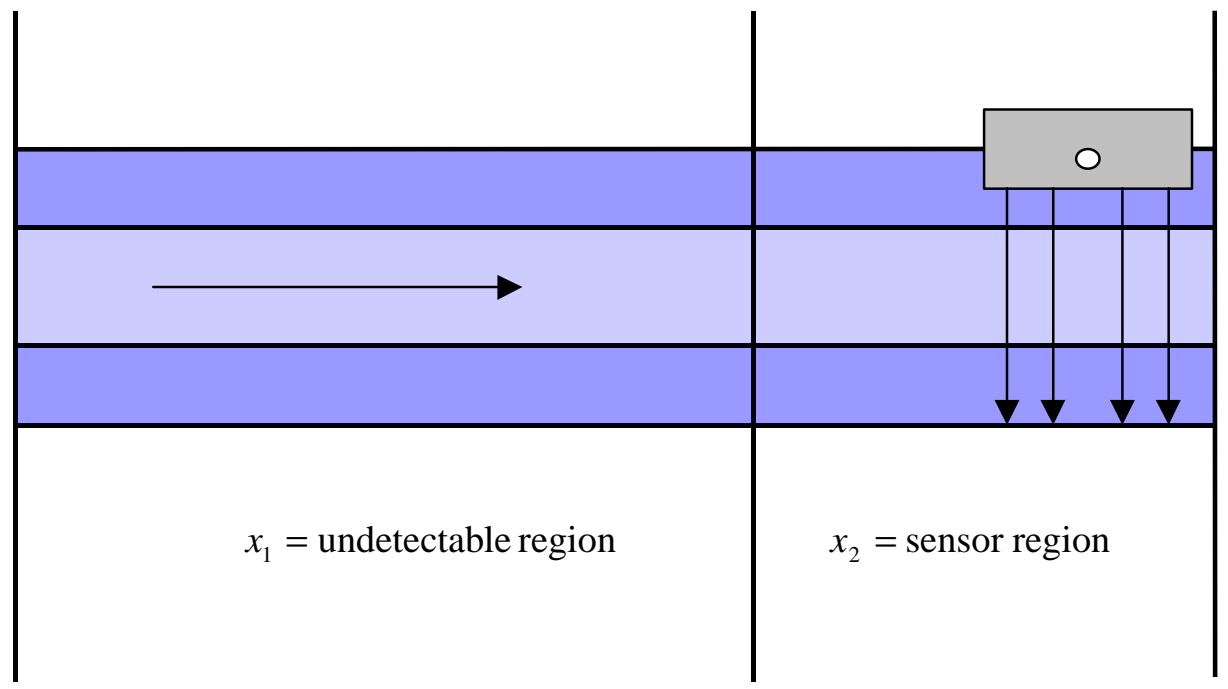

Figure 11: Feed Belt State Space

- $\quad$ State Space $=\left\langle x_{1}, x_{2}\right\rangle$

- where $x_{1} \in D_{1}, x_{2} \in D_{2}$

- $\quad$ Abstract Domains =

$-D_{1}=\{0,1\} \cup\{$ error, hazard $\}=$ absence / presence of plate or safety violation

$-D_{2}=\{0,1\} \cup\{$ error, hazard $\}=$ absence / presence of plate or safety violation 


\subsection{Elevating Rotating Table Model}

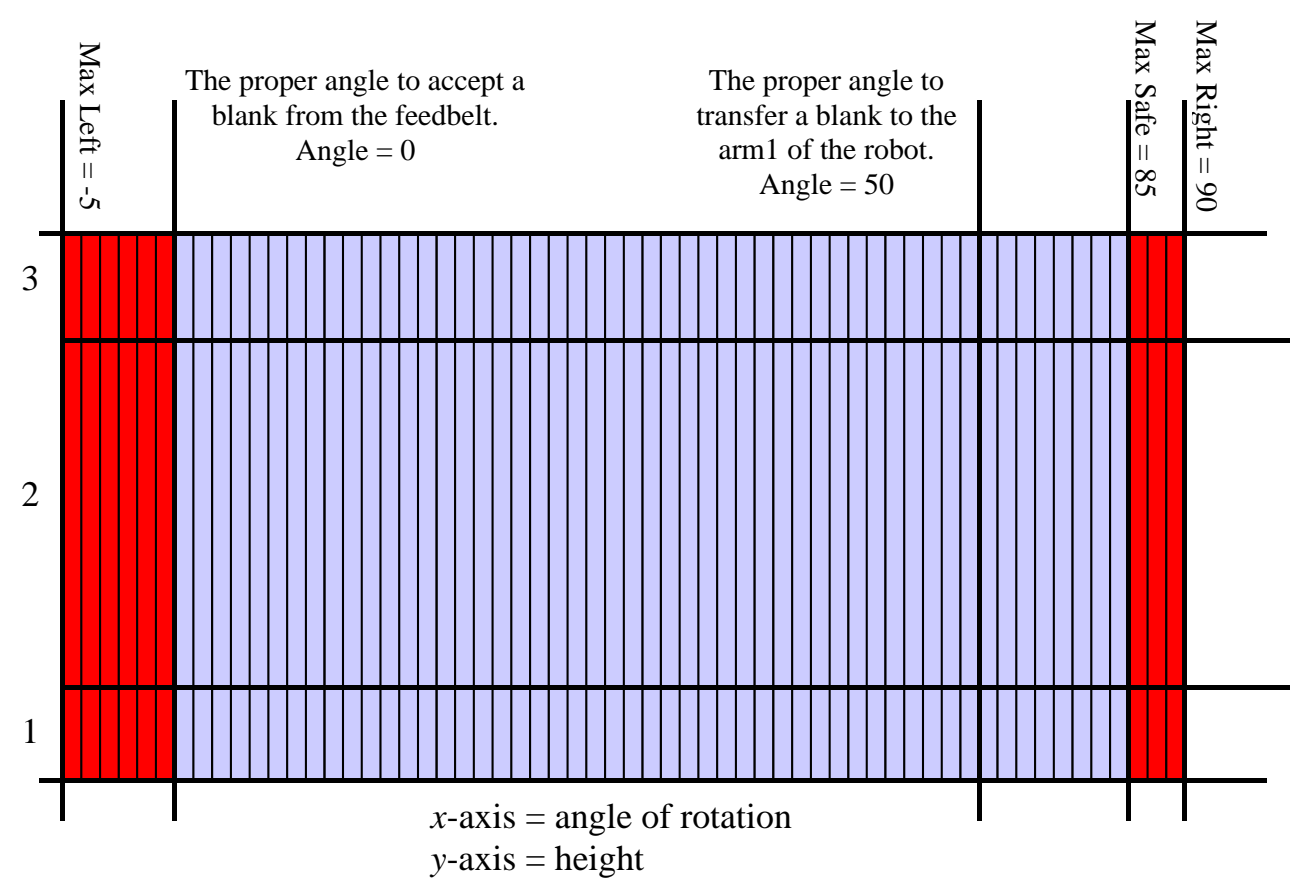

Figure 12: State Space of the Table

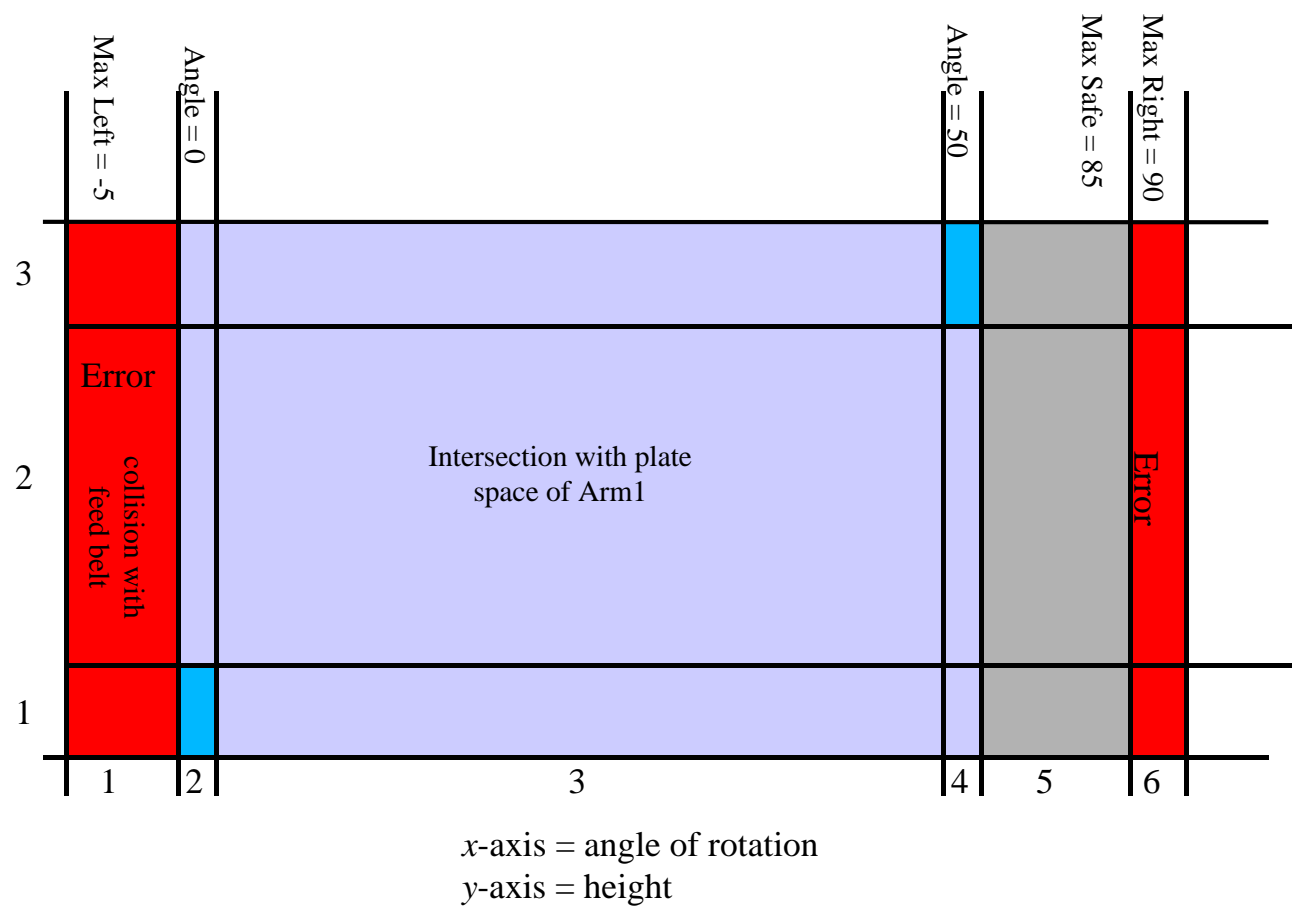

Figure 13: Abstracted State Space of the Table 
- $\quad$ State Space $=\left\langle x_{3}, x_{4}, x_{5}\right\rangle$

- where $x_{3} \in D_{3}, x_{4} \in D_{4}, x_{5} \in D_{5}$

- $\quad$ Abstract Domains =

$-D_{3}=\{1,2,3\}=$ height

$-D_{4}=\{1,2, \ldots, 6\}=$ angle of rotation

$-D_{5}=\{0,1\} \cup\{$ error, hazard $\}=$ presence / absence of plate or safety violation

\subsection{Robot Model}

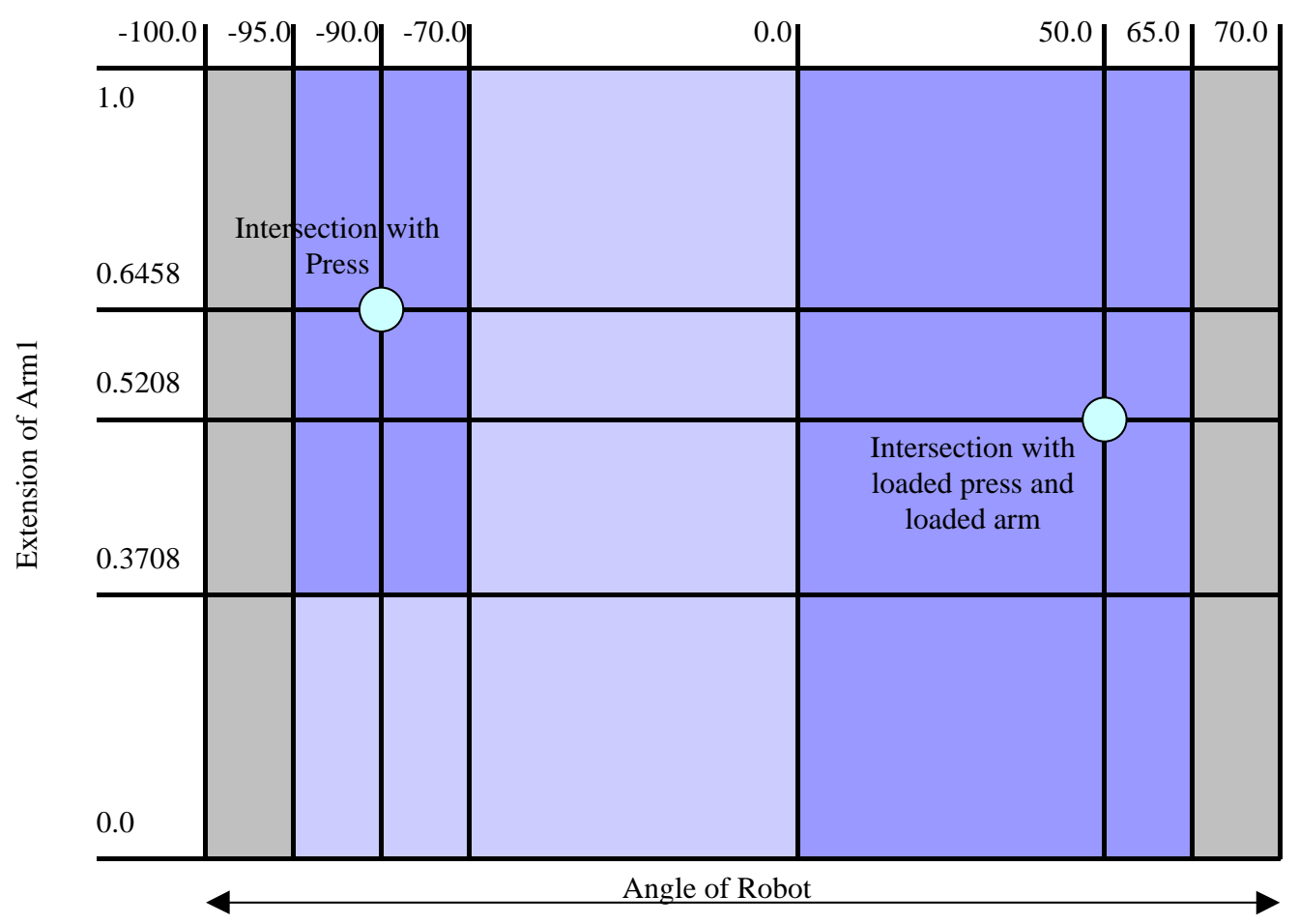

Figure 14: State Space of Robot Arm1 


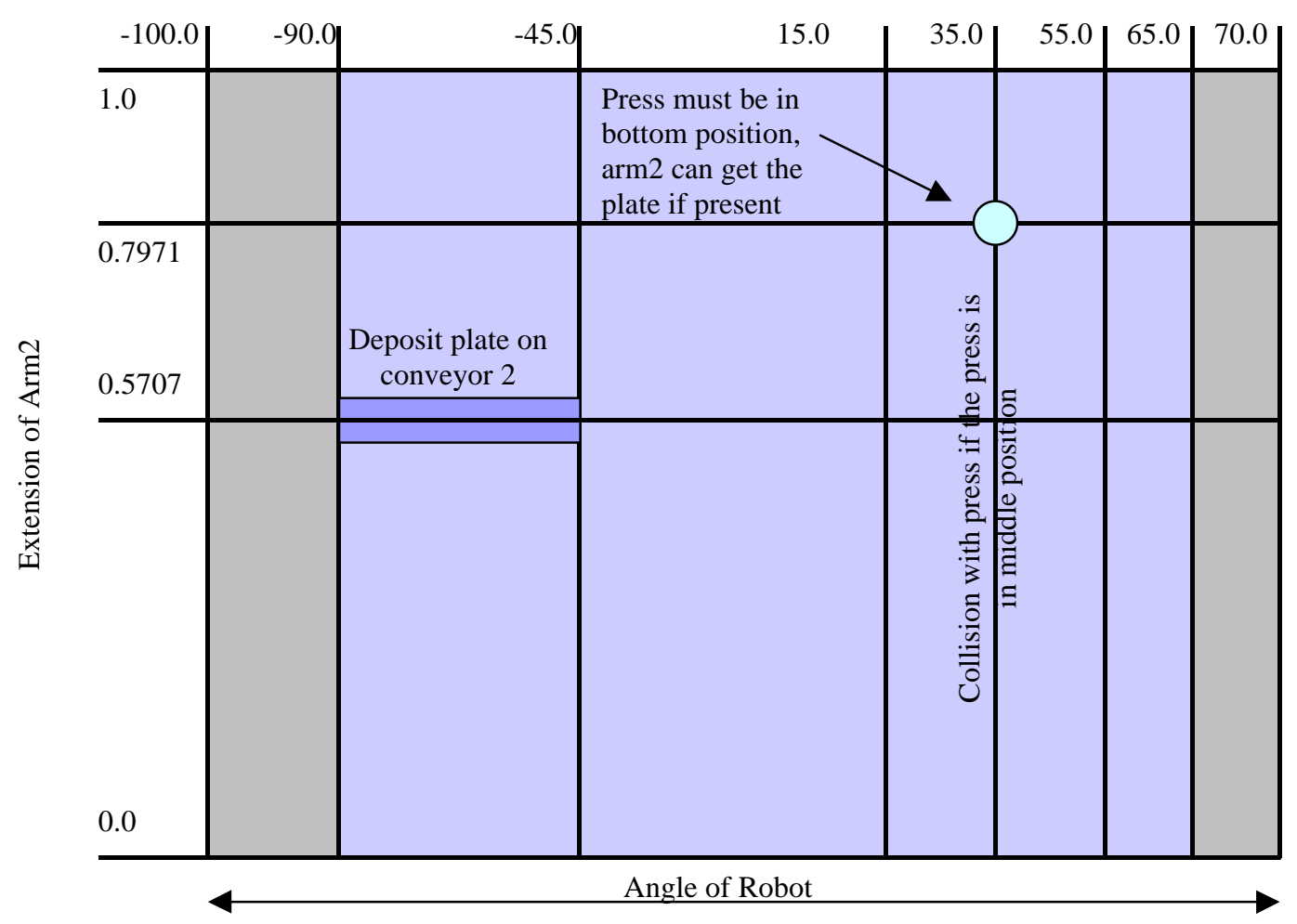

Figure 15: State Space of Robot Arm2

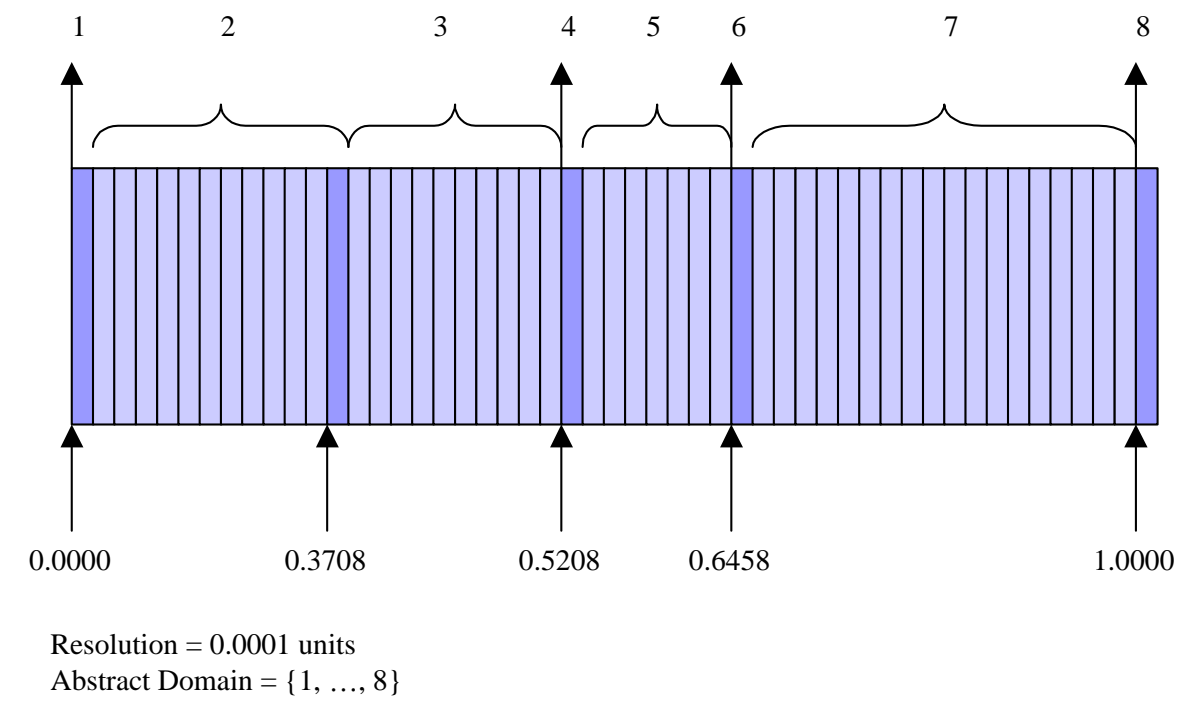

Figure 16: Extension Space of Arm1 


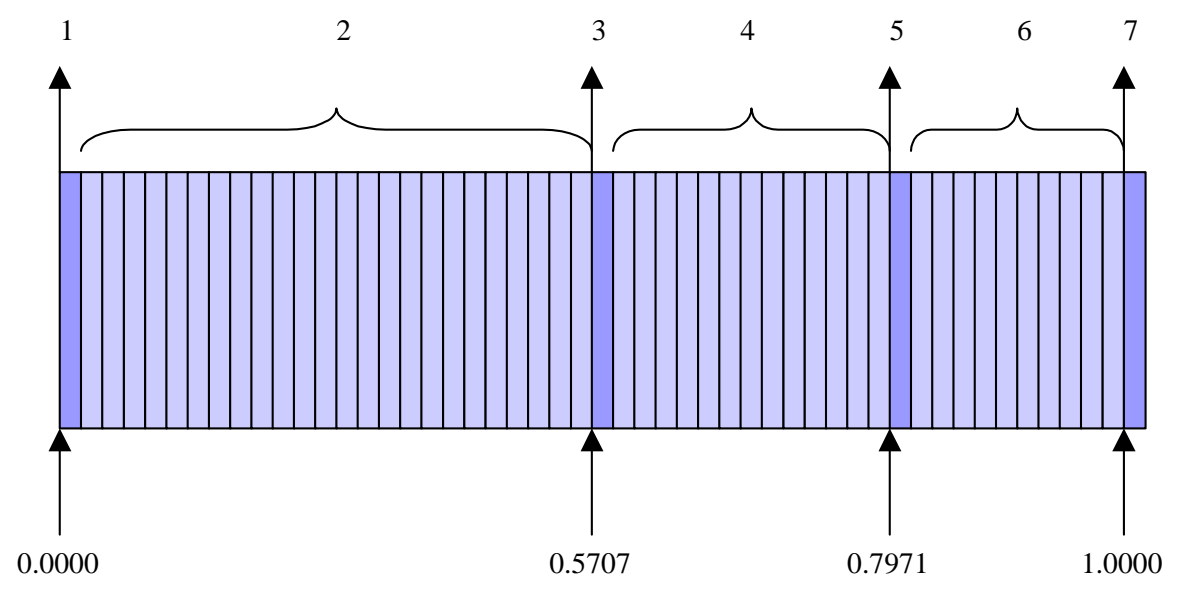

Resolution $=0.0001$ units Abstract Domain $=\{1, \ldots, 7\}$

Figure 17: Extension Space of Arm2

- State Space $=\left\langle x_{6}, x_{7}, x_{8}, x_{9}, x_{10}, x_{11}, x_{12}\right\rangle$

- Abstract Domains =

$-D_{6}=\{1,2, \ldots, 19\}=$ angle of rotation

$-D_{7}=\{1,2, \ldots, 8\}=$ extension of arm 1

$-D_{8}=\{0,1\}=$ arm 1 magnet off $/$ on

$-D_{9}=\{0,1\} \cup\{$ error, hazard $\}=$ absence / presence of plate for arm 1 or safety violation

$-D_{10}=\{1,2, \ldots, 7\}=$ extension of arm 2

$-D_{11}=\{0,1\}=$ arm 2 magnet off $/$ on

$-D_{12}=\{0,1\} \cup\{$ error, hazard $\}=$ absence / presence of plate for arm 2 or safety violation 


\subsection{Press Model}

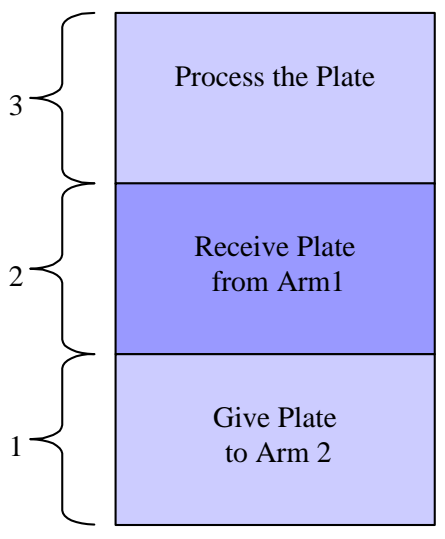

Figure 18: State Space of the Press

- $\quad$ State Space $=\left\langle x, x_{14}\right\rangle$

Abstract Domains $=$

$-D=\{1,2,3\}=$ position

$-D_{14}=\{0,1\} \cup\{\quad$, hazard $\}=$ presencel of plate safetyviolation 


\subsection{Deposit Belt Model}

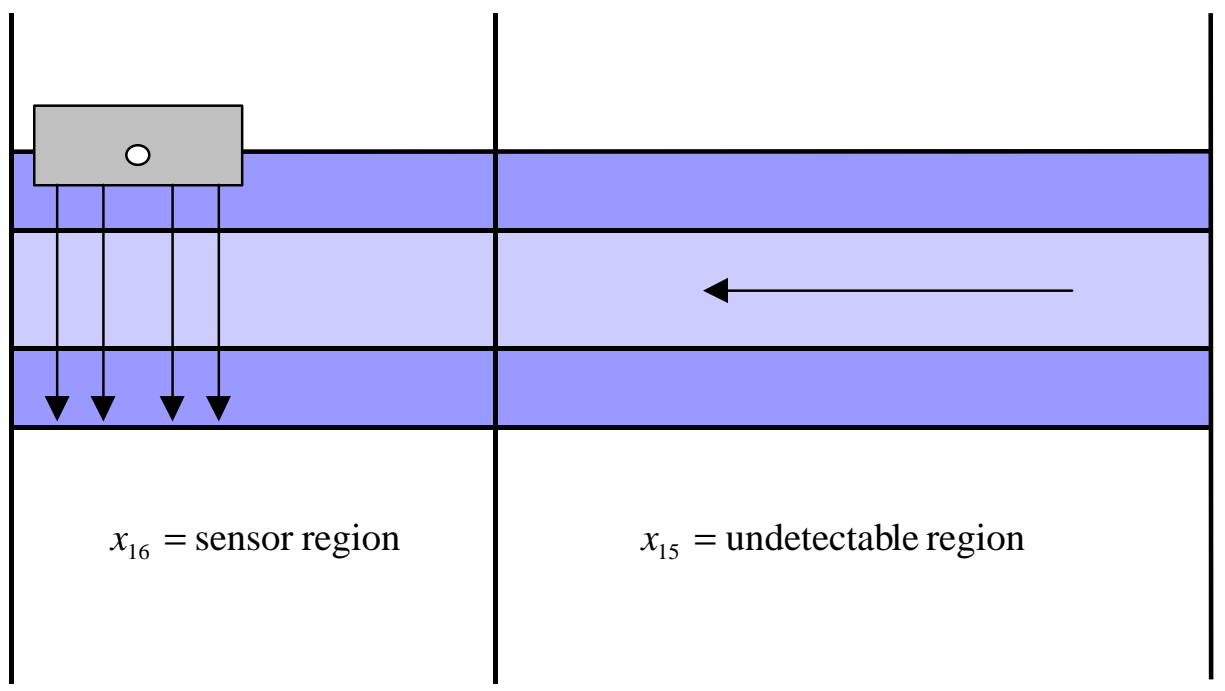

Figure : Deposit Belt State Space

$$
\left\langle x_{15}, x_{16}\right\rangle
$$

- $\quad$ Abstract Domains =

$-D_{15}=\{0,1\} \cup\{$ error, hazard $\}=$ presence / absence of plate or safety violation $-D_{16}=\{0,1\} \cup\{$ error, hazard $\}=$ presence / absence of plate or safety violation 


\subsection{Crane Model}

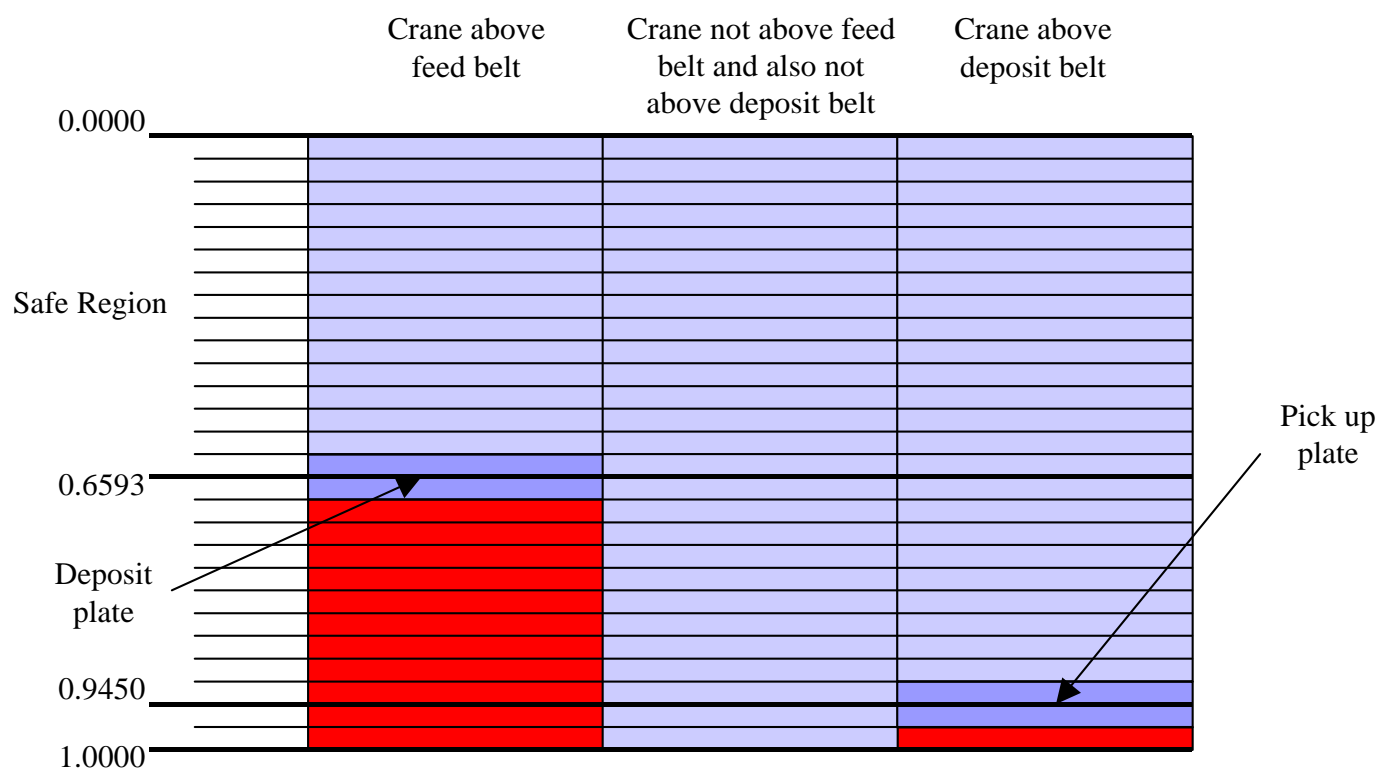

Figure 20: State Space of the Crane

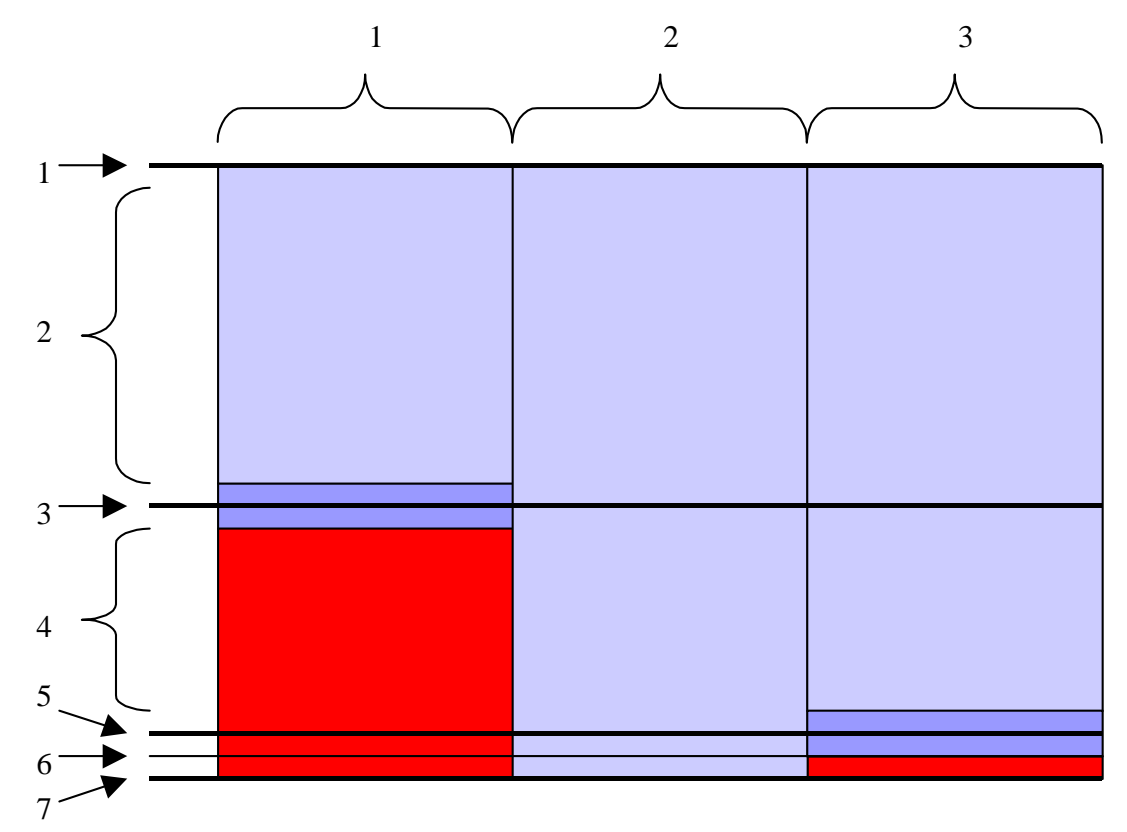

Figure 21: Abstracted State Space of the Crane 
- $\quad$ Crane State Space $=\left\langle x_{17}, x_{18}, x_{19}, x_{20}\right\rangle$

- Abstract Domains =

$-D_{17}=\{1,2, \ldots, 7\}=$ vertical position

$-D_{18}=\{1,2,3\}=$ hotizontal position

$-D_{19}=\{0,1\}=$ magnet off $/$ on

$-D_{20}=\{0,1\} \cup\{$ error, hazard $\}=$ absence / presence of plate or safety violation

\subsection{Floor Model}

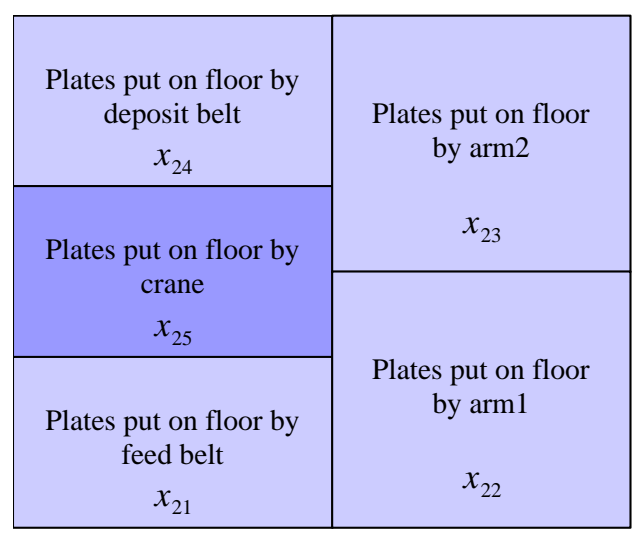

Figure 22: State Space of the Floor

Floor State Space $=\left\langle x_{21}, x_{22}, x_{23}, x_{24}, x_{25}\right\rangle$

Abstract Domains $=$

$-D_{21}=\{0,1,2, \ldots\}=$ plate counter $($ feed belt $)$

$-D_{22}=\{0,1,2, \ldots\}=$ plate counter $($ arm 1$)$

$-D_{23}=\{0,1,2, \ldots\}=$ plate counter $(\operatorname{arm} 2)$

$-D_{24}=\{0,1,2, \ldots\}=$ plate counter (depositbelt)

$-D_{25}=\{0,1,2, \ldots\}=$ plate counter $($ crane $)$ 


\section{Summary}

\section{Production Cell State Space $=$}

$$
\left\langle x_{1}, x_{2}, x_{3}, x_{4}, x_{5}, x_{6}, x_{7}, x_{8}, x_{9}, x_{10}, x_{11}, x_{12}, x_{13}, x_{14}, x_{15}, x_{16}, x_{17}, x_{18}, x_{19}, x_{20}, x_{21}, x_{22}, x_{23}, x_{24}, x_{25}\right\rangle
$$

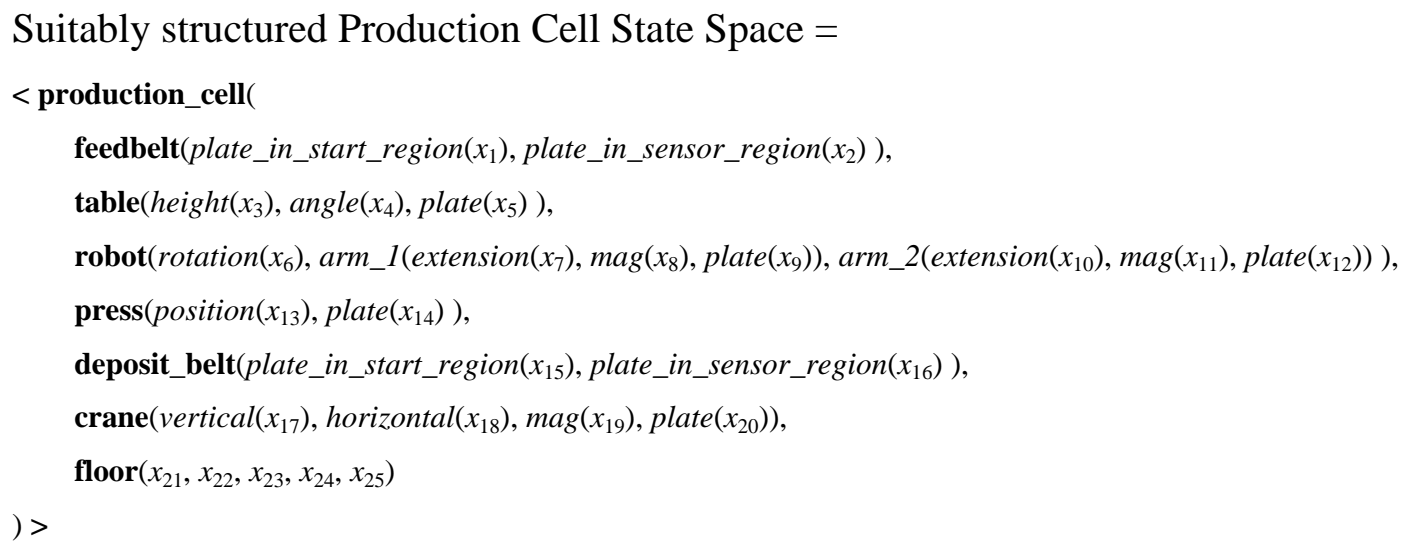




\title{
APPENDIX B: A FORMAL SPECIFICATION OF THE PRODUCTION CELL
}

\author{
by Dr. Victor Winter
}

\section{Overview}

The purpose of this document is to formally describe/specify the production cell in symbolic and graphical terms. This specification consists of three components: (1) a description of individual domains, (2) a description of how domains are configured (i.e., the layout), and (3) a description of transitions.

The production cell can be modeled in terms of aggregates overlapping or non-overlapping cubelike objects (e.g., a 2-dimensional grid of "cubes", an overlapping "fan" of cubes, etc.)

\section{General Constructs}

Below are the general constructs of the specification language. They are not completely formalized, but the semantics should be clear (hopefully).

\subsection{Foundational Types}

We are interested in graphically and symbolically constructing models that contain values of various types. At present we are interested in the following types:

- $\quad$ Symbolic Types

- $\quad$ boolean $=\{$ true, false $\}$

- $\quad$ boolean $_{\perp}=$ boolean $\cup\{$ error $\}$

- $\quad$ string $=\{$ all strings $\}$

- $\quad \operatorname{string}_{\perp}=$ string $\cup\{$ error $\}$ where "error" is somehow distinguishable from other strings

- $\quad$ integer $=\{\ldots,-1,0,1, \ldots\}$

- $\quad$ integer $_{\perp}=$ integer $\cup\{$ error $\}$

- Visual Types

- $\quad$ color $=\{$ all colors $\}$

- $\quad$ symbol $=\{$ all symbols $\}$

\subsection{Graphical Types, Identifiers, Constants, and Variables}

\subsubsection{Primitive Graphical Types}

In this formalism, the primitive types are cube-like objects. I say "cube-like" because they need not be square - they can be bent and stretched as needed. Now these cubes contain visual information, and the type of information that is contained in the cube determines the type of the cube. What we are ultimately after is a formal connection between symbol-based objects and visual objects. The type of a cube 
(i.e., its signature) is defined as the following tuple: $S \times V$, where $S$ is a symbolic type and $V$ is a visual type.

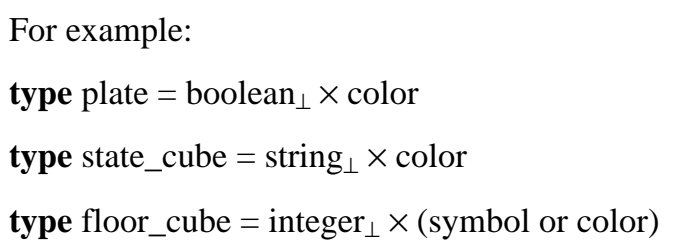

In the above example, a plate is defined as a "cube" whose contents will be of type extended boolean (i.e., boolean ${ }_{\perp}$ ) and whose values will be displayed by "color". Similarly, the floor is a cube whose contents will be of type extended integer and whose values will be displayed by "symbol".

\subsubsection{Identifiers of Graphical Types}

After an (aggregate) graphical type has been defined, we can now declare identifiers of that type. Type identifiers are defined similarly to variables but are nevertheless distinctly different. Type identifiers denote type classes and not elements of a type (which is what is denoted by a variable). Below are some examples of type identifiers:

type id metal_plate: plate;

type id table_state_cube, robot_arm1_state_cube: state_cube;

type id cell_floor_cube: floor_cube;

\subsection{3. (Display) Instances of a Graphical Type}

A type identifier can be instantiated by defining the mapping between its symbol-based and visual-based values. An instance of a graphical type is an enumeration or simple algorithm that binds (maps) symbolic values to display values. This is done by describing a set of tuples whose first element is a specific symbolic element and whose second element is a specific visual element. The resulting value must then be assigned to a variable of the appropriate type. For example:

display metal_plate $=[($ true $=1$, yellow $),($ false $=0$, clear $),($ error, red $)] ;$
display table_state_cube $=[($ present, green $),($ absent, clear $),($ error, red $)] ;$
display robot_arm1_state_cube $=[($ present, green $),($ absent, clear $),($ error, red $)]$;
display cell_floor_cube $=[(0$, clear $),(\mathrm{i}, \operatorname{display}(\mathrm{i}))] ;$

The first statement assigns a cube instance that displays the value true as yellow-fill of the cube, the value false as a clear-fill of the cube, and the error value as a red-fill of the cube. The cell_floor assignment defines a cube that displays the value 0 as a clear-fill, and displays all other integer values in symbolic form. The binding algorithm is a follows: a symbolic value $\mathrm{x}$ is matched with the first element of 
the tuple (i.e., 0 ) if $x=0$ then the match succeeds and "clear" is displayed, if not $x$ is matched with $i$ (which will always unify) - the result of the unification (i.e., $i$ is bound to $x$ ) will then be displayed.

\subsection{Aggregate Concrete Graphical Types}

At this point we assume that we have defined a suitable collection of types, type identifiers, and have instantiated the type identifiers with suitable display definitions. We are now ready to group these instantiated type identifiers into general aggregate structures (which we also call component types).

Aggregates are 1D, 2D, or 3D cube structures. At present there are three basic types of structures (cube composition operators) we have discovered:

- $\quad$ fan - objects are overlapping

- $\quad$ array - objects are touching but not overlapping

We handle aggregations of non-uniform types (e.g., records, structures) as follows: $\operatorname{array}[1 . . n]$ of $\left(t_{1} * t_{2} * \ldots * t_{n}\right)$

is an array in which the first element is of type $t_{1}$ the second is of type $t_{2}$ and the $n^{\text {th }}$ is of type $t_{n}$. The fan and array combinators can be used recursively to create complex structures. At present we are limiting this to three dimensions.

The main issue that arises when describing structures is how objects (cubes, composite structures) relate graphically to other objects. We will restrict ourselves to a three dimensional world with the $x, y, z$ axes being constant (directionwise) across all objects. To address orientation issues, we extend/parameterize the fan and array combinations as follows:

- $\quad \operatorname{fan}(i, j)=\mathrm{a}$ fan that is in the $i j$ plane where $i$ and $j$ are either $x, y$, or $z$.

- $\quad \operatorname{array}(i)=$ an array that is in the $i$-axis where $i$ is either $x, y$, or $z$.

We can now define component types as follows:

component type conveyor_belt $=\operatorname{array}(\mathrm{x})[1 . .2]$ of metal_plate;

component type table_cube $=\operatorname{array}(y)[1 . .2]$ of (table_state_cube $*$ metal_plate);

component type table_level $=$ fan $(\mathrm{x}, \mathrm{z})[1 . .6]$ of table_cube;

component type table_state_space $=\operatorname{array}(\mathrm{z})[1 . .3]$ of table_level;

component type arm1_cube $=\operatorname{array}(y)[1 . .2]$ of $($ metal_plate $*$ robot_arm1_state_cube);

component type arm1_extension_space $=\operatorname{array}(\mathrm{x})[1 . .8]$ of arm1_cube;

component type arm1_state_space = array $(\mathrm{z})[1 . .18]$ of arm1_extension_space;

Note: there is a slight problem here when arrays are bent ... namely they don't conform to the dimension that they have been originally defined with respect to. 


\subsection{Components}

After we define suitable component types we can declare variables of those types as follows:

var feed_belt: conveyor_belt;

var table: table_state_space;

var arm1: arm1_state_space;

Elements of the rotating_table (defined above) can be accessed, in the traditional manner, as follows:

table[1] $=$ level 1 of the table_level

table[1][2] = the second cube of the first level of the table

table[1][2][1] = the table state of the second cube of the first level of the table

\subsection{Configuration Constraints}

The goal here is to describe how components relate to one another spatially. There are two basic spatial relations that we are interested in expressing (1) touching, and (2) intersecting. The touching and intersecting relations will be denoted respectively by the symbols $\|$ and $\cap$. They will be properly subscribed with dimension information when needed. This will enable them to be defined for 1D, 2D, and 3D components.

\subsubsection{Notation}

Often it will be the case that all we can say about two components is that some subset of the first component intersects (or touches) some subset of the second component. In particular, we may not be able (or want) to say anything at a finer grain of resolution (e.g., element 1 intersects only with element 2 , etc.). We need a concise notation to express these ideas. Let $X$ be an aggregate object and let the expression $X\left[i_{1}, \ldots, i_{n}\right]$ be an abbreviation for $X\left[i_{1}\right]\left[i_{2}\right] \ldots\left[i_{n}\right]$. Then the expression

$$
X\left[i_{1}, \ldots, i_{n}\right]:\left\{p\left(i_{1}, \ldots, i_{n}\right)\right\}
$$

denotes a subset of $X$ when $p$ is a predicate.

For example:

table $[y][x]:\{y=3 \wedge(1 \leq x \leq 6)\}$

denotes the set of all table_cubes $(1$ through 6$)$ that are on the top level $($ level = 3 ) of the table state space. Similarly,

$$
\operatorname{arml}[r][x]:\{r>8 \wedge x>1\}
$$

denotes the set of all arm1 cubes that can potentially intersect with the top level of the table (defined previously). 
Given the previously defined spaces, the intersection between the table and arm 1 can be defined by the expression:

table $[y][x]:\{y \geq 2 \wedge(1 \leq x \leq 6)\} \cap \operatorname{arm} 1[r][x]:\{r>8 \wedge x \neq 1\}$

Note that there is discrepancy in the informal spec. In section A.6.1. (pg. 392) [2] talks about a collision possibility when then table is in the top, but then goes on and constrains the table to be in the bottom position (in particular NOT in the middle position) in order to avoid a collision.

\subsection{Transitions}

Transitions are defined as guarded commands on vectors of monitored variables (i.e., the observable state space). The guard is a predicate on the monitored variables, the subscript of the "arrow" is the control variable value that is set, and the expression of the right-hand side of the guard is a function on the monitored variables.

$$
p(\vec{m}) \stackrel{c_{i}}{\longrightarrow} f_{1}(\vec{m}) \text { where } p: \vec{m} \rightarrow \text { boolean and } f_{1}: \vec{m} \rightarrow \vec{m}
$$

\section{The Production Cell}

In this section we formally describe the entire production cell.

\subsection{Primitive Graphical Types for the Production Cell}

type plate $=$ boolean $_{\perp} \times$ color

type simple_state_cube $=\operatorname{string}_{\perp} \times$ color

type complex_state_cube $=\operatorname{string}_{\perp} \times$ color

type $f l o o r \_c u b e=$ integer $\times($ symbol or color $)$

\subsection{Identifiers of Graphical Types for the Production Cell}

type id metal_plate: plate;

type id table_state_cube, press_state: simple_state_cube;

type id robot_arm_state_cubes, crane_state_cube: complex_state_cube;

type id cell_floor_cube:floor_cube;

\subsection{Display Instances of a Graphical Type for the Production Cell}

display metal_plate $=[($ true $=1$, yellow $),($ false $=0$, clear $),($ error, red $)]$;

display table_state_cube $=[$ (present, green $),($ absent, clear $),($ error, red $)]$; 
display robot_arm_state_cube $=[(($ present, off $=0)$, green $),(($ present, on $=1)$, blue $),($ absent, clear), (error, red) ];

display press_state_cube $=[($ present, green $),($ absent, clear $),($ error, red $)]$;

display crane_state_cube $=[(($ present, off $=0)$, green $),(($ present, on $=1)$, blue $),($ absent, clear $)$, (error, red) ];

display cell_floor_cube $=[(0$, clear $),(i, \operatorname{display}(i))]$;

\subsection{Aggregate Concrete Graphical Types for the Production Cell}

\subsubsection{Feed and Deposit Belts}

component type conveyor_belt $=\operatorname{array}(x)[1 . .2]$ of metal_plate;

\subsubsection{Elevating Rotating Table}

component type table_cube $=\operatorname{array}(y)[1 . .2]$ of (table_state_cube $*$ metal_plate);

component type table_level $=\operatorname{fan}(x, z)[1 . .6]$ of table_cube;

component type table_state_space $=\operatorname{array}(z)[1 . .3]$ of table_level;

\subsubsection{Robot Arm1 and Arm2}

component type arm_cube $=\operatorname{array}(y)[1 . .2]$ of $($ metal_plate $*$ robot_arm_state_cube);

component type arm1_extension_space $=\operatorname{array}(x)[1 . .8]$ of arm_cube;

component type arm1_state_space $=\operatorname{array}(z)[1 . .19]$ of arm1_extension_space;

component type arm2_extension_space $=\operatorname{array}(x)[1 . .7]$ of arm_cube;

component type arm2_state_space $=\operatorname{array}(z)[1 . .19]$ of arm2_extension_space;

\subsubsection{Press}

component type press_cube $=\operatorname{array}(y)[1 . .2]$ of $($ press_state_cube $*$ metal_plate $)$

component type press_state_space $=\operatorname{array}(y)[1 . .3]$ of press_cube;

\subsubsection{Crane}

component type crane_cube $=\operatorname{array}(y)[1 . .2]$ of (metal_plate $*$ crane_state_cube);

component type crane_level $=\operatorname{array}(z)[1 . .7]$ of crane_cube;

component type crane_state_space $=\operatorname{array}(y)[1 . .3]$ of crane_level;

\subsubsection{Floor}

component type cell_floor $=\operatorname{array}(z)[1 . .5]$ of floor_region; 


\subsection{Components}

var feed_belt, deposit_belt: conveyor_belt;

var table: table_state_space;

var arm1: arm1_state_space;

var arm2: arm2_state_space;

var press: press_state_space;

var crane: crane_state_space;

var floor: cell_floor;

\subsection{Configuration Constraints}

Technically there is a grid that consists of the cross product of all components. However in this document we only include the components in the grid that have actual constraints.

\subsubsection{Feed Belt and Table}

feed_belt $[x]:\{x=2\} \|_{x}$ table $[y][x]:\{y=1 \wedge x=2\}$. Here $\|_{x}$ denotes "touching along the $x$-axis".

feed_belt $[x]:\{x=2\} \cap$ table $[y][x]:\{x<2\}$

\subsubsection{Table and Arm1}

table $[y][x][k]:\{y \geq 2 \wedge(1 \leq x \leq 6) \wedge k=2\} \cap \operatorname{arml}[r][x][k]:\{r>8 \wedge x \neq 1 \wedge k=1\}$. Note that this intersection is only at the level of the metal_plate subcomponents.

\subsubsection{Arm1 and Press}

$\operatorname{arml}[r][x]:\{r<5 \wedge x>2\} \cap \operatorname{press}[y]:\{y=3\}$

\subsubsection{Press and Arm2}

$\operatorname{arm} 2[r][x]:\{(10<r<15) \wedge x>1\} \cap \operatorname{press}[y]:\{y=2\}$

\subsubsection{Arm2 and Deposit Belt}

$\operatorname{arm} 2[r][x][k]:\{3<r<7 \wedge x=3\} \cap$ deposit_belt $[x]:\{x=1\}$

\subsubsection{Deposit Belt and Crane}

crane $[y][z]:\{y<5 \wedge z>1\} \cap$ deposit_belt $[x]:\{x=2\}$. Note that the constraint $y<5 \wedge z>1$ is different from what is given in the text. What is given in the text is an oversimplification and does not 
faithfully represent reality. The constraint $y<5 \wedge z>1$ is an attempt to describe reality (though a domain expert would need to be consulted to validate this). However, this should not present a problem, because the transitions can still reflect the text.

crane $[y][z]:\{y=5 \wedge z=3\} \|_{y}$ deposit_belt $[x]:\{x=2\}$

\subsubsection{Crane and Feed Belt}

crane $[y][z]:\{y<3 \wedge z<3\} \cap$ feed_belt $[x]:\{x=1\}$. Note that the constraint $y<3 \wedge z<3$ is different from what is given in the text. What is given in the text is an oversimplification and does not faithfully represent reality. The constraint $y<3 \wedge z<3$ is an attempt to describe reality (though a domain expert would need to be consulted to validated this). However, this should not present a problem, because the transitions can still reflect the text.

crane $[y][z]:\{y=3 \wedge z=1\} \|_{y}$ deposit_belt $[x]:\{x=1\}$

\subsection{Transitions}

The transitions below are defined with respect to the observable state space of the production cell. The observable state space consists of a vector of 25 real and virtual monitored variables. The variables in the vector have the following semantics (mappings) with respect to the model we have described so far:

\subsubsection{Feed Belt}

$x_{1}=\{0,1\} \equiv$ feed_belt $[1]=x_{1}$

$x_{2}=\{0,1\} \equiv$ feed_belt $[2]=x_{2}$

\subsubsection{Table}

$x_{3}=\{1,2,3\}$

$x_{4}=\{1,2, \ldots, 6\}$

$x_{5}=\{0,1\} \equiv\left(\operatorname{table}\left[x_{3}\right]\left[x_{4}\right][1]=\right.$ present $) \wedge\left(\operatorname{table}\left[x_{3}\right]\left[x_{4}\right][2]=x_{5}\right) \wedge$

$\left(y_{3} \neq x_{3} \vee y_{4} \neq x_{4}\right) \rightarrow\left(\right.$ table $\left[y_{3}\right]\left[y_{4}\right][1]=$ absent $\wedge$ table $\left.\left[y_{3}\right]\left[y_{4}\right][3]=0\right)$

\subsubsection{Robot}

$x_{6}=\{1,2, \ldots, 19\}$

$x_{7}=\{1,2, \ldots, 8\}$

$x_{8}=\{0,1\}$

$x_{9}=\{0,1\}$ 


$$
\begin{aligned}
& x_{10}=\{1,2, \ldots, 8\} \\
& x_{11}=\{0,1\} \\
& x_{12}=\{0,1\} \equiv\left(\operatorname{arm} 1\left[x_{6}\right]\left[x_{7}\right][1]=\left(\text { present }, x_{8}\right)\right) \wedge\left(\operatorname{arm} 1\left[x_{6}\right]\left[x_{7}\right][2]=x_{9}\right) \wedge \\
& \left(y_{6} \neq x_{6} \vee y_{7} \neq x_{7}\right) \rightarrow\left(\operatorname{arm} 1\left[y_{6}\right]\left[y_{7}\right][1]=\text { absent } \wedge \operatorname{arm} 1\left[y_{6}\right]\left[y_{7}\right][2]=0\right) \wedge \\
& \left(\operatorname{arm} 2\left[x_{6}\right]\left[x_{10}\right][1]=\left(\text { present, } x_{11}\right)\right) \wedge \\
& \left(\operatorname{arm} 2\left[x_{6}\right]\left[x_{10}\right][2]=x_{12}\right) \wedge \\
& \left(y_{6} \neq x_{6} \vee y_{10} \neq x_{10}\right) \rightarrow\left(\operatorname{arm} 2\left[y_{6}\right]\left[y_{10}\right][1]=\text { absent } \wedge \operatorname{arm} 2\left[y_{6}\right]\left[y_{10}\right][2]=0\right)
\end{aligned}
$$

\subsubsection{Press}

$x_{13}=\{1,2,3\}$

$x_{14}=\{0,1\} \equiv\left(\operatorname{press}\left[x_{13}\right][1]=\right.$ present $) \wedge\left(\operatorname{present}\left[x_{13}\right][2]=x_{14}\right) \wedge$

$\left(y_{13} \neq x_{13}\right) \rightarrow\left(\operatorname{press}\left[y_{13}\right][1]=\right.$ absent $\wedge$ press $\left.\left[y_{13}\right][2]=0\right)$

\subsubsection{Deposit Belt}

$x_{15}=\{0,1\} \equiv$ deposit_belt $[1]=x_{15}$

$x_{16}=\{0,1\} \equiv$ deposit_belt $[2]=x_{16}$

\subsubsection{Crane}

$x_{17}=\{1,2, \ldots, 7\}$

$x_{18}=\{1,2,3\}$

$x_{19}=\{0,1\}$

$x_{20}=\{0,1\} \equiv\left(\operatorname{crane}\left[x_{17}\right]\left[x_{18}\right][2]=\left(\right.\right.$ present,$\left.\left.x_{19}\right)\right) \wedge\left(\operatorname{crane}\left[x_{17}\right]\left[x_{18}\right][1]=x_{20}\right) \wedge$

$\left(y_{17} \neq x_{17} \vee y_{18} \neq x_{18}\right) \rightarrow\left(\operatorname{crane}\left[y_{17}\right]\left[y_{18}\right][2]=\right.$ absent $\wedge$ crane $\left.\left[y_{17}\right]\left[y_{18}\right][1]=0\right)$

\subsubsection{Floor}

$x_{21}=\{0,1,2, \ldots\} \equiv$ floor $[1]=x_{21}$

$x_{22}=\{0,1,2, \ldots\} \equiv$ floor $[2]=x_{22}$

$x_{23}=\{0,1,2, \ldots\} \equiv$ floor $[3]=x_{23}$

$x_{24}=\{0,1,2, \ldots\} \equiv$ floor $[4]=x_{24}$

$x_{25}=\{0,1,2, \ldots\} \equiv$ floor $[5]=x_{25}$

\subsection{System Abstraction}

This vector describing the observable state can be structured for human readability as follows: 


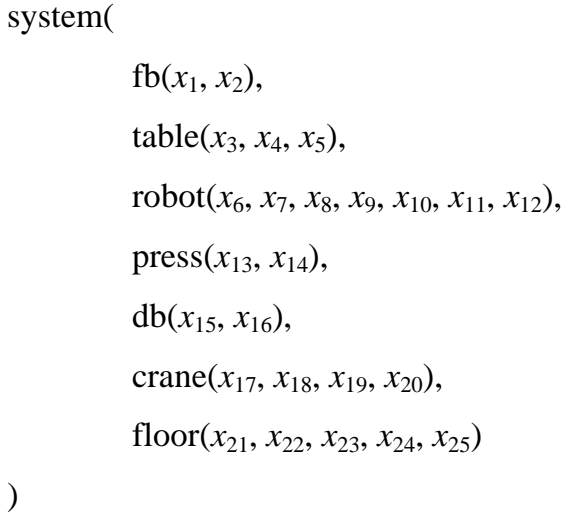

\subsubsection{The control variable: add_blank}

$\operatorname{system}\left(f b\left(x_{1}, x_{2}\right), x \_t a b l e, x \_r o b o t, x \_p r e s s, x \_d b, x \_c r a n e, x \_f l o o r\right)$

$: x_{1}=0$

\{the initial region of the feed belt is empty\}

$\rightarrow$ add_blank $\rightarrow$

$\operatorname{system}\left(f b\left(1, x_{2}\right), x \_t a b l e, x \_r o b o t, x \_p r e s s, x \_d b, x \_c r a n e, x \_f l o o r\right)$

$\operatorname{system}\left(f b\left(x_{1}, x_{2}\right), x \_t a b l e, x \_r o b o t, x \_p r e s s, x \_d b, x \_c r a n e, x \_f l o o r\right)$

$: x_{1} \neq 0$

$\{$ the initial region of the feed belt is empty

$\rightarrow$ add_blank $\rightarrow$

$\operatorname{system}\left(f b\left(\right.\right.$ error,$\left.\left.x_{2}\right), x \_t a b l e, x \_r o b o t, x \_p r e s s, x \_d b, x \_c r a n e, x \_f l o o r\right)$

\subsubsection{The control variable: fb_on}

Note that due to safety assumptions some interesting dependencies exist. For example, in the semantics for the arm1_mag_on/off section, we assume that an error will occur when (1) the magnet of arm1 is on and (2) a plate is on the table or on the press and (3) the table and arm1 are not in the plate exchange position. In that same section, we do however permit the magnet to be turned on when there are no plates on the table or on the press (i.e., anywhere near the magnet of arm1). Thus if feed belt moves a plate onto the table AND the magnet of arm1 is already on, then an error will occur (according to our extremely conservative model).

$\operatorname{system}\left(f b\left(x_{1}, x_{2}\right), x \_t a b l e, x \_r o b o t, x \_p r e s s, x \_d b, x \_c r a n e, x \_f l o o r\right)$

$: x_{2}=0$ 
\{the second region of the feed belt is empty

$\rightarrow \mathbf{f b} \_$motor_on $\rightarrow$

$\operatorname{system}\left(f b\left(0, x_{1}\right), x \_t a b l e, x \_r o b o t, x \_p r e s s, x \_d b, x \_c r a n e, x \_f l o o r\right)$

$\operatorname{system}\left(f b\left(x_{1}, x_{2}\right), \operatorname{table}\left(x_{3}, x_{4}, x_{5}\right)\right.$, robot $\left.\left(x_{6}, x_{7}, x_{8}, x_{9}, x_{10}, x_{11}, x_{12}\right), x \_p r e s s, x \_d b, x \_c r a n e, x \_f l o o r\right)$

$: x_{2}=1 \wedge x_{3}=1 \wedge x_{4}=2 \wedge x_{5}=0 \wedge x_{8}=0$

\{the second region of the feed belt contains a plate and the table is in position and is not holding a plate AND the magnet of arm1 is off! \}

$\rightarrow$ fb_motor_on $\rightarrow$

$\operatorname{system}\left(f b\left(0, x_{1}\right), \operatorname{table}\left(x_{3}, x_{4}, 1\right), \operatorname{robot}\left(x_{6}, x_{7}, x_{8}, x_{9}, x_{10}, x_{11}, x_{12}\right) t, x \_p r e s s, x \_d b, x \_c r a n e, x \_f l o o r\right)$

$\operatorname{system}\left(f b\left(x_{1}, x_{2}\right), \operatorname{table}\left(x_{3}, x_{4}, x_{5}\right), \operatorname{robot}\left(x_{6}, x_{7}, x_{8}, x_{9}, x_{10}, x_{11}, x_{12}\right), x \_\right.$press, $x \_d b, x \_c r a n e, f l o o r\left(x_{21}\right.$, $\left.\left.x_{22}, x_{23}, x_{24}, x_{25}\right)\right)$

$: x_{2}=1 \wedge x_{3}=1 \wedge x_{4}=2 \wedge x_{5}=0 \wedge x_{8}=1$

\{the second region of the feed belt contains a plate and the table is in position and is not holding a plate AND the magnet of arm1 is on!\}

$\rightarrow$ fb_motor_on $\rightarrow$

$\operatorname{system}\left(f b\left(0, x_{1}\right), \operatorname{table}\left(x_{3}, x_{4}\right.\right.$, error $), \operatorname{robot}\left(x_{6}, x_{7}, x_{8}\right.$, error, $\left.x_{10}, x_{11}, x_{12}\right), x \_$press, $x \_d b, x \_c r a n e$, floor $\left.\left(x_{21}+1, x_{22}, x_{23}, x_{24}, x_{25}\right)\right)$

$\operatorname{system}\left(f b\left(x_{1}, x_{2}\right), \operatorname{table}\left(x_{3}, x_{4}, x_{5}\right), x \_\right.$robot, $\left.x \_p r e s s, x \_d b, x \_c r a n e, f l o o r\left(x_{21}, x_{22}, x_{23}, x_{24}, x_{25}\right)\right)$

$: x_{2}=1 \wedge \neg\left(x_{3}=1 \wedge x_{4}=2\right)$

\{the second region of the feed belt contains a plate and the table is out of position

$\rightarrow \mathbf{f b} \_$motor_on $\rightarrow$

$\operatorname{system}\left(f b\left(0, x_{1}\right), \operatorname{table}\left(x_{3}, x_{4}, x_{5}\right), x \_r o b o t, x \_p r e s s, x \_d b, x \_\right.$crane, floor $\left.\left(x_{21}+1, x_{22}, x_{23}, x_{24}, x_{25}\right)\right)$

$\operatorname{system}\left(f b\left(x_{1}, x_{2}\right), \operatorname{table}\left(x_{3}, x_{4}, x_{5}\right), x \_r o b o t, x \_p r e s s, x \_d b, x \_c r a n e, x \_f l o o r\right)$

$: x_{2}=1 \wedge x_{3}=1 \wedge x_{4}=2 \wedge x_{5}=1$

\{the second region of the feed belt contains a plate and the table is in position, but also contains a

plate

$\rightarrow$ fb_motor_on $\rightarrow$

$\operatorname{system}\left(f b(0\right.$, error $), \operatorname{table}\left(x_{3}, x_{4}\right.$, error $\left.), x \_r o b o t, x \_p r e s s, x \_d b, x \_c r a n e, x \_f l o o r\right)$ 


\subsubsection{The control variable: $d b \_o n$}

$\operatorname{system}\left(x \_f b, x \_t a b l e, x \_r o b o t, x \_p r e s s, d b\left(x_{15}, x_{16}\right), x \_c r a n e, x \_f l o o r\right)$

$: x_{16}=0$

\{the second region of the deposit belt is empty\}

$\rightarrow$ db_motor_on $\rightarrow$

$\operatorname{system}\left(x \_f b, x \_t a b l e, x \_r o b o t, x \_p r e s s, d b\left(0, x_{15}\right), x \_c r a n e, x \_f l o o r\right)$

$\operatorname{system}\left(x \_f b, x \_t a b l e, x \_r o b o t, x \_p r e s s, d b\left(x_{15}, x_{16}\right), x \_\right.$crane,$\left.f l o o r\left(x_{21}, x_{22}, x_{23}, x_{24}, x_{25}\right)\right)$

$: x_{16}=1$

\{the second region of the deposit belt is not empty\}

$\rightarrow$ db_motor_on $\rightarrow$

$\operatorname{system}\left(x \_f b, x \_t a b l e, x \_r o b o t, x \_p r e s s, d b\left(0, x_{15}\right), x \_\right.$crane, floor $\left.\left(x_{21}, x_{22}, x_{23}, x_{24}+1, x_{25}\right)\right)$

\subsubsection{The control variable: table_up/table_down}

We assume that the magnet of arm1 should not be "on" while a plate is being moved into its proximity.

$\operatorname{system}\left(x \_f b, \operatorname{table}\left(x_{3}, x_{4}, x_{5}\right)\right.$, robot $\left.\left(x_{6}, x_{7}, x_{8}, x_{9}, x_{10}, x_{11}, x_{12}\right), x \_p r e s s, x \_d b, x \_c r a n e, x \_f l o o r\right)$

$: x_{3}<3 \wedge\left(x_{6} \leq 8 \vee x_{7}=1\right)$

$\{\operatorname{arm} 1$ is not in the vicinity of the table

$\rightarrow$ table_up $\rightarrow$

$\operatorname{system}\left(x \_f b, \operatorname{table}\left(x_{3}+1, x_{4}, x_{5}\right), \operatorname{robot}\left(x_{6}, x_{7}, x_{8}, x_{9}, x_{10}, x_{11}, x_{12}\right), x \_\right.$press, $\left.x \_d b, x \_c r a n e, x \_f l o o r\right)$

$\operatorname{system}\left(x \_f b, \operatorname{table}\left(x_{3}, x_{4}, x_{5}\right), \operatorname{robot}\left(x_{6}, x_{7}, x_{8}, x_{9}, x_{10}, x_{11}, x_{12}\right), x \_p r e s s, x \_d b, x \_c r a n e, x \_f l o o r\right)$

$: x_{3}<3 \wedge x_{5}=0 \wedge \neg\left(x_{6} \leq 8 \vee x_{7}=1\right)$

$\{\operatorname{arm} 1$ is in the vicinity, but the table has no plate $\}$

$\rightarrow$ table_up $\rightarrow$

$\operatorname{system}\left(x \_f b, \operatorname{table}\left(x_{3}+1, x_{4}, x_{5}\right)\right.$, robot $\left.\left(x_{6}, x_{7}, x_{8}, x_{9}, x_{10}, x_{11}, x_{12}\right), x \_p r e s s, x \_d b, x \_c r a n e, x \_f l o o r\right)$

$\operatorname{system}\left(x \_f b, \operatorname{table}\left(x_{3}, x_{4}, x_{5}\right), \operatorname{robot}\left(x_{6}, x_{7}, x_{8}, x_{9}, x_{10}, x_{11}, x_{12}\right), x \_\right.$press, $\left.x \_d b, x \_c r a n e, x \_f l o o r\right)$

$: x_{3}<3 \wedge x_{5}=1 \wedge \neg\left(x_{6} \leq 8 \vee x_{7}=1\right) \wedge x_{8}=0 \wedge x_{9}=0$

$\{\operatorname{arm} 1$ is in the vicinity, the table has plate and the magnet is off $\}$

$\rightarrow$ table_up $\rightarrow$

$\operatorname{system}\left(x \_f b, \operatorname{table}\left(x_{3}+1, x_{4}, x_{5}\right)\right.$, robot $\left.\left(x_{6}, x_{7}, x_{8}, x_{9}, x_{10}, x_{11}, x_{12}\right), x \_p r e s s, x \_d b, x \_c r a n e, x \_f l o o r\right)$ 
$\operatorname{system}\left(x \_f b, \operatorname{table}\left(x_{3}, x_{4}, x_{5}\right), \operatorname{robot}\left(x_{6}, x_{7}, x_{8}, x_{9}, x_{10}, x_{11}, x_{12}\right), x \_p r e s s, x \_d b, x \_c r a n e, x \_f l o o r\right)$

$: x_{3}=1 \wedge x_{5}=1 \wedge x_{9}=1 \wedge \neg\left(x_{6} \leq 8 \vee x_{7}=1\right)$

\{arm1 is in the vicinity and both the table and arm1 have a plate \}

$\rightarrow$ table_up $\rightarrow$

$\operatorname{system}\left(x \_f b, \operatorname{table}\left(x_{3}, x_{4}\right.\right.$, error $)$, robot $\left(x_{6}, x_{7}, x_{8}\right.$, error, $\left.x_{10}, x_{11}, x_{12}\right), x \_$press, $x \_d b, x_{-}$crane, $x \_$floor)

$\operatorname{system}\left(x \_f b, \operatorname{table}\left(x_{3}, x_{4}, x_{5}\right), \operatorname{robot}\left(x_{6}, x_{7}, x_{8}, x_{9}, x_{10}, x_{11}, x_{12}\right), x \_p r e s s, x \_d b, x \_c r a n e, x \_f l o o r\right)$

$: x_{3}=1 \wedge x_{5}=1 \wedge x_{8}=1 \wedge x_{9}=0 \wedge \neg\left(x_{6} \leq 8 \vee x_{7}=1\right)$

$\{$ arm1 is in the vicinity, has no plate but its magnet is on and the table has a plate

$\rightarrow$ table_up $\rightarrow$

$\operatorname{system}\left(x \_f b, \operatorname{table}\left(x_{3}, x_{4}, 0\right), \operatorname{robot}\left(x_{6}, x_{7}, x_{8}\right.\right.$, error, $\left.x_{10}, x_{11}, x_{12}\right), x \_$press, $\left.x \_d b, x \_c r a n e, x \_f l o o r\right)$

$\operatorname{system}\left(x \_f b, \operatorname{table}\left(x_{3}, x_{4}, x_{5}\right), x \_r o b o t, x \_p r e s s, x \_d b, x \_c r a n e, x \_f l o o r\right)$

$: x_{3}=3$

\{the table is in the top position and cannot be raised any more

$\rightarrow$ table_up $\rightarrow$

$\operatorname{system}\left(x \_f b, t a b l e\left(e r r o r, x_{4}, x_{5}\right), x \_r o b o t, x \_p r e s s, x \_d b, x \_c r a n e, x \_f l o o r\right)$

$\operatorname{system}\left(x \_f b, \operatorname{table}\left(x_{3}, x_{4}, x_{5}\right), x \_r o b o t, x \_p r e s s, x \_d b, x \_c r a n e, x \_f l o o r\right)$

$: x_{3}>1$

\{the table is higher than its bottom position

$\rightarrow$ table_down $\rightarrow$

$\operatorname{system}\left(x \_f b, \operatorname{table}\left(x_{3}-1, x_{4}, x_{5}\right), x \_r o b o t, x \_p r e s s, x \_d b, x \_c r a n e, x \_f l o o r\right)$

$\operatorname{system}\left(x \_f b, \operatorname{table}\left(x_{3}, x_{4}, x_{5}\right), x \_r o b o t, x \_p r e s s, x \_d b, x \_c r a n e, x \_f l o o r\right)$

$: x_{3}=1$

\{the table is in its bottom position and cannot be lowered any further\}

$\rightarrow$ table_down $\rightarrow$

$\operatorname{system}\left(x \_f b, t a b l e\left(e r r o r, x_{4}, x_{5}\right), x \_r o b o t, x \_p r e s s, x \_d b, x \_c r a n e, x \_f l o o r\right)$ 


\subsubsection{The control variable: table_left/right}

$\operatorname{system}\left(x \_f b, \operatorname{table}\left(x_{3}, x_{4}, x_{5}\right), x \_r o b o t, x \_p r e s s, x \_d b, x \_c r a n e, x \_f l o o r\right)$

$: x_{4}>2$

\{the table is to the right of its leftmost safe rotational position\}

$\rightarrow$ table_left $\rightarrow$

$\operatorname{system}\left(x \_f b, \operatorname{table}\left(x_{3}, x_{4}-1, x_{5}\right), x \_r o b o t, x \_p r e s s, x \_d b, x \_c r a n e, x \_f l o o r\right)$

$\operatorname{system}\left(x \_f b, \operatorname{table}\left(x_{3}, x_{4}, x_{5}\right), x \_r o b o t, x \_p r e s s, x \_d b, x \_c r a n e, x \_f l o o r\right)$

$: x_{4}=2$

\{the table is in its leftmost safe rotational position

$\rightarrow$ table_left $\rightarrow$

$\operatorname{system}\left(x \_f b, \operatorname{table}\left(x_{3}\right.\right.$, error,$\left.\left.x_{5}\right), x \_r o b o t, x \_p r e s s, x \_d b, x \_c r a n e, x \_f l o o r\right)$

$\operatorname{system}\left(x \_f b, \operatorname{table}\left(x_{3}, x_{4}, x_{5}\right), x \_r o b o t, x \_p r e s s, x \_d b, x \_c r a n e, x \_f l o o r\right)$

$: x_{4}<5$

\{the table is to the left of its rightmost safe rotational position\}

$\rightarrow$ table_right $\rightarrow$

$\operatorname{system}\left(x \_f b, \operatorname{table}\left(x_{3}, x_{4}+1, x_{5}\right), x \_r o b o t, x \_p r e s s, x \_d b, x \_c r a n e, x \_f l o o r\right)$

$\operatorname{system}\left(x \_f b, \operatorname{table}\left(x_{3}, x_{4}, x_{5}\right), x \_r o b o t, x \_p r e s s, x \_d b, x \_c r a n e, x \_f l o o r\right)$

$: x_{4}=5$

\{the table is in its rightmost safe rotational position

$\rightarrow$ table_right $\rightarrow$

$\operatorname{system}\left(x \_f b, \operatorname{table}\left(x_{3}\right.\right.$, error,$\left.\left.x_{5}\right), x \_r o b o t, x \_p r e s s, x \_d b, x \_c r a n e, x \_f l o o r\right)$

\subsubsection{The control variable: arm1_forward/backward}

$\operatorname{system}\left(x \_f b, x \_t a b l e, \operatorname{robot}\left(x_{6}, x_{7}, x_{8}, x_{9}, x_{10}, x_{11}, x_{12}\right), x \_\right.$press, $\left.x \_d b, x \_c r a n e, x \_f l o o r\right)$

$: x_{6} \leq 8 \wedge x_{7}<8$

$\{$ arm1 is in a rotational position where moving it forward will not cause it to enter the state space of the table AND is not fully extended

$\rightarrow$ arm1_forward $\rightarrow$

$\operatorname{system}\left(x \_f b, x \_t a b l e, \operatorname{robot}\left(x_{6}, x_{7}+1, x_{8}, x_{9}, x_{10}, x_{11}, x_{12}\right), x \_\right.$press, $\left.x \_d b, x \_c r a n e, x \_f l o o r\right)$ 
$\operatorname{system}\left(x \_f b, \operatorname{table}\left(x_{3}, x_{4}, x_{5}\right)\right.$, robot $\left.\left(x_{6}, x_{7}, x_{8}, x_{9}, x_{10}, x_{11}, x_{12}\right), x \_p r e s s, x \_d b, x \_c r a n e, x \_f l o o r\right)$

$: \neg\left(x_{6} \leq 8\right) \wedge x_{7}<8 \wedge\left(x_{3}=1 \vee x_{5}=0 \vee\left(x_{5}=1 \wedge x_{8}=0\right)\right)$

$\{\operatorname{arm} 1$ is not fully extended AND is in a rotational position where moving it forward will cause it to enter the state space of the table, AND (the table is out of the way OR the table isn't holding a plate OR the table is holding a plate but arm1 isn't holding a plate and has its magnet off)\}

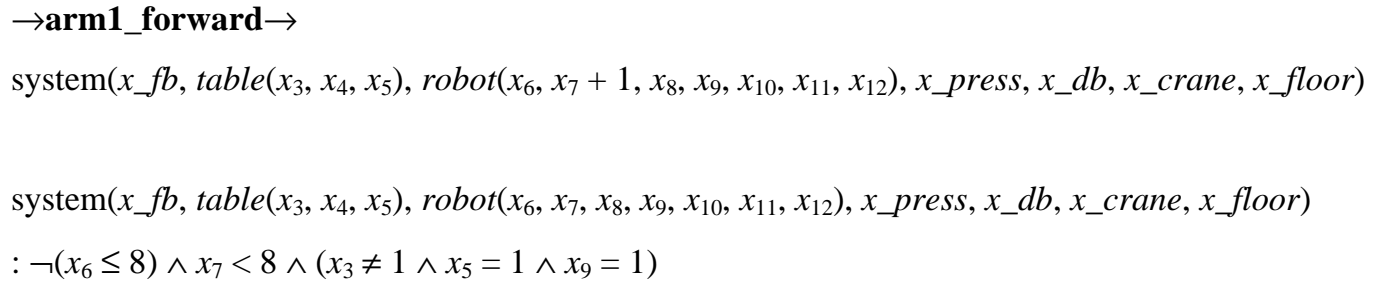

\{arm1 is not fully extended AND is in a rotational position where moving it forward will cause it to enter the state space of the table AND the table is in an unsafe position and is holding a plate and arm1 is also holding a plate

\section{$\rightarrow$ arm1_forward $\rightarrow$}

$\operatorname{system}\left(x \_f b, \operatorname{table}\left(x_{3}, x_{4}\right.\right.$, error $), \operatorname{robot}\left(x_{6}, x_{7}, x_{8}\right.$, error, $\left.x_{10}, x_{11}, x_{12}\right), x \_$press, $x \_d b, x \_c r a n e$, $x \_$floor)

$\operatorname{system}\left(x \_f b, \operatorname{table}\left(x_{3}, x_{4}, x_{5}\right)\right.$, robot $\left.\left(x_{6}, x_{7}, x_{8}, x_{9}, x_{10}, x_{11}, x_{12}\right), x \_p r e s s, x \_d b, x \_c r a n e, x \_f l o o r\right)$

$: \neg\left(x_{6} \leq 8\right) \wedge x_{7}<8 \wedge\left(x_{3} \neq 1 \wedge x_{5}=1 \wedge x_{8}=1 \wedge x_{9}=0\right)$

\{arm1 is not fully extended AND is in a rotational position where moving it forward will cause it to enter the state space of the table AND the table is in an unsafe position and is holding a plate and arm1 is not holding a plate but its magnet is on

$\rightarrow$ arm1_forward $\rightarrow$

$\operatorname{system}\left(x \_f b, \operatorname{table}\left(x_{3}, x_{4}, 0\right)\right.$, robot $\left(x_{6}, x_{7}, x_{8}\right.$, error, $\left.x_{10}, x_{11}, x_{12}\right), x \_$press, $\left.x \_d b, x \_c r a n e, x \_f l o o r\right)$

$\operatorname{system}\left(x \_f b, x \_t a b l e, \operatorname{robot}\left(x_{6}, x_{7}, x_{8}, x_{9}, x_{10}, x_{11}, x_{12}\right), x \_\right.$press, $\left.x \_d b, x \_c r a n e, x \_f l o o r\right)$

$: x_{7}>1$

$\{\operatorname{arm} 1$ is in a position where it can be retracted $\}$

$\rightarrow$ arm1_backward $\rightarrow$

$\operatorname{system}\left(x \_f b, x \_t a b l e, \operatorname{robot}\left(x_{6}, x_{7}-1, x_{8}, x_{9}, x_{10}, x_{11}, x_{12}\right), x \_p r e s s, x \_d b, x \_c r a n e, x \_f l o o r\right)$

$\operatorname{system}\left(x \_f b, x \_t a b l e, r o b o t\left(x_{6}, x_{7}, x_{8}, x_{9}, x_{10}, x_{11}, x_{12}\right), x \_p r e s s, x \_d b, x \_c r a n e, x \_f l o o r\right)$

$: x_{7}=1$

\{arm1 is in a position where it cannot be retracted any further\} 
$\rightarrow \operatorname{arm} 1 \_$backward $\rightarrow$
$\operatorname{system}\left(x \_f b, x \_t a b l e, \operatorname{robot}\left(x_{6}\right.\right.$, error $\left.\left., x_{8}, x_{9}, x_{10}, x_{11}, x_{12}\right), x \_p r e s s, x \_d b, x \_c r a n e, x \_f l o o r\right)$

\subsubsection{The control variable: arm1_mag_on/off}

There are some serious gaps/omissions in the informal document regarding the failure space of the magnet for arm1. For example, if arm1 is near, but not exactly in the proper position to pick up a plate what happens? The answer really is dependent on the strength of the magnet and the definition of "near". In order to deal with this in a reasonable way from a safety perspective we will assume that, when plates are present on the table or in the press, turning on the magnet in any position but the "table-arm1 plate exchange position" will cause an error. Also, without more knowledge we cannot assume that the "tablearm1 plate exchange position" is invertible. These assumptions are extremely restrictive, but without more knowledge of the system we simply can't assume anything else.

- The command to turn the magnet off partitions the state as follows:

- the magnet is already off - in which case the magnet off command does nothing

- the magnet is on and is holding a plate and the proper circumstances exists to transfer the plate to the press - in this case the transfer occurs

- $\quad$ all other states a transition to an error state occurs

- Magnet on partitions the state space as follows:

- the magnet is already on - in which case the magnet on command does nothing

- the magnet can be turned on when it is in a position to pick up a plate from the table and the table is in the proper position

- $\quad$ the magnet can be turned on when neither the table nor the press have a plate

- $\quad$ if the magnet is turned on at any other time an error will occur

$\operatorname{system}\left(x \_f b, x \_t a b l e, \operatorname{robot}\left(x_{6}, x_{7}, x_{8}, x_{9}, x_{10}, x_{11}, x_{12}\right), x \_p r e s s, x \_d b, x \_c r a n e, x \_f l o o r\right)$ $: x_{9}=0$

\{if arm1 is not holding a plate then turning the magnet off cannot cause any problems

$\rightarrow$ arm1_mag_off $\rightarrow$

$\operatorname{system}\left(x \_f b, x \_t a b l e, \operatorname{robot}\left(x_{6}, x_{7}, 0, x_{9}, x_{10}, x_{11}, x_{12}\right), x \_p r e s s, x \_d b, x \_c r a n e, x \_f l o o r\right)$

$\operatorname{system}\left(x \_f b, x \_t a b l e, \operatorname{robot}\left(x_{6}, x_{7}, x_{8}, x_{9}, x_{10}, x_{11}, x_{12}\right), \operatorname{press}\left(x_{13}, x_{14}\right), x \_d b, x \_c r a n e, x \_f l o o r\right)$

$: x_{9}=1 \wedge x_{6}=3 \wedge x_{7}=6 \wedge x_{13}=2 \wedge x_{14}=0$

\{arm1 is holding a plate AND is in a position where it can safely deposit the plate on the press and the press is in the proper position and is not holding a plate. Note that the informal document does not specify what happens if there already is a plate on the press 
$\rightarrow$ arm1_mag_off $\rightarrow$

$\operatorname{system}\left(x \_f b, x \_t a b l e, \operatorname{robot}\left(x_{6}, x_{7}, 0,0, x_{10}, x_{11}, x_{12}\right), \operatorname{press}\left(x_{13}, 1\right), x \_d b, x \_c r a n e, x \_f l o o r\right)$

$\operatorname{system}\left(x \_f b, \operatorname{table}\left(x_{3}, x_{4}, x_{5}\right), \operatorname{robot}\left(x_{6}, x_{7}, x_{8}, x_{9}, x_{10}, x_{11}, x_{12}\right), \operatorname{press}\left(x_{13}, x_{14}\right), x \_d b, x \_c r a n e\right.$, floor $\left.\left(x_{21}, x_{22}, x_{23}, x_{24}, x_{25}\right)\right)$

$: x_{9}=1 \wedge\left(\left(x_{6} \neq 3 \vee x_{7} \neq 6\right) \vee\left(x_{13} \neq 2 \vee x_{14} \neq 0\right)\right)$

\{arm1 is holding a plate AND is not in a position where it can safely deposit the plate on the press or the press is not in the proper position or is holding a plate. Also note that we are extremely generous in describing the error that occurs (that is we assume all reasonably possible errors can occur) $\}$

$\rightarrow$ arm1_mag_off $\rightarrow$

$\operatorname{system}\left(x_{-} f b, \operatorname{table}\left(x_{3}, x_{4}\right.\right.$, error $), \operatorname{robot}\left(x_{6}, x_{7}, 0, \operatorname{error}, x_{10}, x_{11}, x_{12}\right), \operatorname{press}\left(x_{13}\right.$, error $), x_{-} d b$, $x \_$crane,floor $\left.\left(x_{21}, x_{22}+1, x_{23}, x_{24}, x_{25}\right)\right)$

$\operatorname{system}\left(x \_f b, x \_t a b l e, r o b o t\left(x_{6}, x_{7}, x_{8}, x_{9}, x_{10}, x_{11}, x_{12}\right), x \_p r e s s, x \_d b, x \_c r a n e, x \_f l o o r\right)$

$: x_{8}=1$

\{the magnet of arm1 is already on

$\rightarrow$ arm1_mag_on $\rightarrow$

$\operatorname{system}\left(x \_f b, x \_t a b l e, \operatorname{robot}\left(x_{6}, x_{7}, x_{8}, x_{9}, x_{10}, x_{11}, x_{12}\right), x \_\right.$press, $\left.x \_d b, x \_c r a n e, x \_f l o o r\right)$

$\operatorname{system}\left(x \_f b, \operatorname{table}\left(x_{3}, x_{4}, x_{5}\right)\right.$, robot $\left.\left(x_{6}, x_{7}, x_{8}, x_{9}, x_{10}, x_{11}, x_{12}\right), x \_p r e s s, x \_d b, x \_c r a n e, x \_f l o o r\right)$

$: x_{8}=0 \wedge x_{6}=15 \wedge x_{7}=4 \wedge x_{3}=3 \wedge x_{4}=4 \wedge x_{5}=1$

\{the magnet of arm1 is off (i.e., this implies that arm1 is not holding a plate) AND arm1 is in a position where it can obtain a plate from the table

$\rightarrow$ arm1_mag_on $\rightarrow$

$\operatorname{system}\left(x \_f b, \operatorname{table}\left(x_{3}, x_{4}, 0\right), \operatorname{robot}\left(x_{6}, x_{7}, 1, x_{9}, x_{10}, x_{11}, x_{12}\right), x \_p r e s s, x \_d b, x \_c r a n e, x \_f l o o r\right)$

$\operatorname{system}\left(x \_f b, \operatorname{table}\left(x_{3}, x_{4}, x_{5}\right), \operatorname{robot}\left(x_{6}, x_{7}, x_{8}, x_{9}, x_{10}, x_{11}, x_{12}\right), \operatorname{press}\left(x_{13}, x_{14}\right), x \_d b, x_{-}\right.$crane, $x \_$floor)

$: x_{8}=0 \wedge x_{5}=0 \wedge x_{14}=0$

\{the magnet of arm 1 is off AND there are no plates on the table or in the press \}

$\rightarrow$ arm1_mag_on $\rightarrow$

$\operatorname{system}\left(x \_f b, \operatorname{table}\left(x_{3}, x_{4}, x_{5}\right)\right.$, robot $\left.\left(x_{6}, x_{7}, 1, x_{9}, x_{10}, x_{11}, x_{12}\right), \operatorname{press}\left(x_{13}, x_{14}\right), x \_d b, x \_c r a n e, x \_f l o o r\right)$ 
$\operatorname{system}\left(x \_f b, \operatorname{table}\left(x_{3}, x_{4}, x_{5}\right), \operatorname{robot}\left(x_{6}, x_{7}, x_{8}, x_{9}, x_{10}, x_{11}, x_{12}\right), \operatorname{press}\left(x_{13}, x_{14}\right), x \_d b, x \_c r a n e\right.$, floor $\left.\left(x_{21}, x_{22}, x_{23}, x_{24}, x_{25}\right)\right)$

$: x_{8}=0 \wedge\left(x_{5}=1 \vee x_{14}=1\right) \wedge \neg\left(\left(x_{6}=15 \wedge x_{7}=4\right) \wedge\left(x_{3}=3 \wedge x_{4}=4\right)\right)$

\{the magnet of arm 1 is off AND there are plates around (either on the table or on the press) AND the table and arm1 are not in the plate exchange position

$\rightarrow$ arm1_mag_on $\rightarrow$

$\operatorname{system}\left(x \_f b, \operatorname{table}\left(x_{3}, x_{4}\right.\right.$, error $), \operatorname{robot}\left(x_{6}, x_{7}, 1, \operatorname{error}, x_{10}, x_{11}, x_{12}\right), \operatorname{press}\left(x_{13}\right.$, error $), x_{-} d b$, $x_{\text {_crane }}$ floor $\left.\left(x_{21}, x_{22}+1, x_{23}, x_{24}, x_{25}\right)\right)$

\subsubsection{The control variable: arm2_forward/backward}

$\operatorname{system}\left(x \_f b, x \_t a b l e, \operatorname{robot}\left(x_{6}, x_{7}, x_{8}, x_{9}, x_{10}, x_{11}, x_{12}\right), \operatorname{press}\left(x_{13}, x_{14}\right), x \_d b, x \_c r a n e, x \_f l o o r\right)$

$: x_{10}<7 \wedge\left(x_{6} \geq 16 \vee x_{6} \leq 11 \vee x_{13} \neq 2\right)$

$\{$ arm2 is not fully extended AND arm2 and the press are in position where moving arm2 forward will not cause it to collide with the press $\}$

$\rightarrow$ arm2_forward $\rightarrow$

$\operatorname{system}\left(x \_f b, x \_t a b l e, \operatorname{robot}\left(x_{6}, x_{7}, x_{8}, x_{9}, x_{10}+1, x_{11}, x_{12}\right), \operatorname{press}\left(x_{13}, x_{14}\right), x \_d b, x \_c r a n e, x \_f l o o r\right)$

$\operatorname{system}\left(x \_f b, x \_t a b l e, \operatorname{robot}\left(x_{6}, x_{7}, x_{8}, x_{9}, x_{10}, x_{11}, x_{12}\right), \operatorname{press}\left(x_{13}, x_{14}\right), x \_d b, x \_c r a n e, x \_f l o o r\right)$

$: x_{10}<7 \wedge \neg\left(x_{6} \geq 16 \vee x_{6} \leq 11 \vee x_{13} \neq 2\right)$

\{arm2 is not fully extended AND arm2 and the press are in position where moving arm 2 forward will cause it to collide with the press $\}$

$\rightarrow$ arm2_forward $\rightarrow$

$\operatorname{system}\left(x \_f b, x \_t a b l e, \operatorname{robot}\left(x_{6}, x_{7}, x_{8}, x_{9}, \operatorname{error}, x_{11}, x_{12}\right)\right.$, press $\left(\right.$ error,$\left.\left.x_{14}\right), x \_d b, x \_c r a n e, x \_f l o o r\right)$

$\operatorname{system}\left(x \_f b, x \_t a b l e, \operatorname{robot}\left(x_{6}, x_{7}, x_{8}, x_{9}, x_{10}, x_{11}, x_{12}\right), x \_\right.$press, $\left.x \_d b, x \_c r a n e, x \_f l o o r\right)$

$: x_{10}=7$

$\{\operatorname{arm} 2$ is fully extended $\}$

$\rightarrow$ arm2_forward $\rightarrow$

$\operatorname{system}\left(x \_f b, x \_t a b l e, \operatorname{robot}\left(x_{6}, x_{7}, x_{8}, x_{9}\right.\right.$, error, $\left.\left.x_{11}, x_{12}\right), x \_p r e s s, x \_d b, x \_c r a n e, x \_f l o o r\right)$

$\operatorname{system}\left(x \_f b, x \_t a b l e, \operatorname{robot}\left(x_{6}, x_{7}, x_{8}, x_{9}, x_{10}, x_{11}, x_{12}\right), x \_\right.$press, $\left.x \_d b, x \_c r a n e, x \_f l o o r\right)$

$: x_{10}>1$

$\{\operatorname{arm} 2$ is not fully retracted $\}$ 


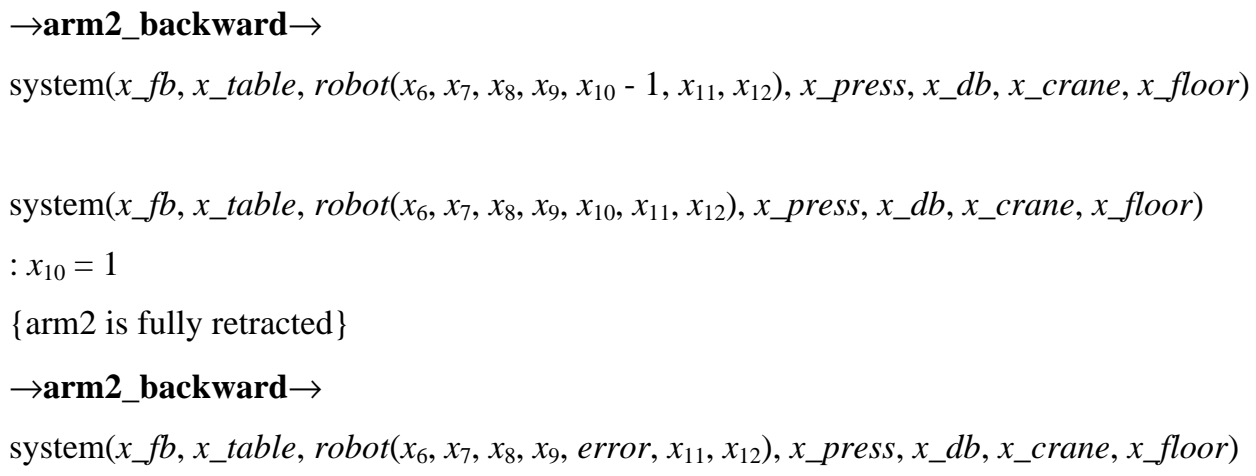

\subsubsection{The control variable: arm2_mag_on/off}

There are some serious gaps/omissions in the informal document regarding the failure space of the magnet for arm2. For example, if arm2 is near, but not exactly in the proper position to pick up a plate what happens? The answer really is dependent on the strength of the magnet and the definition of "near". In order to deal with this in a reasonable way from a safety perspective we will assume that, when a plate is present in the press, turning on the magnet in any position but the "press-arm2 plate exchange position" will cause an error. Also, without more knowledge we cannot assume that the "press-arm2 plate exchange" position is invertible. These assumptions are extremely restrictive, but without more knowledge of the system we simply can't assume anything else.

- The command to turn the magnet off partitions the state space as follows:

- the magnet is already off - in which case the magnet off command does nothing

- the magnet is on and is holding a plate and the proper circumstances exists to transfer the plate to the deposit belt - in this case the transfer occurs

- $\quad$ all other states a transition to an error state occurs

- Magnet on partitions the state space as follows:

- the magnet is already on - in which case the magnet on command does nothing

- the magnet can be turned on when it is in a position to pick up a plate from the press and the press is in the proper position

- the magnet can be turned on in arbitrary positions only when the press does not have a plate and the first region of the deposit belt does not have a plate

- if the magnet is turned on at any other time an error will occur

$\operatorname{system}\left(x \_f b, x \_t a b l e, \operatorname{robot}\left(x_{6}, x_{7}, x_{8}, x_{9}, x_{10}, x_{11}, x_{12}\right), x \_p r e s s, x \_d b, x \_c r a n e, x \_f l o o r\right)$

$: x_{12}=0$

\{If arm2 is not holding a plate then turning the magnet off cannot cause any problems \} 
$\rightarrow$ arm2_mag_off $\rightarrow$

$\operatorname{system}\left(x \_f b, x \_t a b l e, r o b o t\left(x_{6}, x_{7}, x_{8}, x_{9}, x_{10}, 0, x_{12}\right), x \_p r e s s, x \_d b, x \_c r a n e, x \_f l o o r\right)$

$\operatorname{system}\left(x \_f b, x \_t a b l e, \operatorname{robot}\left(x_{6}, x_{7}, x_{8}, x_{9}, x_{10}, x_{11}, x_{12}\right), x \_\right.$press $, d b\left(x_{15}, x_{16}\right), x \_$crane, $\left.x \_f l o o r\right)$

$: x_{12}=1 \wedge\left(3<x_{6}<7 \wedge x_{10}=3\right) \wedge x_{15}=0$

$\{$ arm2 is holding a plate AND is in a position where it can safely deposit the plate on the deposit belt AND the first region of the deposit belt is not holding a plate

$\rightarrow$ arm2_mag_off $\rightarrow$

$\operatorname{system}\left(x \_f b, x \_t a b l e, r o b o t\left(x_{6}, x_{7}, x_{8}, x_{9}, x_{10}, 0,0\right), x \_\right.$press $, d b\left(1, x_{16}\right), x \_$crane, $\left.x \_f l o o r\right)$

$\operatorname{system}\left(x \_f b, x \_t a b l e, \operatorname{robot}\left(x_{6}, x_{7}, x_{8}, x_{9}, x_{10}, x_{11}, x_{12}\right), \operatorname{press}\left(x_{13}, x_{14}\right), d b\left(x_{15}, x_{16}\right), x_{-}\right.$crane, floor $\left.\left(x_{21}, x_{22}, x_{23}, x_{24}, x_{25}\right)\right)$

$: x_{12}=1 \wedge \neg\left(3<x_{6}<7 \wedge x_{10}=3\right)$

\{arm2 is holding a plate AND is not in a position where it can safely deposit the plate on the deposit belt \}

$\rightarrow$ arm2_mag_off $\rightarrow$

$\operatorname{system}\left(x \_f b, x \_t a b l e, \operatorname{robot}\left(x_{6}, x_{7}, x_{8}, x_{9}, x_{10}, 0,0\right), \operatorname{press}\left(x_{13}\right.\right.$, error $), d b\left(\right.$ error, $\left.x_{16}\right), x_{-}$crane, floor $\left.\left(x_{21}, x_{22}, x_{23}+1, x_{24}, x_{25}\right)\right)$

$\operatorname{system}\left(x \_f b, x \_t a b l e, \operatorname{robot}\left(x_{6}, x_{7}, x_{8}, x_{9}, x_{10}, x_{11}, x_{12}\right), x \_p r e s s, x \_d b, x \_c r a n e, x \_f l o o r\right)$

$: x_{11}=1$

\{the magnet of arm2 is on - so turning it on doesn't change anything

$\rightarrow$ arm2_mag_on $\rightarrow$

$\operatorname{system}\left(x \_f b, x \_t a b l e, \operatorname{robot}\left(x_{6}, x_{7}, x_{8}, x_{9}, x_{10}, x_{11}, x_{12}\right), x \_\right.$press, $\left.x \_d b, x \_c r a n e, x \_f l o o r\right)$

$\operatorname{system}\left(x \_f b, x \_t a b l e, \operatorname{robot}\left(x_{6}, x_{7}, x_{8}, x_{9}, x_{10}, x_{11}, x_{12}\right), \operatorname{press}\left(x_{13}, x_{14}\right), x \_d b, x \_c r a n e, x \_f l o o r\right)$

$:\left(x_{6}=13 \wedge x_{10}=5 \wedge x_{11}=0\right) \wedge\left(x_{13}=1 \wedge x_{14}=1\right)$

$\{\operatorname{arm} 2$ is in a position to pick up a plate from the press AND the press is in position and is holding

a plate

$\rightarrow$ arm2_mag_on $\rightarrow$

$\operatorname{system}\left(x \_f b, x \_t a b l e, \operatorname{robot}\left(x_{6}, x_{7}, x_{8}, x_{9}, x_{10}, 1, x_{12}\right), \operatorname{press}\left(x_{13}, 0\right), x \_d b, x \_c r a n e, x \_f l o o r\right)$

$\operatorname{system}\left(x \_f b, x \_t a b l e, \operatorname{robot}\left(x_{6}, x_{7}, x_{8}, x_{9}, x_{10}, x_{11}, x_{12}\right), \operatorname{press}\left(x_{13}, x_{14}\right), d b\left(x_{15}, x_{16}\right), x \_c r a n e, x \_f l o o r\right)$

$: x_{11}=0 \wedge x_{14}=0 \wedge x_{15}=0$ 
\{the magnet is off AND there are no plates anywhere nearby (i.e., on the press or the first region of the deposit belt

$\rightarrow$ arm2_mag_on $\rightarrow$

$\operatorname{system}\left(x \_f b, x \_t a b l e, \operatorname{robot}\left(x_{6}, x_{7}, x_{8}, x_{9}, x_{10}, 1, x_{12}\right), \operatorname{press}\left(x_{13}, x_{14}\right), d b\left(x_{15}, x_{16}\right), x \_c r a n e, x \_\right.$floor $)$

$\operatorname{system}\left(x \_f b, x \_t a b l e, \operatorname{robot}\left(x_{6}, x_{7}, x_{8}, x_{9}, x_{10}, x_{11}, x_{12}\right), \operatorname{press}\left(x_{13}, x_{14}\right), d b\left(x_{15}, x_{16}\right), x \_c r a n e\right.$, floor $\left.\left(x_{21}, x_{22}, x_{23}, x_{24}, x_{25}\right)\right)$

$: x_{11}=0 \wedge \neg\left(x_{6}=13 \wedge x_{10}=5\right) \wedge \neg\left(x_{14}=0 \wedge x_{15}=0\right)$

\{the magnet is off AND arm $2 \mathrm{~s}$ out of position for a plate pickup AND there are plates nearby (i.e., on the press or the initial region of the deposit belt

$\rightarrow$ arm2_mag_on $\rightarrow$

$\operatorname{system}\left(x \_f b, x \_t a b l e, \operatorname{robot}\left(x_{6}, x_{7}, x_{8}, x_{9}, x_{10}, 1\right.\right.$, error $), \operatorname{press}\left(x_{13}\right.$, error $), d b\left(\right.$ error, $\left.x_{16}\right), x_{-}$crane, floor $\left.\left(x_{21}, x_{22}, x_{23}+1, x_{24}, x_{25}\right)\right)$

\subsubsection{The control variable: robot_left/right}

$\operatorname{system}\left(x \_f b, x \_t a b l e, \operatorname{robot}\left(x_{6}, x_{7}, x_{8}, x_{9}, x_{10}, x_{11}, x_{12}\right), \operatorname{press}\left(x_{13}, x_{14}\right), x \_d b, x \_\right.$crane,$\left.x \_f l o o r\right)$

$: x_{6}>2 \wedge\left(x_{6}>5 \vee x_{7} \leq 2 \vee x_{13} \leq 2\right) \wedge\left(x_{6} \neq 16 \vee x_{10}=1 \vee x_{13} \neq 2\right)$

\{the robot is not in its leftmost position AND arm1 will not collide (after the rotation) with the press AND arm2 will not collide with the press - Note that moving the robot left cannot cause arm1 to "enter" the space of the table

$\rightarrow$ robot_left $\rightarrow$

$\operatorname{system}\left(x \_f b, x \_t a b l e, \operatorname{robot}\left(x_{6}-1, x_{7}, x_{8}, x_{9}, x_{10}, x_{11}, x_{12}\right), \operatorname{press}\left(x_{13}, x_{14}\right), x \_d b, x \_c r a n e, x \_f l o o r\right)$

$\operatorname{system}\left(x \_f b, x \_t a b l e, \operatorname{robot}\left(x_{6}, x_{7}, x_{8}, x_{9}, x_{10}, x_{11}, x_{12}\right), \operatorname{press}\left(x_{13}, x_{14}\right), x \_d b, x \_c r a n e, x \_f l o o r\right)$

$: x_{6}=5 \wedge x_{7}>2 \wedge x_{13}=3$

\{arm1 of the robot is just to the right of the press AND the arm1 and the press are in position so that a collision will occur of the robot is rotated to the left

$\rightarrow$ robot_left $\rightarrow$

$\operatorname{system}\left(x \_f b, x \_t a b l e\right.$, robot(error, error, $\left.x_{8}, x_{9}, x_{10}, x_{11}, x_{12}\right)$, press $\left(\right.$ error, $\left.x_{14}\right), x \_d b, x \_c r a n e$, $x \_$floor)

$\operatorname{system}\left(x \_f b, x \_t a b l e, \operatorname{robot}\left(x_{6}, x_{7}, x_{8}, x_{9}, x_{10}, x_{11}, x_{12}\right), \operatorname{press}\left(x_{13}, x_{14}\right), x \_d b, x \_c r a n e, x \_f l o o r\right)$

$: x_{6}=16 \wedge x_{10}>1 \wedge x_{13}=2$ 
\{arm2 of the robot is just to the right of the press AND the arm2 and the press are in a position so that a collision will occur if the robot is rotated to the left

$\rightarrow$ robot_left $\rightarrow$

$\operatorname{system}\left(x \_f b, x \_t a b l e\right.$, robot(error, $x_{7}, x_{8}, x_{9}$, error, $\left.x_{11}, x_{12}\right)$, press $\left(\right.$ error, $\left.x_{14}\right), x \_d b, x \_c r a n e$, $x \_$floor)

$\operatorname{system}\left(x \_f b, x \_t a b l e, \operatorname{robot}\left(x_{6}, x_{7}, x_{8}, x_{9}, x_{10}, x_{11}, x_{12}\right), x \_\right.$press, $x \_d b, x \_$crane, $\left.x \_f l o o r\right)$

$: x_{6}=2$

\{the robot is in its leftmost safe position - Note that moving the robot left cannot cause arm 1 to "enter" the space of the table\}

$\rightarrow$ robot_left $\rightarrow$

$\operatorname{system}\left(x \_f b, x \_t a b l e, r o b o t\left(e r r o r, x_{7}, x_{8}, x_{9}, x_{10}, x_{11}, x_{12}\right), x \_p r e s s, x \_d b, x \_c r a n e, x \_f l o o r\right)$

$\operatorname{system}\left(x \_f b, \operatorname{table}\left(x_{3}, x_{4}, x_{5}\right), \operatorname{robot}\left(x_{6}, x_{7}, x_{8}, x_{9}, x_{10}, x_{11}, x_{12}\right), \operatorname{press}\left(x_{13}, x_{14}\right), x \_d b, x \_c r a n e\right.$, $x \_$floor)

$: x_{6}<18 \wedge\left(x_{6} \neq 9 \vee x_{7}=1 \vee x_{3}=1 \vee x_{5}=0 \vee x_{9}=0\right) \wedge\left(x_{6} \neq 11 \vee x_{10}=1 \vee x_{13} \neq 2\right)$

\{the robot is not in its rightmost position AND arm1 will not collide with the table (i.e., the plate space) AND arm 2 will not collide with the press. Note that in a right rotation, all we are concerned about is crossing a collision boundary when moving from left to right\}

$\rightarrow$ robot_right $\rightarrow$

$\operatorname{system}\left(x \_f b, \operatorname{table}\left(x_{3}, x_{4}, x_{5}\right), \operatorname{robot}\left(x_{6}+1, x_{7}, x_{8}, x_{9}, x_{10}, x_{11}, x_{12}\right), \operatorname{press}\left(x_{13}, x_{14}\right), x \_d b, x \_c r a n e\right.$, $x \_$floor)

$\operatorname{system}\left(x \_f b, \operatorname{table}\left(x_{3}, x_{4}, x_{5}\right), \operatorname{robot}\left(x_{6}, x_{7}, x_{8}, x_{9}, x_{10}, x_{11}, x_{12}\right), \operatorname{press}\left(x_{13}, x_{14}\right), x \_d b, x \_c r a n e\right.$, $x \_$floor)

$: x_{6}<18 \wedge x_{6}=9 \wedge x_{7} \neq 1 \wedge x_{3} \neq 1 \wedge x_{5}=1 \wedge x_{9}=1$

\{the robot is not in its rightmost position AND after rotation, arm1 will collide with the table (i.e., the plate space) $\}$

$\rightarrow$ robot_right $\rightarrow$

$\operatorname{system}\left(x \_f b, \operatorname{table}\left(x_{3}, x_{4}\right.\right.$, error $), \operatorname{robot}\left(\right.$ error, $x_{7}, x_{8}$, error, $\left.x_{10}, x_{11}, x_{12}\right)$, press $\left(\right.$ error, $\left.x_{14}\right), x \_d b$, $x \_$crane, $x \_$floor)

$\operatorname{system}\left(x \_f b, x \_t a b l e, \operatorname{robot}\left(x_{6}, x_{7}, x_{8}, x_{9}, x_{10}, x_{11}, x_{12}\right), \operatorname{press}\left(x_{13}, x_{14}\right), x \_d b, x \_c r a n e, x \_f l o o r\right)$

$: x_{6}<18 \wedge x_{6}=11 \wedge x_{10}>1 \wedge x_{13}=2$ 
\{the robot is not in its rightmost position AND arm2 will collide with the press. Note that in a right rotation, all we are concerned about is crossing a collision boundary when moving from left to right $\}$

$\rightarrow$ robot_right $\rightarrow$

$\operatorname{system}\left(x \_f b, x \_t a b l e\right.$, robot(error, $x_{7}, x_{8}, x_{9}$, error, $\left.x_{11}, x_{12}\right)$, press $\left(\right.$ error, $\left.x_{14}\right), x \_d b, x \_c r a n e$, $x \_$floor)

$\operatorname{system}\left(x \_f b, x \_t a b l e, \operatorname{robot}\left(x_{6}, x_{7}, x_{8}, x_{9}, x_{10}, x_{11}, x_{12}\right), x \_\right.$press, $\left.x \_d b, x \_c r a n e, x \_f l o o r\right)$

$: x_{6}=18$

\{the robot is in its rightmost position

$\rightarrow$ robot_right $\rightarrow$

$\operatorname{system}\left(x \_f b, x \_t a b l e, r o b o t\left(e r r o r, x_{7}, x_{8}, x_{9}, x_{10}, x_{11}, x_{12}\right), x \_p r e s s, x \_d b, x \_c r a n e, x \_f l o o r\right)$

\subsubsection{The control variable: crane to belt1/belt 2}

The horizontal movement of the crane is considerably restricted in the informal document.

$\operatorname{system}\left(x \_f b, x \_t a b l e, x \_r o b o t, x \_p r e s s, x \_d b, \operatorname{crane}\left(x_{17}, x_{18}, x_{19}, x_{20}\right), x \_\right.$floor $)$

$: x_{17} \leq 3 \wedge x_{18}<3$

\{the crane is in a position where it can move to the deposit belt

$\rightarrow$ crane_to_belt $2 \rightarrow$

$\operatorname{system}\left(x \_f b, x \_t a b l e, x \_r o b o t, x \_p r e s s, x \_d b, \operatorname{crane}\left(x_{17}, x_{18}+1, x_{19}, x_{20}\right), x \_\right.$floor $)$

$\operatorname{system}\left(x \_f b, x \_t a b l e, x \_r o b o t, x \_p r e s s, x \_d b, \operatorname{crane}\left(x_{17}, x_{18}, x_{19}, x_{20}\right), x \_\right.$floor $)$

$: x_{18}=3$

\{the crane cannot be moved any further in the direction of the deposit belt

$\rightarrow$ crane_to_belt $2 \rightarrow$

$\operatorname{system}\left(x \_f b, x \_t a b l e, x \_r o b o t, x \_p r e s s, x \_d b, \operatorname{crane}\left(x_{17}\right.\right.$, error $\left., x_{19}, x_{20}\right), x \_$floor $)$

$\operatorname{system}\left(x \_f b, x \_t a b l e, x \_r o b o t, x \_p r e s s, x \_d b, \operatorname{crane}\left(x_{17}, x_{18}, x_{19}, x_{20}\right), x \_\right.$floor $)$

$: x_{17}>3$

\{the crane is to low to be moved horizontally\}

$\rightarrow$ crane_to_belt $2 \rightarrow$

$\operatorname{system}\left(x \_f b, x \_t a b l e, x \_r o b o t, x \_p r e s s, x \_d b, \operatorname{crane}\left(\right.\right.$ error, error $\left., x_{19}, x_{20}\right), x \_$floor $)$

$\operatorname{system}\left(x \_f b, x \_t a b l e, x \_r o b o t, x \_p r e s s, x \_d b, \operatorname{crane}\left(x_{17}, x_{18}, x_{19}, x_{20}\right), x \_\right.$floor $)$ 
$: x_{17} \leq 3 \wedge x_{18}>1$

\{the crane is in a position where it can move to the feed belt $\}$

$\rightarrow$ crane_to_belt1 $\rightarrow$

$\operatorname{system}\left(x \_f b, x \_t a b l e, x \_r o b o t, x \_p r e s s, x \_d b, \operatorname{crane}\left(x_{17}, x_{18}-1, x_{19}, x_{20}\right), x \_\right.$floor $)$

$\operatorname{system}\left(x \_f b, x \_t a b l e, x \_r o b o t, x \_p r e s s, x \_d b, \operatorname{crane}\left(x_{17}, x_{18}, x_{19}, x_{20}\right), x \_\right.$floor $)$

$: x_{18}=1$

\{the crane cannot be moved any further in the direction of the feed belt

$\rightarrow$ crane_to_belt1 $\rightarrow$

$\operatorname{system}\left(x \_f b, x \_t a b l e, x \_r o b o t, x \_p r e s s, x \_d b, \operatorname{crane}\left(x_{17}\right.\right.$, error $\left., x_{19}, x_{20}\right), x \_$floor $)$

$\operatorname{system}\left(x \_f b, x \_t a b l e, x \_r o b o t, x \_p r e s s, x \_d b, \operatorname{crane}\left(x_{17}, x_{18}, x_{19}, x_{20}\right), x \_\right.$floor $)$

$: x_{17}>3$

\{the crane is to low to be moved horizontally\}

$\rightarrow$ crane_to_belt1 $\rightarrow$

$\operatorname{system}\left(x \_f b, x \_t a b l e, x \_r o b o t, x \_p r e s s, x \_d b\right.$, crane $\left(\right.$ error, error $\left., x_{19}, x_{20}\right), x \_$floor $)$

\subsubsection{The control variable: crane lift/lower}

Given the restrictions on the horizontal movement of the crane it appears to be safest to only permit vertical motion below $x_{17}=3$ when the crane is directly above the deposit belts. It also appears that there is another omission in the informal document - namely what happens if the crane moves to deposit a plate on the feed belt but there already is a plate in the initial region of the feed belt (e.g., does a plate collision occur)? The same omission exists for the crane and the deposit belt.

The horizontal movement of the crane is considerably restricted in the informal document.

$\operatorname{system}\left(x \_f b, x \_t a b l e, x \_r o b o t, x \_p r e s s, d b\left(x_{15}, x_{16}\right), \operatorname{crane}\left(x_{17}, x_{18}, x_{19}, x_{20}\right), x \_\right.$floor $)$

$: x_{17}=1$

\{the crane is in its uppermost position (a plate clash cannot occur after lowering it)

$\rightarrow$ crane_lower $\rightarrow$

$\operatorname{system}\left(x \_f b, x \_t a b l e, x \_r o b o t, x \_p r e s s, d b\left(x_{15}, x_{16}\right)\right.$, crane $\left(x_{17}+1, x_{18}, x_{19}, x_{20}\right), x \_$floor $)$

$\operatorname{system}\left(f b\left(x_{1}, x_{2}\right), x \_t a b l e, x \_r o b o t, x \_p r e s s, x \_d b, \operatorname{crane}\left(x_{17}, x_{18}, x_{19}, x_{20}\right), x \_\right.$floor $)$

$: x_{17}=2 \wedge\left(x_{1}=0 \vee x_{20}=0 \vee x_{18} \neq 1\right)$ 
\{ the crane is above the (general) unsafe vertical boundary AND a plate collision with the feed belt cannot occur\}

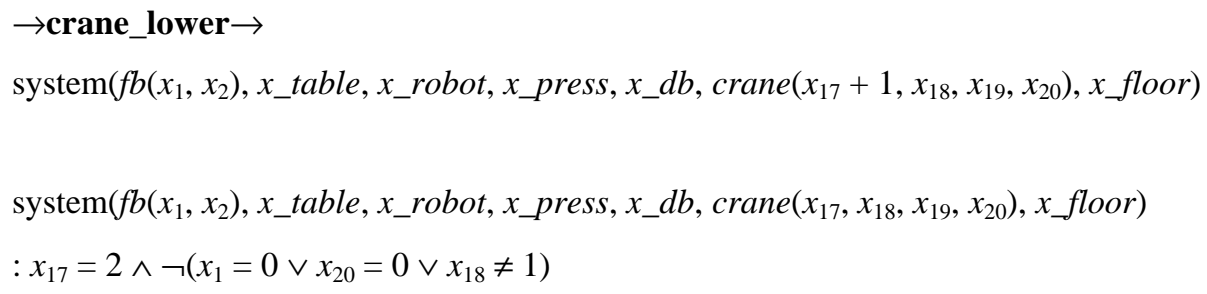

\{the crane is above the (general) unsafe vertical boundary AND a plate collision with the feed belt will occur\}

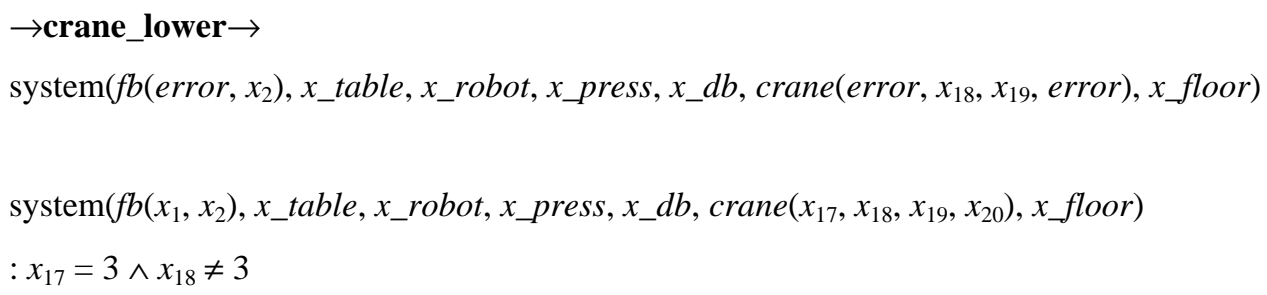

\{the crane is one above its next-to bottom-most (i.e., to avoid the potential of a plate clash between the crane and the deposit belt) safe position AND is above the deposit belt

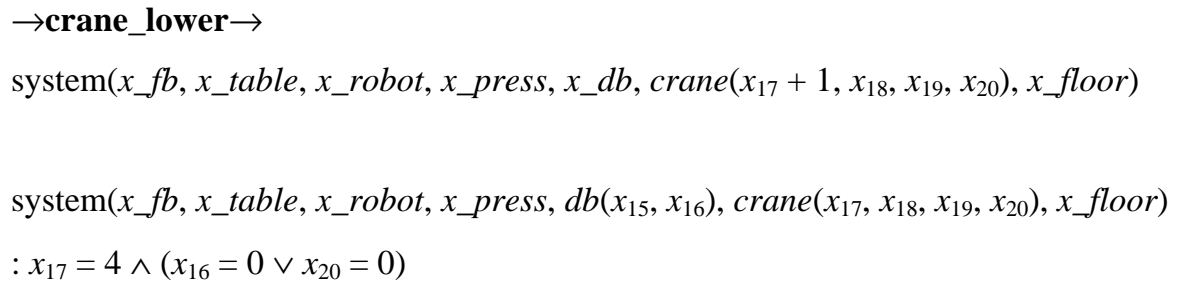

\{the crane is in its next-to bottom-most safe position AND a plate clash will not occur between the crane and the deposit belt $\}$

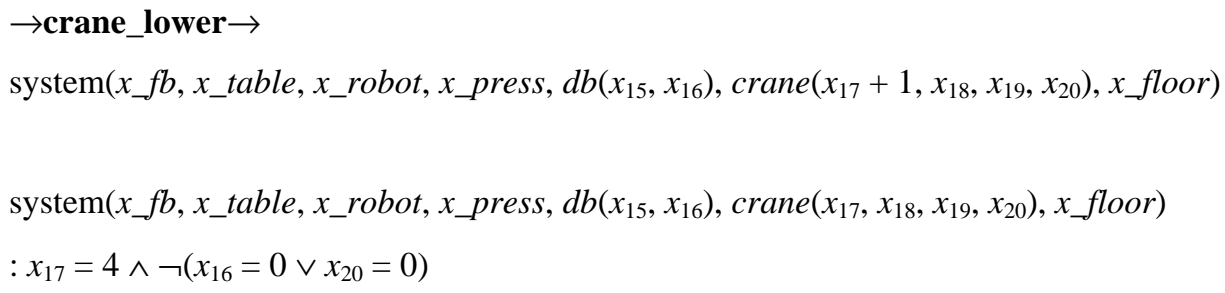


\{ the crane is in its next-to bottom-most safe position AND a plate clash will occur between the crane and the deposit belt $\}$

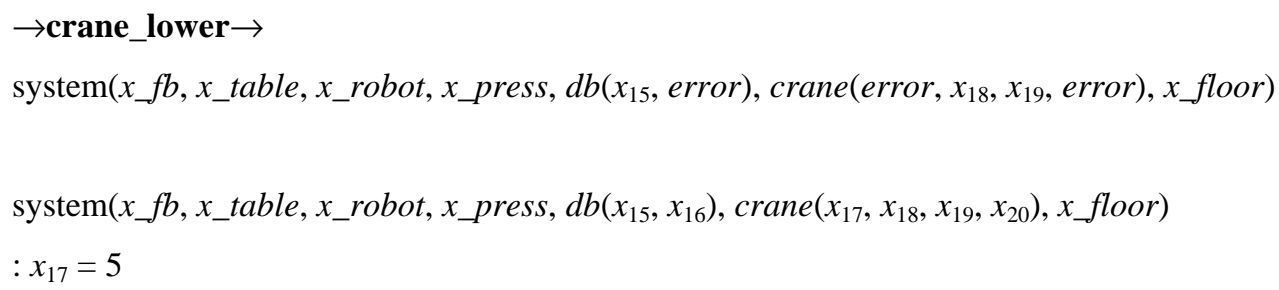

\{the crane is in its bottom-most position (this can only happen when the crane is above the deposit belt)\}

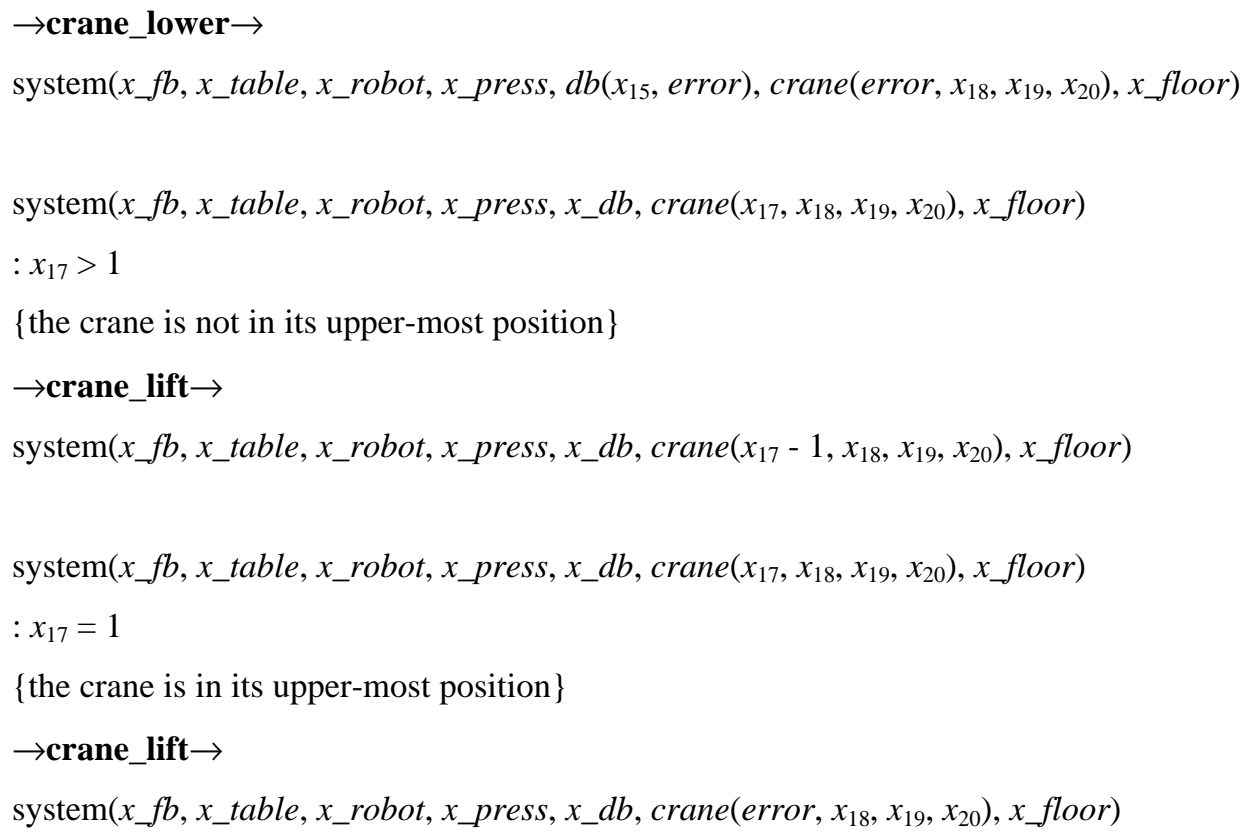

\subsubsection{The control variable: crane_mag_on/off}

The problem with the magnet on the crane is similar to the problem with the magnets for arm 1 and $\operatorname{arm} 2$ of the robot. Namely, we want to restrict when the magnet can be turned on - specifically the magnet of the crane should only be turned on when (1) conditions exist that enable the crane to pick up a plate from the deposit belt, OR (2) there are no plates in the vicinity (in the initial region of the feed belt or in the final region of the deposit belt). Again, we assume that the "picking up" (from the deposit belt) and "depositing" (on the feed belt) operations are not invertible (e.g., the crane cannot safely deposit a plate on the deposit belt).

$\operatorname{system}\left(x \_f b, x \_t a b l e, x \_r o b o t, x \_p r e s s, x \_d b, \operatorname{crane}\left(x_{17}, x_{18}, x_{19}, x_{20}\right), x \_\right.$floor $)$ 
$: x_{19}=1$

\{the crane magnet is already on\}

$\rightarrow$ crane_mag_on $\rightarrow$

$\operatorname{system}\left(x \_f b, x \_t a b l e, x \_r o b o t, x \_p r e s s, x \_d b, \operatorname{crane}\left(x_{17}, x_{18}, 1, x_{20}\right), x \_f l o o r\right)$

$\operatorname{system}\left(x \_f b, x \_t a b l e, x \_r o b o t, x \_p r e s s, d b\left(x_{15}, x_{16}\right), \operatorname{crane}\left(x_{17}, x_{18}, x_{19}, x_{20}\right), x \_\right.$floor $)$

$: x_{19}=0 \wedge\left(x_{17}=5 \wedge x_{18}=3\right) \wedge x_{16}=1$

\{the crane magnet is off AND the crane is above the deposit belt AND the final region of the deposit belt contains a plate

$\rightarrow$ crane_mag_on $\rightarrow$

$\operatorname{system}\left(x \_f b, x \_t a b l e, x \_r o b o t, x \_p r e s s, d b\left(x_{15}, 0\right)\right.$, crane $\left(x_{17}, x_{18}, 1,1\right), x \_$floor $)$

$\operatorname{system}\left(f b\left(x_{1}, x_{2}\right), x \_t a b l e, x \_r o b o t, x \_p r e s s, d b\left(x_{15}, x_{16}\right), \operatorname{crane}\left(x_{17}, x_{18}, x_{19}, x_{20}\right), x \_f l o o r\right)$

$: x_{19}=0 \wedge \neg\left(x_{17}=5 \wedge x_{18}=3\right) \wedge\left(x_{1}=1 \vee x_{16}=1\right)$

\{ the crane magnet is off AND the crane is not in a position to pick up a plate from the deposit belt AND there is a plate in the "vicinity"

$\rightarrow$ crane_mag_on $\rightarrow$

$\operatorname{system}\left(f b\left(\right.\right.$ error,$\left.x_{2}\right), x \_t a b l e, x \_r o b o t, x \_p r e s s, d b\left(x_{15}\right.$, error $)$, crane $\left(x_{17}, x_{18}, 1\right.$, error $), x \_$floor $)$

$\operatorname{system}\left(f b\left(x_{1}, x_{2}\right), x \_t a b l e, x \_r o b o t, x \_p r e s s, d b\left(x_{15}, x_{16}\right), \operatorname{crane}\left(x_{17}, x_{18}, x_{19}, x_{20}\right), x \_f l o o r\right)$

$: x_{19}=0 \wedge\left(x_{1}=0 \wedge x_{16}=0\right)$

\{the crane magnet is off AND there are no plates in the "vicinity"

$\rightarrow$ crane_mag_on $\rightarrow$

$\operatorname{system}\left(f b\left(x_{1}, x_{2}\right), x \_t a b l e, x \_r o b o t, x \_p r e s s, d b\left(x_{15}, x_{16}\right), \operatorname{crane}\left(x_{17}, x_{18}, 1, x_{20}\right), x \_\right.$floor $)$

$\operatorname{system}\left(x \_f b, x \_t a b l e, x \_r o b o t, x \_p r e s s, x \_d b, \operatorname{crane}\left(x_{17}, x_{18}, x_{19}, x_{20}\right), x \_\right.$floor $)$

$: x_{20}=0$

\{the crane is not holding a plate $\}$

$\rightarrow$ crane_mag_off $\rightarrow$

$\operatorname{system}\left(x \_f b, x \_t a b l e, x \_r o b o t, x \_p r e s s, x \_d b, \operatorname{crane}\left(x_{17}, x_{18}, 0, x_{20}\right), x \_f l o o r\right)$

$\operatorname{system}\left(f b\left(x_{1}, x_{2}\right), x \_t a b l e, x \_r o b o t, x \_p r e s s, x \_d b, \operatorname{crane}\left(x_{17}, x_{18}, x_{19}, x_{20}\right), x \_\right.$floor $)$

$: x_{19}=1 \wedge x_{20}=1 \wedge\left(x_{17}=3 \wedge x_{18}=1 \wedge x_{1}=0\right)$ 
\{ the crane magnet is on AND the crane is holding a plate AND the crane is in a position to deposit a plate on the feed belt and the feed belt is ready to receive a plate

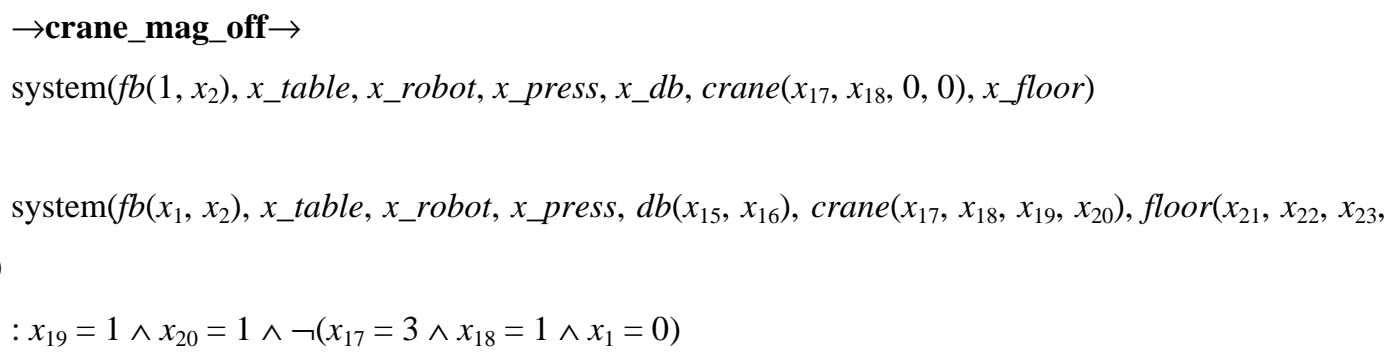

\{ the crane magnet is on AND the crane is holding a plate AND the crane is out of position to deposit a plate on the feed belt or the feed belt is not ready to receive a plate. Note that this error could be modeled a little more precisely (e.g., the crane drops a plate on the floor, the crane drops a plate on another plate, etc.) $\}$

$\rightarrow$ crane_mag_off $\rightarrow$

$\operatorname{system}\left(f b\left(\right.\right.$ error,$\left.x_{2}\right), x \_t a b l e, x \_r o b o t, x \_p r e s s, d b\left(x_{15}\right.$, error $)$, crane $\left(x_{17}, x_{18}, 0\right.$, error $)$, floor $\left(x_{21}\right.$, $\left.\left.x_{22}, x_{23}, x_{24}, x_{25}+1\right)\right)$

\subsubsection{The control variable: press_upward/downward}

$\operatorname{system}\left(x \_f b, x \_t a b l e, \operatorname{robot}\left(x_{6}, x_{7}, x_{8}, x_{9}, x_{10}, x_{11}, x_{12}\right), \operatorname{press}\left(x_{13}, x_{14}\right), x \_d b, x \_c r a n e, x \_f l o o r\right)$

$: x_{6}<5 \wedge x_{7}>2 \wedge x_{13}=2$

\{the robot is in a rotational space where arm1 can collide with the press AND the extension of arm 1 is such that a collision is possible AND the press is in the middle position - moving it up will cause a collision - here we also assume that it is not the case that both arm1 and the press are holding a plate because otherwise an error state would have resulted

$\rightarrow$ press_upward $\rightarrow$

$\operatorname{system}\left(x \_f b, x \_t a b l e, \operatorname{robot}\left(\right.\right.$ error, error, $\left.x_{8}, x_{9}, x_{10}, x_{11}, x_{12}\right)$, press $\left(\right.$ error, $\left.x_{14}\right), x \_d b, x \_c r a n e$, $x \_$floor)

$\operatorname{system}\left(x \_f b, x \_t a b l e, \operatorname{robot}\left(x_{6}, x_{7}, x_{8}, x_{9}, x_{10}, x_{11}, x_{12}\right), \operatorname{press}\left(x_{13}, x_{14}\right), x \_d b, x \_\right.$crane, $x \_$floor $)$

$: x_{6}<5 \wedge x_{7}>2 \wedge x_{13}=1 \wedge\left(x_{9}=0 \vee x_{14}=0\right)$

\{the robot is in a rotational space where arm 1 can collide with the press AND the extension of arm1 is such that a collision is possible AND the press is in the bottom position AND arm1 and the press are not both holding a plate (note that this is not stated in the informal specification)

$\rightarrow$ press_upward $\rightarrow$ 
$\operatorname{system}\left(x \_f b, x \_t a b l e, \operatorname{robot}\left(x_{6}, x_{7}, x_{8}, x_{9,} x_{10}, x_{11}, x_{12}\right), \operatorname{press}\left(x_{13}+1, x_{14}\right), x \_d b, x \_c r a n e, x \_f l o o r\right)$

$\operatorname{system}\left(x \_f b, x \_t a b l e, \operatorname{robot}\left(x_{6}, x_{7}, x_{8}, x_{9}, x_{10}, x_{11}, x_{12}\right), \operatorname{press}\left(x_{13}, x_{14}\right), x \_d b, x \_\right.$crane, $\left.x \_f l o o r\right)$

$: \neg\left(x_{6}<5 \wedge x_{7}>2\right) \wedge x_{13}=2$

\{ the robot is in a space where arm 1 cannot collide with the press AND the press is in the middle position

$\rightarrow$ press_upward $\rightarrow$

$\operatorname{system}\left(x \_f b, x \_t a b l e, \operatorname{robot}\left(x_{6}, x_{7}, x_{8}, x_{9}, x_{10}, x_{11}, x_{12}\right), \operatorname{press}\left(x_{13}+1, x_{14}\right), x \_d b, x \_c r a n e, x \_f l o o r\right)$

$\operatorname{system}\left(x \_f b, x \_t a b l e, \operatorname{robot}\left(x_{6}, x_{7}, x_{8}, x_{9}, x_{10}, x_{11}, x_{12}\right), \operatorname{press}\left(x_{13}, x_{14}\right), x \_d b, x \_c r a n e, x \_f l o o r\right)$

$: x_{6}>10 \wedge x_{6}<15 \wedge x_{10}>1 \wedge x_{13}=1$

$\{\operatorname{arm} 2$ is in position where it can collide with the press $\}$

$\rightarrow$ press_upward $\rightarrow$

$\operatorname{system}\left(x \_f b, x \_t a b l e, \operatorname{robot}\left(x_{6}, x_{7}, x_{8}, x_{9}, x_{10}, x_{11}\right.\right.$, error $), \operatorname{press}\left(x_{13}\right.$, error $\left.), x \_d b, x \_c r a n e, x \_f l o o r\right)$

$\operatorname{system}\left(x \_f b, x \_t a b l e, \operatorname{robot}\left(x_{6}, x_{7}, x_{8}, x_{9}, x_{10}, x_{11}, x_{12}\right), \operatorname{press}\left(x_{13}, x_{14}\right), x \_d b, x \_c r a n e, x \_f l o o r\right)$

$: \neg\left(x_{6}>10 \wedge x_{6}<15 \wedge x_{10}>1\right) \wedge x_{13}=1$

$\{\operatorname{arm} 2$ is not in position where it can collide with the press $\}$

$\rightarrow$ press_upward $\rightarrow$

$\operatorname{system}\left(x \_f b, x \_t a b l e, \operatorname{robot}\left(x_{6}, x_{7}, x_{8}, x_{9}, x_{10}, x_{11}, x_{12}\right), \operatorname{press}\left(x_{13}, x_{14}+1\right), x \_d b, x \_c r a n e, x \_f l o o r\right)$

$\operatorname{system}\left(x \_f b, x \_t a b l e, x \_r o b o t, p r e s s\left(x_{13}, x_{14}\right), x \_d b, x \_c r a n e, x \_f l o o r\right)$

$: x_{13}=3$

$\{$ the press is in uppermost position

$\rightarrow$ press_upward $\rightarrow$

$\operatorname{system}\left(x \_f b, x \_t a b l e, x \_r o b o t, p r e s s\left(e r r o r, x{ }_{14}\right), x \_d b, x \_c r a n e, x \_f l o o r\right)$

$\operatorname{system}\left(x \_f b, x \_\right.$table, $\operatorname{robot}\left(x_{6}, x_{7}, x_{8}, x_{9}, x_{10}, x_{11}, x_{12}\right), \operatorname{press}\left(x_{13}, x_{14}\right), x \_d b, x \_$crane,$\left.x \_f l o o r\right)$

$: \neg\left(x_{6}>10 \wedge x_{6}<15 \wedge x_{10}>1\right) \wedge x_{13}=3$

\{the press is in uppermost position and cannot collide with robot arm2\}

$\rightarrow$ press_downward $\rightarrow$

$\operatorname{system}\left(x \_f b, x \_t a b l e, \operatorname{robot}\left(x_{6}, x_{7}, x_{8}, x_{9}, x_{10}, x_{11}, x_{12}\right), \operatorname{press}\left(x_{13}-1, x_{14}\right), x \_d b, x \_c r a n e, x \_f l o o r\right)$

$\operatorname{system}\left(x \_f b, x \_t a b l e, \operatorname{robot}\left(x_{6}, x_{7}, x_{8}, x_{9}, x_{10}, x_{11}, x_{12}\right), \operatorname{press}\left(x_{13}, x_{14}\right), x \_d b, x \_\right.$crane,$\left.x \_f l o o r\right)$ 
$: x_{6}>10 \wedge x_{6}<15 \wedge x_{10}>1 \wedge x_{13}=3$

\{the press is in uppermost position and can collide with robot arm2\}

$\rightarrow$ press_downward $\rightarrow$

$\operatorname{system}\left(x \_f b, x_{-}\right.$table, $\operatorname{robot}\left(x_{6}, x_{7}, x_{8}, x_{9}, x_{10}, x_{11}\right.$, error $), \operatorname{press}\left(\right.$ error,$\left.x_{14}\right), x_{-} d b, x_{-}$crane,$x_{-}$floor $)$

$\operatorname{system}\left(x \_f b, x \_t a b l e, x \_r o b o t, p r e s s\left(x_{13}, x_{14}\right), x \_d b, x \_\right.$crane,$\left.x \_f l o o r\right)$

$: x_{13}=2$

\{the press is in middle position

$\rightarrow$ press_downward $\rightarrow$

$\operatorname{system}\left(x \_f b, x \_t a b l e, x \_r o b o t, p r e s s\left(x_{13}-1, x_{14}\right), x \_d b, x \_\right.$crane,$x \_$floor $)$

$\operatorname{system}\left(x \_f b, x \_t a b l e, x \_r o b o t, p r e s s\left(x_{13}, x_{14}\right), x \_d b, x \_\right.$crane,$\left.x \_f l o o r\right)$

$: x_{13}=1$

\{the press is in bottom position $\}$

$\rightarrow$ press_downward $\rightarrow$

$\operatorname{system}\left(x \_f b, x \_t a b l e, x \_r o b o t, p r e s s\left(e r r o r, x_{14}\right), x \_d b, x \_c r a n e, x \_f l o o r\right)$ 


\section{APPENDIX C: SAFETY CONSTRAINTS IN THE PRODUCTION CELL}

by Dejan Desovski

\section{Overwiew}

The purpose of this document is to formally extend the formal specification of the Production Cell in order to define safety constraints and the way they are displayed in addition to the functional specification described previously. This extension consists of two parts: (1) an extension of the individual domains, and (2) description of safety constraints.

\section{Extension of the Individual Domains}

We are interested in graphically and symbolically representing the safety constraints in the Production Cell, in addition to the functional capabilities defined by the formal specification. We take incremental approach in order to achieve this goal. Having already defined the abstracted state space of the model, and the functional specification, we will extend the individual domains in order to specify the safety constraints that we are interested in, and then specify the actual safety constraints.

There are two types of safety violations that we like to display:

- error states, which represent a terminating safety violations (e.g., a collision has already occurred, a plate has fallen to the floor);

- hazardous states, representing states that are one or more transitions away from a terminating safety violations.

\subsection{Extension of the Symbolic Foundational Types}

In order to represent these types of safety violations first we need to extend the symbolic foundational types:

- Symbolic Types

- boolean $=\{$ true, false $\}$

- $\quad$ boolean $_{\perp}=$ boolean $\cup\{$ error, hazard $\}$ 
- $\quad$ string $=\{$ all strings $\}$

- string $_{\perp}=$ string $\cup\{$ error, hazard $\}$ where "error" and "hazard" are somehow distinguishable from other strings

- $\quad$ integer $=\{\ldots,-1,0,1, \ldots\}$

- $\quad$ integer $_{\perp}=$ integer $\cup\{$ error, hazard $\}$

\subsection{Extension of the display instances of the graphical types}

We extend the display instances of the graphical types for the Production Cell in order to display the safety violations with different colors:

display metal_plate $=[($ true $=1$, yellow $),($ false $=0$, clear $),($ hazard, red $),($ error, black) ];

display table_state_cube $=[$ (present, green $),($ absent, clear $),($ hazard, red $),($ error, black) ];

display robot_arm_state_cube $=[(($ present, off $=0)$, green $),(($ present, on $=1)$, blue), (absent, clear), (hazard, red), (error, black) ];

display press_state_cube $=[$ (present, green $),($ absent, clear $),($ hazard, red $),($ error, black) ];

display crane_state_cube $=[(($ present, off $=0)$, green $),(($ present, on $=1)$, blue $)$, (absent, clear), (hazard, red), (error, black) ];

display cell_floor_cube $=[(0$, clear $),(\mathrm{i}, \operatorname{display}(\mathrm{i}))]$;

The rest of the formal specification stays the same. Now we are ready to define the safety constraints.

\section{Safety constraints}

The safety constraints we are going to define represent the safety violations of the current state in stable instance of time, or the possible safety violations that exist within one or more transitions from the current stable state. This aggregate information provides important information during the validation phase. For example it provides information about the possible hazardous states during the operation of the system, and more careful 
planing and design of control algorithms can be applied in order these states to be avoided. The safety constraints can be used as guarding conditions in the transitions, restricting execution of transitions that are hazardous or produce errors.

We are defining the safety constraints similarly like the transitions, with only difference being that we are not specifying an assignment to control variable (all the possible assignments are considered): $P(\vec{m}) \longrightarrow F(\vec{m}) . \quad P: \vec{m} \rightarrow$ bool represents a predicate on the observable state, and $F: \vec{m} \rightarrow \vec{m}$ is a function on the observable state. Predicate $P$ represents the precondition of the safety constraint and function $F$ modifies the state by assigning \{error, hazard $\}$ to the states that are in some type of safety violation.

\subsection{Feed Belt Safety Constraints}

$\operatorname{system}\left(f b\left(x_{1}, x_{2}\right)\right.$, table $\left.\left(x_{3}, x_{4}, x_{5}\right), x \_r o b o t, x \_p r e s s, x \_d b, x \_c r a n e, x \_f l o o r\right)$

$: x_{2}=1 \wedge \neg\left(x_{3}=1 \wedge x_{4}=2\right)$

\{the second region of the feed belt contains a plate and the table is out of position $\}$

$\rightarrow$

$\operatorname{system}\left(f b\left(x_{1}\right.\right.$, hazard $)$, table $\left(x_{3}, x_{4}, x_{5}\right), x \_r o b o t, x \_p r e s s, x \_d b, x \_c r a n e, x \_$floor $)$

$\operatorname{system}\left(f b\left(x_{1}, x_{2}\right), \operatorname{table}\left(x_{3}, x_{4}, x_{5}\right), x \_r o b o t, x \_p r e s s, x \_d b, x \_c r a n e, x \_f l o o r\right)$

$: x_{2}=1 \wedge x_{3}=1 \wedge x_{4}=2 \wedge x_{5}=1$

\{the second region of the feed belt contains a plate and the table is in position, but also contains a

plate

$\rightarrow$

$\operatorname{system}\left(f b\left(x_{1}\right.\right.$, hazard $), \operatorname{table}\left(x_{3}, x_{4}\right.$, hazard $\left.), x \_r o b o t, x \_p r e s s, x \_d b, x \_c r a n e, x \_f l o o r\right)$

$\operatorname{system}\left(f b\left(x_{1}, x_{2}\right), \operatorname{table}\left(x_{3}, x_{4}, x_{5}\right)\right.$, robot $\left.\left(x_{6}, x_{7}, x_{8}, x_{9}, x_{10}, x_{11}, x_{12}\right), x \_p r e s s, x \_d b, x \_c r a n e, x \_f l o o r\right)$

$: x_{2}=1 \wedge x_{3}=1 \wedge x_{4}=2 \wedge x_{5}=0 \wedge x_{8}=1$

\{the second region of the feed belt contains a plate and the table is in position and is not holding a plate AND the magnet of arm1 is on!\} 
$\operatorname{system}\left(f b\left(x_{1}\right.\right.$, hazard $), \operatorname{table}\left(x_{3}, x_{4}, x_{5}\right), \operatorname{robot}\left(x_{6}, x_{7}, x_{8}, x_{9}, x_{10}, x_{11}, x_{12}\right), x \_$press, $x \_d b, x \_c r a n e$, $x$ floor)

\subsection{Deposit Belt Safety Constraints}

$\operatorname{system}\left(x \_f b, x \_t a b l e, x \_r o b o t, x \_p r e s s, d b\left(x_{15}, x_{16}\right), x \_c r a n e, x \_f l o o r\right)$

$: x_{16}=1$

$\{$ the second region of the deposit belt is not empty\}

$\rightarrow$

$\operatorname{system}\left(x \_f b, x \_t a b l e, x \_r o b o t, x \_p r e s s, d b\left(x_{15}\right.\right.$, hazard $\left.), x \_c r a n e, x \_f l o o r\right)$

\subsection{Table Safety Constraints}

$\operatorname{system}\left(x \_f b, \operatorname{table}\left(x_{3}, x_{4}, x_{5}\right), \operatorname{robot}\left(x_{6}, x_{7}, x_{8}, x_{9}, x_{10}, x_{11}, x_{12}\right), x \_p r e s s, x \_d b, x \_c r a n e, x \_f l o o r\right)$

$: x_{3}=1 \wedge x_{5}=1 \wedge x_{9}=1 \wedge \neg\left(x_{6} \leq 8 \vee x_{7}=1\right)$

$\{\operatorname{arm} 1$ is in the vicinity and both the table and arm1 have a plate $\}$

$\rightarrow$

$\operatorname{system}\left(x \_f b, \operatorname{table}\left(x_{3}+1, x_{4}\right.\right.$, hazard $), \operatorname{robot}\left(x_{6}, x_{7}, x_{8}\right.$, hazard $\left., x_{10}, x_{11}, x_{12}\right), x \_p r e s s, x \_d b, x \_c r a n e$, $x \_$floor)

$\operatorname{system}\left(x \_f b, \operatorname{table}\left(x_{3}, x_{4}, x_{5}\right), \operatorname{robot}\left(x_{6}, x_{7}, x_{8}, x_{9}, x_{10}, x_{11}, x_{12}\right), x \_p r e s s, x \_d b, x \_c r a n e, x \_f l o o r\right)$ $: x_{3}=2 \wedge x_{5}=1 \wedge x_{9}=1 \wedge \neg\left(x_{6} \leq 8 \vee x_{7}=1\right)$

\{the plates of arm1 and table have colided

$\rightarrow$

$\operatorname{system}\left(x \_f b, \operatorname{table}\left(x_{3}, x_{4}\right.\right.$, error $), \operatorname{robot}\left(x_{6}, x_{7}, x_{8}\right.$, error, $\left.x_{10}, x_{11}, x_{12}\right), x \_$press, $x \_d b, x \_c r a n e$, $x \_$floor)

$\operatorname{system}\left(x \_f b, \operatorname{table}\left(x_{3}, x_{4}, x_{5}\right), \operatorname{robot}\left(x_{6}, x_{7}, x_{8}, x_{9}, x_{10}, x_{11}, x_{12}\right), x \_p r e s s, x \_d b, x \_c r a n e, x \_f l o o r\right)$

$: x_{3}=1 \wedge x_{5}=1 \wedge x_{8}=1 \wedge x_{9}=0 \wedge \neg\left(x_{6} \leq 8 \vee x_{7}=1\right)$

\{arm1 is in the vicinity, has no plate but its magnet is on and the table has a plate

$\rightarrow$

$\operatorname{system}\left(x \_f b, \operatorname{table}\left(x_{3}+1, x_{4}\right.\right.$, hazard $), \operatorname{robot}\left(x_{6}, x_{7}, x_{8}\right.$, hazard $\left., x_{10}, x_{11}, x_{12}\right), x \_p r e s s, x \_d b, x \_c r a n e$, $x \_$floor) 
$\operatorname{system}\left(x \_f b, \operatorname{table}\left(x_{3}, x_{4}, x_{5}\right), x \_r o b o t, x \_p r e s s, x \_d b, x \_c r a n e, x \_f l o o r\right)$

$: x_{3}=3$

\{the table is in the top position and cannot be raised any more

$\rightarrow$

$\operatorname{system}\left(x \_f b, \operatorname{table}\left(x_{3}, x_{4}\right.\right.$, hazard $\left.), x \_r o b o t, x \_p r e s s, x \_d b, x \_c r a n e, x \_f l o o r\right)$

$\operatorname{system}\left(x \_f b, \operatorname{table}\left(x_{3}, x_{4}, x_{5}\right), x \_r o b o t, x \_p r e s s, x \_d b, x \_c r a n e, x \_f l o o r\right)$

$: x_{3}=1$

\{the table is in its bottom position and cannot be lowered any further

$\rightarrow$

$\operatorname{system}\left(x \_f b, \operatorname{table}\left(x_{3}, x_{4}\right.\right.$, hazard $\left.), x \_r o b o t, x \_p r e s s, x \_d b, x \_c r a n e, x \_f l o o r\right)$

$\operatorname{system}\left(x \_f b, \operatorname{table}\left(x_{3}, x_{4}, x_{5}\right), x \_r o b o t, x \_p r e s s, x \_d b, x \_c r a n e, x \_f l o o r\right)$

$: x_{4}=2$

\{the table is in its leftmost safe rotational position

$\rightarrow$

$\operatorname{system}\left(x \_f b, \operatorname{table}\left(x_{3}, x_{4}\right.\right.$, hazard $\left.), x \_r o b o t, x \_p r e s s, x \_d b, x \_c r a n e, x \_f l o o r\right)$

$\operatorname{system}\left(f b\left(x_{1}, x_{2}\right), \operatorname{table}\left(x_{3}, x_{4}, x_{5}\right), x \_r o b o t, x \_p r e s s, x \_d b, x \_c r a n e, x \_f l o o r\right)$

$: x_{4}=1$

\{the table has collided with the feed belt

$\rightarrow$

$\operatorname{system}\left(f b\left(x_{1}\right.\right.$, error $), \operatorname{table}\left(x_{3}, x_{4}\right.$, error $\left.), x \_r o b o t, x \_p r e s s, x \_d b, x \_c r a n e, x \_f l o o r\right)$

$\operatorname{system}\left(x \_f b, \operatorname{table}\left(x_{3}, x_{4}, x_{5}\right), x \_r o b o t, x \_\right.$press, $x \_d b, x \_c r a n e, x \_$floor $)$

$: x_{4}=5$

\{the table is in its rightmost safe rotational position

$\rightarrow$

$\operatorname{system}\left(x \_f b, \operatorname{table}\left(x_{3}, x_{4}\right.\right.$, hazard $\left.), x \_r o b o t, x \_p r e s s, x \_d b, x \_c r a n e, x \_f l o o r\right)$

\subsection{Robot Safety constraints}

$\operatorname{system}\left(x \_f b, \operatorname{table}\left(x_{3}, x_{4}, x_{5}\right), \operatorname{robot}\left(x_{6}, x_{7}, x_{8}, x_{9}, x_{10}, x_{11}, x_{12}\right), x \_p r e s s, x \_d b, x \_c r a n e, x \_f l o o r\right)$ $: \neg\left(x_{6} \leq 8\right) \wedge x_{7}<8 \wedge\left(x_{3} \neq 1 \wedge x_{5}=1 \wedge x_{9}=1\right)$ 
\{arm1 is not fully extended AND is in a rotational position where moving it forward will cause it to enter the state space of the table AND the table is in an unsafe position and is holding a plate and arm1 is also holding a plate

$\rightarrow$

$\operatorname{system}\left(x \_f b, \operatorname{table}\left(x_{3}, x_{4}\right.\right.$, hazard $), \operatorname{robot}\left(x_{6}, x_{7}+1, x_{8}\right.$, hazard $\left., x_{10}, x_{11}, x_{12}\right), x \_$press $, x \_d b, x \_$crane, $x \_$floor)

$\operatorname{system}\left(x \_f b, \operatorname{table}\left(x_{3}, x_{4}, x_{5}\right), \operatorname{robot}\left(x_{6}, x_{7}, x_{8}, x_{9}, x_{10}, x_{11}, x_{12}\right), x \_\right.$press, $x \_d b, x \_$crane,$\left.x \_f l o o r\right)$

$: \neg\left(x_{6} \leq 8\right) \wedge x_{7}<8 \wedge\left(x_{3} \neq 1 \wedge x_{5}=1 \wedge x_{8}=1 \wedge x_{9}=0\right)$

\{arm1 is not fully extended AND is in a rotational position where moving it forward will cause it to enter the state space of the table AND the table is in an unsafe position and is holding a plate and arm1 is not holding a plate but its magnet is on $\}$

$\rightarrow$

$\operatorname{system}\left(x \_f b, \operatorname{table}\left(x_{3}, x_{4}, \operatorname{hazard}\right), \operatorname{robot}\left(x_{6}, x_{7}+1, x_{8}\right.\right.$, hazard $\left., x_{10}, x_{11}, x_{12}\right), x \_$press, $x \_d b, x \_$crane, $x \_$floor)

$\operatorname{system}\left(x \_f b, x \_t a b l e, r o b o t\left(x_{6}, x_{7}, x_{8}, x_{9}, x_{10}, x_{11}, x 12\right), x \_p r e s s, x \_d b, x \_c r a n e, x \_f l o o r\right)$

$: x_{7}=1$

\{arm1 is in a position where it cannot be retracted any further\}

$\rightarrow$

$\operatorname{system}\left(x \_f b, x \_t a b l e, r o b o t\left(x_{6}, x_{7}, x_{8}\right.\right.$, hazard $\left.\left., x_{10}, x_{11}, x_{12}\right), x \_p r e s s, x \_d b, x \_c r a n e, x \_f l o o r\right)$

$\operatorname{system}\left(x \_f b, x \_t a b l e, \operatorname{robot}\left(x_{6}, x_{7}, x_{8}, x_{9}, x_{10}, x_{11}, x_{12}\right), \operatorname{press}\left(x_{13}, x_{14}\right), x \_d b, x \_\right.$crane,$\left.x \_f l o o r\right)$

$: x_{10}<7 \wedge \neg\left(x_{6} \geq 16 \vee x_{6} \leq 11 \vee x_{13} \neq 2\right)$

\{arm2 is not fully extended AND arm 2 and the press are in position where moving arm2 forward will cause it to collide with the press

$\rightarrow$

$\operatorname{system}\left(x \_f b, x \_t a b l e, \operatorname{robot}\left(x_{6}, x_{7}, x_{8}, x_{9}, x_{10}+1, x_{11}\right.\right.$, hazard $), \operatorname{press}\left(x_{13}\right.$, hazard $), x \_d b, x \_c r a n e$, $x \_$floor)

$\operatorname{system}\left(x \_f b, x \_t a b l e, \operatorname{robot}\left(x_{6}, x_{7}, x_{8}, x_{9}, x_{10}, x_{11}, x_{12}\right), \operatorname{press}\left(x_{13}, x_{14}\right), x \_d b, x \_c r a n e, x \_f l o o r\right)$

$: x_{10}>7 \wedge \neg\left(x_{6} \geq 16 \vee x_{6} \leq 11 \vee x_{13} \neq 2\right)$

$\{\operatorname{arm} 2$ has collided with the press $\}$

$\rightarrow$ 
$\operatorname{system}\left(x \_f b, x \_t a b l e, \operatorname{robot}\left(x_{6}, x_{7}, x_{8}, x_{9}, x_{10}, x_{11}\right.\right.$, error $), \operatorname{press}\left(x_{13}\right.$, error $\left.), x \_d b, x \_c r a n e, x \_f l o o r\right)$

$\operatorname{system}\left(x \_f b, x \_t a b l e, \operatorname{robot}\left(x_{6}, x_{7}, x_{8}, x_{9}, x_{10}, x_{11}, x_{12}\right), x \_p r e s s, x \_d b, x \_c r a n e, x \_f l o o r\right)$

$: x_{10}=1$

$\{\operatorname{arm} 2$ is fully retracted $\}$

$\rightarrow$

$\operatorname{system}\left(x \_f b, x \_t a b l e, \operatorname{robot}\left(x_{6}, x_{7}, x_{8}, x_{9}, x_{10}, x_{11}\right.\right.$, hazard $\left.), x \_p r e s s, x \_d b, x \_c r a n e, x \_f l o o r\right)$

$\operatorname{system}\left(x \_f b, x \_t a b l e, \operatorname{robot}\left(x_{6}, x_{7}, x_{8}, x_{9}, x_{10}, x_{11}, x_{12}\right), \operatorname{press}\left(x_{13}, x_{14}\right), x \_d b, x \_c r a n e, x \_f l o o r\right)$

$: x_{6}=5 \wedge x_{7}>2 \wedge x_{13}=3$

\{arm1 of the robot is just to the right of the press AND the arm1 and the press are in position so that a collision will occur of the robot is rotated to the left $\}$

$\rightarrow$

$\operatorname{system}\left(x \_f b, x \_t a b l e, \operatorname{robot}\left(x_{6}-1, x_{7}, x_{8}\right.\right.$, hazard, $\left.x_{10}, x_{11}, x_{12}\right)$, press $\left(x_{13}\right.$, hazard $), x \_d b, x \_c r a n e$, $x \_$floor)

$\operatorname{system}\left(x \_f b, x \_t a b l e, \operatorname{robot}\left(x_{6}, x_{7}, x_{8}, x_{9}, x_{10}, x_{11}, x_{12}\right), \operatorname{press}\left(x_{13}, x_{14}\right), x \_d b, x \_c r a n e, x \_f l o o r\right)$

$: x_{6}=16 \wedge x_{10}>1 \wedge x_{13}=2$

$\{\operatorname{arm} 2$ of the robot is just to the right of the press AND the arm2 and the press are in a position so that a collision will occur if the robot is rotated to the left

$\rightarrow$

$\operatorname{system}\left(x \_f b, x \_t a b l e, \operatorname{robot}\left(x_{6}-1, x_{7}, x_{8}, x_{9}, x_{10}, x_{11}\right.\right.$, hazard $), \operatorname{press}\left(x_{13}\right.$, hazard $), x \_d b, x \_c r a n e$, $x \_$floor)

$\operatorname{system}\left(x \_f b, x \_t a b l e, \operatorname{robot}\left(x_{6}, x_{7}, x_{8}, x_{9}, x_{10}, x_{11}, x_{12}\right), x \_\right.$press, $\left.x \_d b, x \_c r a n e, x \_f l o o r\right)$

$: x_{6}=2$

\{the robot is in its leftmost safe position - Note that moving the robot left cannot cause arm1 to "enter" the space of the table\}

$\rightarrow$

$\operatorname{system}\left(x \_f b, x \_t a b l e, \operatorname{robot}\left(x_{6}-1, x_{7}, x_{8}\right.\right.$, hazard $, x_{10}, x_{11}$, hazard $\left.), x \_p r e s s, x \_d b, x \_c r a n e, x \_f l o o r\right)$

$\operatorname{system}\left(x \_f b, x \_t a b l e, \operatorname{robot}\left(x_{6}, x_{7}, x_{8}, x_{9}, x_{10}, x_{11}, x_{12}\right), x \_\right.$press, $\left.x \_d b, x \_c r a n e, x \_f l o o r\right)$

$: x_{6}=1$

\{the robot has rotated too far $\}$ 


\section{$\rightarrow$}

$\operatorname{system}\left(x \_f b, x \_t a b l e, r o b o t\left(x_{6}, x_{7}, x_{8}\right.\right.$, error $, x_{10}, x_{11}$, error $\left.), x \_p r e s s, x \_d b, x \_c r a n e, x \_f l o o r\right)$

$\operatorname{system}\left(x_{-} f b, \operatorname{table}\left(x_{3}, x_{4}, x_{5}\right), \operatorname{robot}\left(x_{6}, x_{7}, x_{8}, x_{9}, x_{10}, x_{11}, x_{12}\right), \operatorname{press}\left(x_{13}, x_{14}\right), x \_d b, x \_\right.$crane, $x \_$floor)

$: x_{6}<18 \wedge x_{6}=9 \wedge x_{7} \neq 1 \wedge x_{3} \neq 1 \wedge x_{5}=1 \wedge x_{9}=1$

\{the robot is not in its rightmost position AND after rotation, arm1 will collide with the table (i.e., the plate space)\}

$\rightarrow$

$\operatorname{system}\left(x \_f b, \operatorname{table}\left(x_{3}, x_{4}, \operatorname{hazard}\right), \operatorname{robot}\left(x_{6}+1, x_{7}, x_{8}, \operatorname{hazard} d x_{10}, x_{11}, x_{12}\right), \operatorname{press}\left(\right.\right.$ error,$\left.x_{14}\right), x \_d b$, x_crane, $x \_$floor)

$\operatorname{system}\left(x \_f b, x \_t a b l e, \operatorname{robot}\left(x_{6}, x_{7}, x_{8}, x_{9}, x_{10}, x_{11}, x_{12}\right), \operatorname{press}\left(x_{13}, x_{14}\right), x \_d b, x \_\right.$crane,$\left.x \_f l o o r\right)$

$: x_{6}<18 \wedge x_{6}=11 \wedge x_{10}>1 \wedge x_{13}=2$

\{the robot is not in its rightmost position AND arm2 will collide with the press. Note that in a right rotation, all we are concerned about is crossing a collision boundary when moving from left to right $\}$

$\rightarrow$

$\operatorname{system}\left(x \_f b, x \_t a b l e, \operatorname{robot}\left(x_{6}+1, x_{7}, x_{8}, x_{9}, x_{10}, x_{11}\right.\right.$, hazard $), \operatorname{press}\left(x_{13}\right.$, hazard $), x \_d b, x \_$crane, $x \_$floor)

$\operatorname{system}\left(x \_f b, x \_t a b l e, r o b o t\left(x_{6}, x_{7}, x_{8}, x_{9}, x_{10}, x_{11}, x_{12}\right), x \_p r e s s, x \_d b, x \_c r a n e, x \_f l o o r\right)$

$: x_{6}=18$

\{the robot is in its rightmost position \}

$\rightarrow$

$\operatorname{system}\left(x \_f b, x \_t a b l e, \operatorname{robot}\left(x_{6}, x_{7}, x_{8}\right.\right.$, hazard $, x_{10}, x_{11}$, hazard $\left.), x \_p r e s s, x \_d b, x \_c r a n e, x \_f l o o r\right)$

\subsection{Crane Safety Constraints}

$\operatorname{system}\left(x \_f b, x \_t a b l e, x \_r o b o t, x \_p r e s s, x \_d b, \operatorname{crane}\left(x_{17}, x_{18}, x_{19}, x_{20}\right), x \_f l o o r\right)$

$: x_{18}=3$

\{the crane cannot be moved any further in the direction of the deposit belt\}

$\rightarrow$

$\operatorname{system}\left(x \_f b, x \_t a b l e, x \_r o b o t, x \_p r e s s, x \_d b, \operatorname{crane}\left(x_{17}, x_{18}, x_{19}\right.\right.$, hazard $\left.), x \_f l o o r\right)$ 
$\operatorname{system}\left(x \_f b, x \_t a b l e, x \_r o b o t, x \_p r e s s, x \_d b, \operatorname{crane}\left(x_{17}, x_{18}, x_{19}, x_{20}\right), x \_\right.$floor $)$

$: x_{17}>3$

\{the crane is to low to be moved horizontally\}

$\rightarrow$

$\operatorname{system}\left(x \_f b, x \_t a b l e, x \_r o b o t, x \_p r e s s, x \_d b, \operatorname{crane}\left(x_{17}, x_{18}, x_{19}\right.\right.$, hazard $), x \_$floor $)$

$\operatorname{system}\left(x \_f b, x \_t a b l e, x \_r o b o t, x \_p r e s s, x \_d b, \operatorname{crane}\left(x_{17}, x_{18}, x_{19}, x_{20}\right), x \_\right.$floor $)$

$: x_{18}=1$

\{the crane cannot be moved any further in the direction of the feed belt

$\rightarrow$

$\operatorname{system}\left(x \_f b, x \_t a b l e, x \_r o b o t, x \_p r e s s, x \_d b, \operatorname{crane}\left(x_{17}, x_{18}, x_{19}\right.\right.$, hazard $), x \_$floor $)$

$\operatorname{system}\left(f b\left(x_{1}, x_{2}\right), x \_t a b l e, x \_r o b o t, x \_p r e s s, x \_d b, \operatorname{crane}\left(x_{17}, x_{18}, x_{19}, x_{20}\right), x \_\right.$floor $)$

$: x_{17}=2 \wedge \neg\left(x_{1}=0 \vee x_{20}=0 \vee x_{18} \neq 1\right)$

\{the crane is above the (general) unsafe vertical boundary AND a plate collision with the feed belt can occur\}

$\rightarrow$

$\operatorname{system}\left(f b\left(h a z a r d, x_{2}\right), x \_t a b l e, x \_r o b o t, x \_p r e s s, x \_d b, \operatorname{crane}\left(x_{17}, x_{18}, x_{19}\right.\right.$, hazard $), x \_$floor $)$

$\operatorname{system}\left(f b\left(x_{1}, x_{2}\right), x \_t a b l e, x \_r o b o t, x \_p r e s s, x \_d b, \operatorname{crane}\left(x_{17}, x_{18}, x_{19}, x_{20}\right), x \_\right.$floor $)$

$: x_{17}=3 \wedge x_{18} \neq 3$

\{the crane is at the (general) unsafe vertical boundary AND is not above the deposit belt

$\rightarrow$

$\operatorname{system}\left(f b\left(h a z a r d, x_{2}\right), x \_t a b l e, x \_r o b o t, x \_p r e s s, x \_d b, \operatorname{crane}\left(x_{17}, x_{18}, x_{19}\right.\right.$, hazard $), x \_$floor $)$

$\operatorname{system}\left(x \_f b, x \_t a b l e, x \_r o b o t, x \_p r e s s, d b\left(x_{15}, x_{16}\right), \operatorname{crane}\left(x_{17}, x_{18}, x_{19}, x_{20}\right), x \_\right.$floor $)$

$: x_{17}=4 \wedge \neg\left(x_{16}=0 \vee x_{20}=0\right)$

\{ the crane is in its next-to bottom-most safe position AND a plate clash can occur between the crane and the deposit belt\}

$\rightarrow$

$\operatorname{system}\left(x \_f b, x \_t a b l e, x \_r o b o t, x \_p r e s s, d b\left(x_{15}\right.\right.$, hazard $), \operatorname{crane}\left(x_{17}, x_{18}, x_{19}\right.$, hazard $\left.), x \_f l o o r\right)$

$\operatorname{system}\left(x \_f b, x \_t a b l e, x \_r o b o t, x \_p r e s s, d b\left(x_{15}, x_{16}\right), \operatorname{crane}\left(x_{17}, x_{18}, x_{19}, x_{20}\right), x \_\right.$floor $)$

$: x_{17}=5$ 
\{the crane is in its bottom-most position (this can only happen when the crane is above the deposit belt)\}

$\rightarrow$

$\operatorname{system}\left(x \_f b, x \_t a b l e, x \_r o b o t, x \_p r e s s, d b\left(x_{15}\right.\right.$, hazard $), \operatorname{crane}\left(x_{17}, x_{18}, x_{19}\right.$, hazard $), x \_$floor $)$

$\operatorname{system}\left(x \_f b, x \_t a b l e, x \_r o b o t, x \_p r e s s, x \_d b, \operatorname{crane}\left(x_{17}, x_{18}, x_{19}, x_{20}\right), x \_f l o o r\right)$

$: x_{17}=1$

\{the crane is in its upper-most position\}

$\rightarrow$

$\operatorname{system}\left(x \_f b, x \_t a b l e, x \_r o b o t, x \_p r e s s, x \_d b, \operatorname{crane}\left(x_{17}, x_{18}, x_{19}, h a z a r d\right), x \_f l o o r\right)$

\subsection{Press Safety Constraints}

$\operatorname{system}\left(x \_f b, x \_t a b l e, \operatorname{robot}\left(x_{6}, x_{7}, x_{8}, x_{9}, x_{10}, x_{11}, x_{12}\right), \operatorname{press}\left(x_{13}, x_{14}\right), x \_d b, x \_\right.$crane, $\left.x \_f l o o r\right)$

$: x_{6}<5 \wedge x_{7}>2 \wedge x_{9}=1 \wedge x_{13}=3$

$\{$ arm1 and press have collided $\}$

$\rightarrow$

$\operatorname{system}\left(x \_f b, x \_t a b l e, \operatorname{robot}\left(x_{6}, x_{7}, x_{8}\right.\right.$, error $\left., x_{10}, x_{11}, x_{12}\right), \operatorname{press}\left(x_{13}\right.$, error $), x \_d b, x \_$crane,$\left.x \_f l o o r\right)$

$\operatorname{system}\left(x \_f b, x \_t a b l e, r o b o t\left(x_{6}, x_{7}, x_{8}, x_{9}, x_{10}, x_{11}, x_{12}\right), \operatorname{press}\left(x_{13}, x_{14}\right), x \_d b, x \_\right.$crane,$\left.x \_f l o o r\right)$

$: x_{13}=2 \wedge x_{6}<5 \wedge x_{7}>2$

\{press can collide with arm1\}

$\rightarrow$

$\operatorname{system}\left(x \_f b, x \_t a b l e, \operatorname{robot}\left(x_{6}, x_{7}, x_{8}\right.\right.$, hazard $\left., x_{10}, x_{11}, x_{12}\right)$, press $\left(x_{13}+1\right.$, hazard $), x \_d b, x \_c r a n e$, $x \_$floor)

$\operatorname{system}\left(x \_f b, x \_t a b l e, \operatorname{robot}\left(x_{6}, x_{7}, x_{8}, x_{9}, x_{10}, x_{11}, x_{12}\right), \operatorname{press}\left(x_{13}, x_{14}\right), x \_d b, x \_\right.$crane,$\left.x \_f l o o r\right)$

$: x_{13}=3 \wedge x_{6}<5 \wedge x_{7}>2 \wedge x_{9}=0$

\{states of arm1 which can collide with the press $\}$

$\rightarrow$

$\operatorname{system}\left(x \_f b, x \_t a b l e, \operatorname{robot}\left(x_{6}, x_{7}, x_{8}\right.\right.$, hazard $\left., x_{10}, x_{11}, x_{12}\right), \operatorname{press}\left(x_{13}, x_{14}\right), x \_d b, x \_$crane,$\left.x \_f l o o r\right)$

$\operatorname{system}\left(x \_f b, x \_t a b l e, \operatorname{robot}\left(x_{6}, x_{7}, x_{8}, x_{9}, x_{10}, x_{11}, x_{12}\right), \operatorname{press}\left(x_{13}, x_{14}\right), x \_d b, x \_\right.$crane,$\left.x \_f l o o r\right)$ 
$: x_{6}>10 \wedge x_{6}<15 \wedge x_{10}>1 \wedge x_{12}=1 \wedge x_{13}=2$

$\{$ arm2 and press have collided $\}$

$\rightarrow$

$\operatorname{system}\left(x \_f b, x \_\right.$table, $\operatorname{robot}\left(x_{6}, x_{7}, x_{8}, x_{9}, x_{10}, x_{11}\right.$, error $), \operatorname{press}\left(x_{13}\right.$, error $), x_{-} d b, x \_$crane,$x_{-}$floor $)$

$\operatorname{system}\left(x \_f b, x \_t a b l e, \operatorname{robot}\left(x_{6}, x_{7}, x_{8}, x_{9}, x_{10}, x_{11}, x_{12}\right), \operatorname{press}\left(x_{13}, x_{14}\right), x \_d b, x \_\right.$crane,$\left.x \_f l o o r\right)$

$: x_{6}>10 \wedge x_{6}<15 \wedge x_{10}>1 \wedge x_{12}=0 \wedge x_{13}=2$

\{states of arm2 which can collide with the press \}

$\rightarrow$

$\operatorname{system}\left(x \_f b, x \_t a b l e, \operatorname{robot}\left(x_{6}, x_{7}, x_{8}, x_{9}, x_{10}, x_{11}\right.\right.$, hazard $), \operatorname{press}\left(x_{13}, x_{14}\right), x \_d b, x \_$crane,$\left.x \_f l o o r\right)$

$\operatorname{system}\left(x \_f b, x \_t a b l e, \operatorname{robot}\left(x_{6}, x_{7}, x_{8}, x_{9}, x_{10}, x_{11}, x_{12}\right), \operatorname{press}\left(x_{13}, x_{14}\right), x \_d b, x \_\right.$crane,$\left.x \_f l o o r\right)$

$: x_{6}>10 \wedge x_{6}<15 \wedge x_{10}>1 \wedge x_{13}=3$

$\{\operatorname{arm} 2$ and press can colide $\}$

$\rightarrow$

$\operatorname{system}\left(x \_f b, x \_t a b l e, \operatorname{robot}\left(x_{6}, x_{7}, x_{8}, x_{9}, x_{10}, x_{11}\right.\right.$, hazard $), \operatorname{press}\left(x_{13}-1, x_{14}\right), x \_d b, x \_c r a n e$, $x \_$floor) 